\title{
LOS MIRMELEÓNIDOS (HORMIGAS-LEÓN) DE LA PENÍNSULA IBÉRICA E ISLAS BALEARES (INSECTA, NEUROPTERIDA, NEUROPTERA, MYRMELEONTIDAE)
}

\author{
V. J. Monserrat* \& F. Acevedo**
}

\section{RESUMEN}

V. J. Monserrat \& F. Acevedo. 2013. Los mirmeleónidos (hormigas-león) de la Península Ibérica e Islas Baleares (Insecta, Neuropterida, Neuroptera, Myrmeleontidae). Grael/sia, 69(2): 283-321.

Se revisan las especies de mirmeleónidos u hormigas-león (Insecta, Neuropterida, Neuroptera: Myrmeleontidae) de la Península lbérica e Islas Baleares. Con una muy diversa presencia, frecuencia y abundancia, 26 especies pertenecientes a 15 géneros de esta familia son conocidas en la zona estudiada. De ellas, se incluye una clave de identificación de sus imagos, se recopila toda la información bibliográfica existente referente al área geográfica estudiada, y se recopilan y se anotan los datos conocidos sobre su biología, sus estadios larvarios y su distribución fenológica y altitudinal en la zona estudiada. Para 24 de estas 26 especies, se anotan nuevos datos sobre su distribución y biología en la zona tratada.

Palabras clave: Península Ibérica; Faunística; Biología; Neuropterida; Neuroptera; Myrmeleontidae; hormiga-león.

\section{SUMMARY}

V. J. Monserrat \& F. Acevedo. 2013. The ants-lion from the Iberian Peninsula and Balearic Islands (Insecta, Neuropterida, Neuroptera, Myrmeleontidae). Grael/sia, 69(2): 283-321 (in Spanish).

We review the ants-lion (Insecta, Neuropterida, Neuroptera: Myrmeleontidae) species known from the lberian Peninsula and Balearic Islands. With very different degrees of presence, frequence and abundance, 26 ant-lion species belonging to 15 genera of this family are known in the area studied. Of these, an identification key of imagoes is provided, all the existing bibliographical information from the area is compiled, and a review of current knowledge about their biology and larval stages as well as their phaenological and altitudinal distribution in the studied region is provided. For 24 of these 26 species, new data on their distribution and biology within in the area are also provided.

Key Words: Iberian Peninsula; Faunistical; Biology; Neuropterida; Neuroptera; Myrmeleontidae; Ant-Lion.

1 Departamento de Zoología y Antropología Física, Facultad de Biología. Universidad Complutense E-28040 Madrid, Spain. *artmad@bio.ucm.es

**facevedoramos@gmail.com 


\section{Introducción}

La familia Myrmeleontidae es una de las familias de neurópteros más interesantes, familiares y conocidas. Presenta una amplia distribución geográfica (cosmopolita salvo la Antártida), mayoritariamente asociada a medios térmicos y xéricos, y está ausente en climas fríos y zonas de alta montaña. Algunas de sus especies alcanzan tamaños notables, y sus poblaciones son monovoltinas $\mathrm{y}$, en ocasiones, mantienen un elevado número de ejemplares. De carácter mayoritariamente depredador y en general torpes voladores, su éxito evolutivo suele atribuirse a las sorprendentes adaptaciones en la colonización de hábitats, tanto de sus imagos, como especialmente de sus fases juveniles (hormigas león), especialmente adaptadas a medios arenosos, donde desarrollan sorprendentes estrategias de caza (Morton Wheeler, 1930; Gardiner, 1932; New, 1986, 1989; Gepp \& Hölzel, 1989; Stange \& Miller, 1990; Mansell, 1996, 1999; Stange, 2004; Gepp, 2010; Krivokhatsky, 2011). Son conocidas por sus curiosos conos de caza en la arena, pero sólo las especies de los géneros Myrmeleon, Euroleon, y el tercer estadio de Myrmecaelurus lo practican. Sus estadios larvarios son conocidos desde la Antigüedad como animales mitológicos (hormigas león), y fueron frecuentemente citados en la Literatura Clásica Greco-Romana y Medieval, que las han hecho legendarias, siendo Albertus Magnus, en su De Animalibus Libri (1478, 26, 21) (ver enlace adjunto), quien las asignó al grupo que tratamos (información sobre este particular puede recabarse en Druce, 1923; Morton Wheeler, 1930; Gerhardt, 1965; McKevan, 1992; Monserrat, 2010).

La familia Myrmeleontidae está constituida por 1522 especies según Stange (2004), a las que se han añadido nuevos elementos desde entonces, alcanzando casi las 2000 especies, siendo la familia con mayor número de especies dentro de los Neuroptera (Aspöck et al., 1980, 2001). A nivel general, su sistemática y taxonomía ha sido recientemente revisada por Stange (2004), si bien muchos de sus criterios no han sido reconocidos de forma generalizada, por lo que la sistemática y la taxonomía de la familia requiere una revisión más profunda y actualizada. Las especies europeas fueron mayoritariamente revisadas por Aspöck et al. (1980), quienes recogen un total de 41 especies en esta región, de las que 24 eran entonces conocidas en la fauna ibérica y balear. Nuevas aportaciones a la fauna paleártica occidental/ europea han sido añadidas desde entonces (Krivokhatsky \& Zakaharenko, 1994; Krivokhatsky, 1990, 1992a, b, c, 1994a, 1995, 1996a, b; Hölzel \& Monserrat, 2002; Pantaleoni et al., 2010; Krivokhatsky, 2011; Pantaleoni \& Badano, 2012, etc.).

En relación a nuestra fauna, ha de indicarse que a la larga lista de especies históricamente descritas o citadas en la zona de estudio (Rambur, 1842; Walker, 1853; Rosenhauer, 1856; Hagen, 1860a, b; Pictet, 1865; Hagen, 1866b; McLachlan, 1873, 1889; Navás, 1900a, 1903, 1904b, d, 1912a, 1913b, $1916 b, 1925 a$, etc.), se han ido añadiendo nuevas citas para la fauna de España o de Portugal con recientes aportaciones (Hölzel, 1974, 1976, 1987; Monserrat, 1985a, b, c, 1987b, 2010; Letardi, 1998; Tröger, 1999; Hölzel \& Monserrat, 2002, Monserrat \& Acevedo, 2011, etc.), y algunas novedades se han venido añadiendo a su fauna (Myrmeleon bore, M. gerlindae, Tricholeon relictus), y recientemente se ha resuelto tanto la validez de alguna que otra especie de posición taxonómica problemática, como la identidad de ciertas especies incorrecta-/erróneamente citadas en la zona tratada (Monserrat, 2011). Hasta el presente 26 especies son conocidas en la Península Ibérica y Baleares, y como es habitual en la fauna entomológica iberobalear, no descartamos que aparezcan futuras novedades, especialmente en los géneros Myrmeleon y Creoleon, donde es más probable que aparezcan nuevos taxa o se revaliden sinonimias actualmente aceptadas.

Con respecto a la multitud de citas que existenten en la bibliografía relacionadas con la zona tratada (293 referencias bibliográficas), tanto de sus numerosas especies, sinonimias o combinaciones nomenclatoriales utilizadas (ver relación más adelante), conviene indicar que muchas especies son fácilmente distinguibles, bien en base a caracteres de morfología externa (ver clave de géneros y especies) - con lo que cabe suponer son/ eran inconfundibles por los autores que las citaron basándose en estas características (Synclisis baetica, Acanthaclisis occitanica, Creoleon aegyptiacus, C. lugdunensis, Distoleon annulatus, D. tetragrammicus, Palpares hispanus, P. libelluloides) - o bien a que a esta circunstancia se suman especies de numerosos géneros con un único representante en la fauna de la zona estudiada (Euroleon, Gymnocnemia, Macronemurus, Myrmecaelurus, Megistopus, Nemoleon, Solter), con lo que unas y 
otras podrían, sin gran margen de riesgo, ser consideradas (Monserrat \& Triviño, 2013) (93 ejemplares ibéricos citados en la bibliografía han sido considerados). Mucho más problemáticas son las citas antiguas de algunas especies pertenecientes a géneros como Creoleon, Neuroleon o Myrmeleon (con nuevas especies recientemente descritas en la Región Mediterránea y que, sin duda, nos traerá novedades cuando alguna de sus variables especies ibéricas sean más intensamente estudiadas), o también quizás puedan resultar problemáticas ciertas citas dadas sobre especies consideradas tanto sinónimas como válidas según autores, escuelas $\mathrm{y}$ periodos (ej.: Palpares hispanus/ P. libelluloides) (ver Kolbe, 1884; Aspöck et al., 1980, 2001; Krivokhatsky, 2011; Ábrahám, 2012). En ambos casos, algunas de estas citas en la bibliografía deberían tomarse con cautela ante la posibilidad de mezclar datos de unas y otras especies, salvo el caso de las citas basadas en material que ha sido posteriormente revisado.

Al margen de estas consideraciones, en conjunto constituye una de las familias de neurópteros que con más fiabilidad podrían tenerse en cuenta sus registros bibliográficos, y la han llevado a ser una de las mejores conocidas, y representar una de las familias más diversas y ricas en especies dentro del área ahora estudiada (Monserrat \& Triviño, 2013), aunque es cierto que aún existen numerosas áreas ibero-baleares escasamente prospectadas, y varias especies son muy poco conocidas, apenas se disponen, o no existen, datos sobre su biología y/o estadios juveniles, o han sido muy escasamente citadas, $\mathrm{y}$ por ello desconocemos su distribución real y fenología en la Península Ibérica y/o Baleares. Contribuir a este mayor conocimiento es uno de los objetivos del presente artículo.

\section{Material y método}

Para la realización de esta revisión se han tenido en cuenta todas las citas ibéricas existentes en la bibliografía que ahora recopilamos (293 referencias bibliográficas), de las que en 166 de ellas se anota material ibérico (93 ejemplares) que ha sido considerado, bien por ser de identificación incuestionable/ fiable, o porque han sido adecuadamente revisadas por más recientes autores, descartando aquellas citas que pueden resultar cuestionables o dudosas (ver criterios anteriormente anotados), y que alcanzan un total de 3788 ejemplares, de los que 3695 ejemplares corresponden a material que ya ha sido previamente recolectado, estudiado y/o citado por nosotros.

Las referencias bibliográficas existentes para cada especie se anotan cronológicamente ordenadas según las sinonimias habitualmente aceptadas $\mathrm{y} / \mathrm{o}$ las diferentes combinaciones nomenclatoriales bajo las cuales han sido mencionadas, y para una mayor información y comodidad del lector, en ellas se exponen las páginas donde la información se aporta. Salvo que el material citado haya sido posteriormente estudiado por los autores, o las citas hayan sido dadas por autores de reconocida solvencia, la recopilación bibliográfica anotada no implica la total asunción de sus contenidos.

A toda esta información, añadimos ahora 1159 nuevos ejemplares pertenecientes a 24 especies (de las 26 especies conocidas en la zona de estudio) correspondiente a nuevo material inédito recolectado y/o estudiado por nosotros que ahora citamos, alcanzando un total de 4947 ejemplares en los que basamos esta revisión. Este nuevo material que ahora citamos, inédito hasta la fecha, corresponde tanto al que más recientemente hemos recolectado, como aquel correspondiente a material o información que nos han proporcionado algunos compañeros y colegas, y cuyo material nos ha sido legado. Para no hacer reiterativo el recolector/ recolectores de todo este nuevo material, solo se indicará el recolector si no ha sido alguno de los autores de esta contribución, y en cuya colección personal este material permanece. También entre el material estudiado, se cita otro material recolectado en la Península Ibérica o Baleares que pertenece a diferentes colecciones privadas o a diversas instituciones, cuyas siglas se relacionan a continuación y que, solo en estos casos, las siglas que anotamos serán empleadas en la exposición del material estudiado:

BM: Colección Bruno Michel, Montpellier, Francia.

MB: $\quad$ Museo de Zoologia, Barcelona, España.

MNCM: Museo Nacional de Ciencias Naturales, Madrid, España.

MRH: Colección M.R. Honey, London, United Kingdom.

NHM: Natural History Museum, London, United Kingdom. NHMW: Naturhistorisches Museum Wien, Viena, Austria.

TAMU: Department of Entomology, Texas A \& M University, College Station, USA.

UAB: Universidad Autónoma de Bellaterra, Barcelona, España.

UCM: Universidad Complutense, Madrid, España.

US: $\quad$ Universidad de Salamanca, Salamanca, España. 
El nuevo material ibérico y balear estudiado se cita ordenado por países (España, Portugal), anotándose por orden alfabético las provincias, islas, localidades, y por orden cronológico las fechas de recolección, número de ejemplares estudiados ( $\sigma^{\top} \sigma^{\top}$, 우 우, pupas y larvas), y en su caso, citando los periodos entre la recolección de las larvas, su pupación y la emergencia de los correspondientes imagos (aunque perdamos información sobre su potencial fenología, los ejemplares adultos obtenidos en laboratorio, en condiciones no naturales, no se han considerado a la hora de anotar la fenología espontánea de los imagos que ahora citamos), y también, en algunos casos, se anota el sustrato vegetal sobre el que algunos ejemplares han sido hallados o ciertos datos sobre su biología, así como su recolector e institución a la que los ejemplares pertenecen, según las siglas anteriormente citadas. Para hacer más ágil y menos cansina la lectura del material estudiado, y para no reiterar en esta exposición los datos del país, provincia, isla, localidad, fecha de captura, etc., los datos se separan por comas o puntos según se haya citado, o no, parte de la información (país, provincia, isla, localidad, fecha de captura, etc.) de los ejemplares mencionados inmediatamente antes de los que se exponen, y como se ha indicado, solo se indicará el recolector y las siglas de estas instituciones cuando este material no haya sido recolectado por los autores o no pertenezca a su colección personal.

Las fotografías del aspecto general de las alas de los adultos (Figs. 1- 8, 10-26) fueron tomadas con una cámara Nikon ${ }^{\circledR}$ D40; Objetivo Sigma $50 \mathrm{~mm}$ $\mathrm{F} / 2,8 \mathrm{D}$; Longitud Focal $50 \mathrm{~mm}$; Enfoque y Exposición manual; Diafragma F 7,1; Velocidad Obturador $1 / 100$ a $1 / 40$ según las fotos. Por su parte, las fotografías de los detalles de los abdómenes de las especies del género Palpares (Figs. 2728) o Neuroleon y detalle de sus alas (Figs. 29-30), así como de los pronotos del género Myrmeleon (Figs. 36-40) fueron realizadas con una lupa Olympus ${ }^{\circledR}$ SZX7, con cámara Olympus ${ }^{\circledR}$ S-C-30 integrada, utilizando para su proceso el software analySIS getIT. Las imégenes obtenidas fueron procesadas y retocadas usando el software Adobe Photoshop ${ }^{\circledR}$ CS6.

Para la morfología general (Figs. 1-2) utilizada en la clave identificación de las especies consideradas se sigue la terminología habitualmente usada para esta familia (Aspöck et al., 1980; Krivokhatsky, 2011). Para la distribución general de cada una de las espe- cies anotadas se sigue la recopilada por Aspöck et al. (1980, 2001). Los datos de distribución en la Península Ibérica y Baleares que se anotan son generales, simplemente se indica si su distribución en la zona de estudio se circunscribe a zonas de influencia eurosiberiana, mediterránea, o ambas; para un mayor detalle sobre la distribución de las especies en la zona estudiada puede utilizarse Monserrat \& Triviño (2013). Los datos sobre la biología, fenología y amplitud altitudinal (que contabilizamos desde $10 \mathrm{~m}$ como dato a nivel del mar) que ahora anotamos sobre las especies citadas se basan en nuestra propia información, a la que hemos añadido la aportada por autores de reconocida solvencia, la de los datos bibiográficos según los criterios anotados por Monserrat \& Triviño (2013), y el nuevo material inédito ahora anotado (1159 ejemplares), que hacen un total de 4947 ejemplares pertenecientes a esta familia en los que basamos esta revisión.

\section{Los mirmeleónidos de la Península Ibérica y Baleares}

Entre las muchas opiniones que se han vertido sobre la taxonomía y sistemática de esta familia, para la ordenación de los taxa citados se siguen los criterios utilizados por Aspöck et al. (2001) y Krivokhatsky (2011).

\section{LISTADO DE LAS ESPECIES CONSIDERADAS:}

MYRMEMELONTIDAE Latreille, 1802

Palparinae Banks, 1911

Palparini Banks, 1911

Palpares libelluloides (Linnaeus, 1764)

Palpares hispanus Hagen, 1860

Acanthaclisinae Navás, 1912

Acanthaclisini Navás, 1912

Acanthaclisis occitanica (Villers, 1789)

Synclisis baetica (Rambur, 1842)

Myrmecaelurinae Esben-Petersen, 1919

Myrmecaelurini Esben-Petersen, 1919

Myrmecaelurus trigrammus (Pallas, 1771)

Myrmeleontinae Latreille, 1802

Myrmeleontini Latreille, 1802

Myrmeleon formicarius Linnaeus, 1767

Myrmeleon hyalinus Olivier, 1811

Myrmeleon inconspicuus Rambur, 1842

Myrmeleon bore (Tjeder, 1941)

Myrmeleon gerlindae Hölzel, 1974

Euroleon nostras (Geoffroy en Fourcroy, 1785) 
Gepini Markl, 1954

Solter liber Navás, 1912

Dendroleontinae Banks, 1899

Dendroleontini Banks, 1899

Tricholeon relictus Hölzel \& Monserrat, 2002

Nemoleontinae Banks, 1911

Nemoleontini Banks, 1911

Nemoleon notatus (Rambur, 1842)

Creoleontini Mark1, 1954

Creoleon aegyptiacus (Rambur, 1842)

Creoleon lugdunensis (Villers, 1789)

Distoleontini Tillyard, 1916

Distoleon tetragrammicus (Fabricius, 1798)

Distoleon annulatus (Klug, 1834)

Neuroleontini Navás, 1912

Neuroleon nemausiensis (Borkhausen, 1791)

Neuroleon distichus (Navás, 1903)

Neuroleon ocreatus (Navás, 1904)

Neuroleon arenarius (Navás, 1904)

Neuroleon egenus (Navás, 1915)

Macronemurini Esben-Petersen, 1919

Macronemurus appendiculatus (Latreille, 1807)

Glenurinae Banks, 1927

Glenurini Banks, 1927

Megistopus flavicornis (Rossi, 1790)

Gymnocnemini Navás, 1912

Gymnocnemia variegata (Schneider, 1845)

\section{Revisión de los Myrmeleontidae de la Península Ibérica y Baleares}

Agrupadas por subfamilias, tribus y géneros, según la clasificación anteriormente anotada, se citan las 26 especies consideradas bajo el nombre actualmente válido, anotando las referencias bibliográficas que las han citado (exclusivamente en relación a la zona considerada), así como las citas existentes dadas bajo el nombre de sus sinonimias comúnmente aceptadas o de las diferentes combinaciones nomenclatoriales y categorías subespecíficas bajo las cuales han sido citadas en la bibliografía relativa a la fauna de la Península Ibérica e Islas Baleares, siempre que unas y otras afecten a la fauna considerada, sean de las especies tratadas, de sus sinonimias aceptadas, o de cualquier otro tipo de combinación nomenclatorial o nominación que así se recogen. Es decir, toda esta relación de taxa no es exclusivamente un listado taxonómico, sino una lista de nominaciones que afectan a las citas existentes en la bibliografía relacionadas con la fauna de la Península Ibérica e Islas Baleares.

De cada especie se aporta una breve información sobre su distribución geográfica general, y una sinopsis sobre su biología, distribución geográfica, fenológica y altitudinal en la Península Ibérica e Islas Baleares. También anotamos diferentes referencias donde puede encontrarse información sobre los estadios larvarios de las diferentes especies citadas.

Finalizamos con una breve relación de alguna especie sugerida como probable en la fauna estudiada; de otras citadas en la zona, cuya veracidad en su identificación está aún por demostrar; y también se anotan las referencias bibliográficas que han mencionado el nombre y combinaciones nomenclatoriales de otras especies actualmente válidas o no, que no están presentes en la fauna considerada, pero bajo cuya denominación han sido errónea/incorrectamente citadas en ella.

Myrmeleontidae

Palparinae Banks, 1911

Palparini Banks, 1911

Palpares libelluloides (Linnaeus, 1764)

Palpares libelluloides (Linnaeus, 1764): Rambur, 1842a: 368; Rosenhauer, 1856: 367; Pictet, 1865: 75; Hagen, 1866a: 288; Brauer, 1876: 289; Cuní y Martorell, 1880a: 242; Kolbe, 1884: 136; Novak, 1891: 51; Cuní y Martorell, 1897: 324, 1899: 5; Navás, 1900a: 96, 1904a: 10, 1905c: 27, 1907b: 100, 1912c: 1, 1912e: 183, 1913a: 80, 1913b: 67, 1913d: 10, 1914a: 749, 1914f: 607, 1915: 29, 47, 1916a: 154, 1917: 86, 1919a: 193; Lucas, 1922: 263; Navás, 1924a: 39, 43, 1925b: 23, 1927b: 112, 1930b: 160; Vidal y López, 1943: 14; Principi, 1966: 378; Cammaerts, 1967: 184; Steffan, 1975: 386; Popov, 1977: 274; Aspöck et al., 1980: 10; Monserrat, 1984d: 45, 1985a: 476; Díaz-Aranda et al., 1986b: 1134; Monserrat \& Díaz-Aranda, 1987: 175; Monserrat, 1996: 12; Whittington, 2002: 385; Stange, 2004: 55; Monserrat \& Acevedo, 2011: 125; Monserrat \& Triviño, 2013: 19, 107; Monserrat et al., 2013: 5.

Myrmeleon libelluloides Linnaeus, 1764: Hagen, 1860a: 40.

Palpares libelloides (Linnaeus, 1764): Krivokhatsky, 2011: 93; Ábrahám, 2012: 76, 94.

La denominación de esta especie como Palpares libelluloides o Palpares libelloides sigue siendo motivo de controversia nomenclatorial (Ábrahám, 2012), y nosotros mantenemos el nombre habitualmente utilizado. Los caracteres utilizados en ocasiones para diferenciar esta especie de Palpares hispanus, como son la extensión y el aspecto de manchas pardas de las alas (Figs. 1, 3), color de la frente, etc. (Ábrahám, 2012) son a veces variables y no deben utilizarse.

Se trata de una especie holomediterránea extendida al Cáucaso, Siria, Azerbaiyán, Irán e Irak. Es conocida en toda la Península Ibérica, tanto en zonas septentrionales como meridionales, pero especialmente en zonas de influencia mediterránea. Sus imagos generalmente habitan en medios abiertos y soleados, a veces claros de bosquetes 


\section{Clave de identificación de los imagos de Myrmeleontidae de la Península lbérica y Baleares}

Tratamos de utilizar para esta clave ciertos caracteres de morfología externa y venación, lo más sencillos posibles, que sean suficientes para la identificación específica de los ejemplares. Para la terminología alar puede seguirse la información anotada en las figuras 1-2.

En esta clave se segregan los taxa a nivel de género y de especie. Para los géneros monoespecificos (Acanthaclisis, Synclisis, Euroleon, Gymnocnemia, Macronemurus, Myrmecaelurus, Megistopus, Nemoleon, Solter, Tricholeon), alcanzado el nivel de género, se consigue la identificación a nivel de especie, según se indica. Para los restantes géneros (Palpares, Myrmeleon, Creoleon, Neuroleon, Distoleon) se añaden otros pasos para la identificación de sus correspondientes especies, y en alguno de estos casos puede seguirse la información anotada en las figuras 27-40.

1. Alas anchas, subtriangulares, portadoras de abundantes manchas pardas (Figs. 1, 3). En las alas anteriores, las venas $\mathrm{CUa}_{2}$ y CUp están fuertemente recurvadas en su paralelo recorrido antes de confluir, y la vena CUp es independiente de $A_{1}$ (Fig. 1) Palpos labiales alargados, con el palpómero distal más largo que la distancia interocular ................................ Palpares (2)

- $\quad$ Alas estrechas, espatuladas o acintadas, sin abundantes manchas pardas o con pocas sombras de escasa extensión (Figs. 2, 4-26). En las alas anteriores, las venas $\mathrm{CUa}_{2}$ y CUp son rectas y convergentes en su recorrido antes de confluir, y la vena CUp está fusionada con $\mathrm{A}_{1}$ (Fig. 2) Palpos labiales cortos, con el palpómero distal más corto que la distancia interocular

2. Manchas pardas del abdomen interrumpidas en cada segmento (Fig. 28)

Palpares hispanus

- Manchas pardas del abdomen formando líneas contínuas (Fig. 27) Palpares libelluloides

3. Campo costal de las alas anteriores con dos series de celdillas (Figs. 2, 4). Espolones distales de las tibias robustos, fuertemente acodados en ángulo recto

- Campo costal de las alas anteriores con una única serie de celdillas (Figs. 5-26). Espolones distales de las tibias tenues, rectos o levemente curvados, o no existen

4. En las alas anteriores, las series anterior y posterior de celdillas del campo costal son de similar tamaño (Fig. 4) Synclisis, Synclisis baetica

- En las alas anteriores, la serie anterior de celdillas del campo costal es menor que las de la serie posterior (Fig. 2) Acanthaclisis, Acanthaclisis occitanica

5. En las alas posteriores existen al menos 4-6 venillas trasversales entre el origen del SR + Ma y la base del ala (Figs. 5-12) .............................................. (6)

- En las alas posteriores existen 1, 2 al máximo, venillas trasversales entre el origen del SR + Ma y la base del ala (Figs. 13-26)

6. Alas amarillento-pajizas, de coloración uniforme, sin manchas más oscuras, con venillas trasversales que se alinean con otras aparentando ser dos venas longitudinales (líneas de Banks, Fig. 5). Abdomen del macho con dos pares de pinceles pilosos en los segmentos $6^{\circ}$ y $7^{\circ}$

Myrmecaelurus, Myrmecaelurus trigrammus

- Alas pardo-pálidas o hialinas, con (Figs. 11, 12) o sin (Figs. 6-10) numerosas sombras en las alas anteriores, sin venillas trasversales que se alinean con otras aparentando ser dos venas longitudinales (Figs. 6-12). Abdomen del macho sin dos pares de pinceles pilosos en los segmentos $6^{\circ}$ y $7^{\circ}$

7. Ala anterior con vena $\mathrm{CUp}+\mathrm{A}_{1}$ paralelas a $\mathrm{CUa}_{2}$ por una larga distancia. Alas anteriores y posteriores llamativamente manchadas (Fig. 11) ........................................................................................................................... Euroleon, Euroleon nostras Ala anterior con vena CUp $+\mathrm{A}_{1}$ oblícuas y convergentes a $\mathrm{CUa}_{2}$. Alas anteriores y posteriores con leves manchas pardas (Fig. 12) o sin manchas (Figs. 6-10)

8. Alas anteriores con leves manchas pardas (Fig. 12)

Solter, Solter liber

- Alas anteriores sin manchas (Fig. 6-10) Myrmeleon (9)

9. Pronoto pálido con dos manchas oscuras sobre la línea media y dos alargadas a cada lado (Fig. 37) .... Myrmeleon hyalinus

- Pronoto negro sin estas manchas oscuras (Figs. 36, 38-40)

10. Pronoto con una banda pálida sobre la línea media y dos manchas pálidas circulares, una a cada lado (Fig. 38)

Myrmeleon inconspicuus

- Pronoto sin banda pálida sobre la línea media y sin estas manchas pálidas circulares (Figs. $36,39,40)$

11. Alas anteriores $<35 \mathrm{~mm}$. Sus campos cubital y anal sin o con un par (al máximo) de celdillas pentagonales (Figs. 8, 10). Pronoto con mancha pálida sobre el margen anterolateral que no se extiende por su región lateral (Figs. 39, 40) ............. 12

- Alas anteriores > $35 \mathrm{~mm}$. Sus campos cubital y anal con numerosas celdillas pentagonales (Fig. 6). Pronoto con mancha pálida sobre el margen anterolateral que se extiende de forma marcada sobre su región lateral (Fig. 36)

Myrmeleon formicarius

12. Pronoto con mancha pálida sobre el margen anterolateral que se extiende por su región anterior media (Fig. 40)

Myrmeleon gerlindae 
- $\quad$ Pronoto con mancha pálida sobre el margen anterolateral que no se extiende por su región anterior media (Fig. 39)

Myrmeleon bore

13. Patas delgadas. Tibias sin espolones distales Gymnocnemia, Gymnocnemia variegata

- Patas robustas. Tibias con espolones más o menos desarrollados, pero existentes

14. Alas anteriores con Cup $+A_{1}$ paralela al margen alar (Figs. 13, 15, 16)

- Alas anteriores con Cup $+A_{1}$ oblícua y convergente con el margen alar (Figs. 14, 17, 25)

15. Alas anteriores con Cup $+\mathrm{A}_{1}$ apenas un final tramo paralela con $\mathrm{Cua}_{2}$, bifurcación de Cua distal al origen de $\mathrm{Sr}+\mathrm{Ma}$, alas posteriores marcadamente manchadas (Fig. 13), antenas, abdomen y patas alternativamente pálido-oscuro

Tricholeon, Tricholeon relictus

- Alas anteriores con Cup + $\mathrm{A}_{1}$ paralela a $\mathrm{CUa}_{2}$ por un largo tramo, bifurcación de Cua basal al origen de $\mathrm{Sr}+\mathrm{Ma}$, alas posteriores sin manchas, salvo un leve punto (Figs. 15, 16), antenas, abdomen y patas uniformemente pardos-grisáceos

Creoleon (16)

16. Alas anteriores marcadamente manchadas, destacando una mancha en forma de $\mathrm{V}$ sobre el margen alar en la convergencia de Cup + $\mathrm{A}_{1}$ y $\mathrm{CUa}_{2}$ (Fig. 15)

- Alas anteriores sin manchas destacables (Fig. 16)

Creoleon aegyptiacus Creoleon lugdunensis

17. Patas largas y finas, tibias apenas más gruesas que el primer tarsómero, alas anteriores con una única mancha oscura sobre el margen posterior (Fig. 25) Megistopus, Megistopus flavicornis

- Patas robustas, tibias mucho más gruesas que el primer tarsómero, alas anteriores con o sin manchas, pero de tenerlas, son varias y no una única mancha oscura sobre el margen posterior (Figs. 14, 17, 18, 19, 20, 24)

18. Tarsos de las patas de mayor longitud que las tibias, alas muy estrechas, las anteriores con margen posterior salpicado de pequeñas manchitas pardas-negras (Fig. 14) ............................................................................... Nemoleon, Nemoleon notatus

- Tarsos de las patas de similar o menor longitud que las tibias, alas no tan estrechas, las anteriores con o sin manchas, pero el margen posterior sin pequeñas manchas pardas-negras (Figs. 17-24)

19. Espolones de las tibias anteriores algo más largos que los tres tarsómeros basales juntos

Distoleon (20)

- Espolones de las tibias anteriores más cortos que los tres tarsómeros basales juntos

20. Alas posteriores, y especialmente las anteriores manchadas (Fig. 17), abdomen uniformemente negro con un par de pequeñas manchitas amarillas por segmento

- Alas sin manchas (Fig. 18), abdomen alternado de pardo y pálido

Distoleon tetragrammicus Distoleon annulatus

21. Espolones de las tibias posteriores algo más largos que los dos tarsómeros basales juntos, alas sin manchas (Fig. 24). Machos con largos cercos (ectoproctos) Macronemurus, Macronemurus appendiculatus

- Espolones de las tibias posteriores algo más cortos que los dos tarsómeros basales juntos, alas anteriores con dos bandas oblícuas más oscuras (Figs. 19-23). Machos sin largos cercos (ectoproctos)

Neuroleon (22)

22. Todas las estrías pardas sobre la vena radial de las alas anteriores son coincidentes con las venillas trasversales situadas bajo ella (Fig. 29)

- Solo algunas estrías pardas sobre la vena radial de las alas anteriores son coincidentes con las venillas trasversales situadas bajo ella (Fig. 30)

23. Mancha pálida situada en el lateral de los segmentos anteriores del abdomen recorriéndolos de forma continua (Fig. 34) .... Neuroleon arenarius

- Manchas pálidas situada en el lateral de los segmentos anteriores del abdomen interrumpidas en cada segmento (Fig. 33) Neuroleon ocreatus

24. Existen dos manchas pálidas situadas en el lateral de los segmentos abdominales anteriores (Fig. 32), espolones tibiales del tercer par de patas de similar longitud que el tarsómero basal

Neuroleon distichus

- Sin o con una única mancha pálida situada en el lateral de los segmentos abdominales anteriores (Figs. 31, 35), espolones tibiales del tercer par de patas o más cortos o más largos que el tarsómero basal

25. Espolones tibiales del primer par de patas tan largos como los dos primeros tarsómeros basales juntos, espolones tibiales del tercer par de patas algo más largos que el tarsómero basal. Cara externa del fémur del tercer par de patas negro en su porción media. Manchas pálidas situadas en el lateral de los segmentos abdominales anteriores no suparan la antecosta (Fig. 31) Neuroleon nemausiensis

- Espolones tibiales del primer par de patas algo más largos que el primer tarsómero basal, espolones tibiales del tercer par de patas más cortos que el tarsómero basal. Cara externa del fémur del tercer par de patas pálido en su porción media. Manchas pálidas situadas en el lateral de los segmentos abdominales anteriores cabalgando sobre la antecosta (Fig. 35) .. 

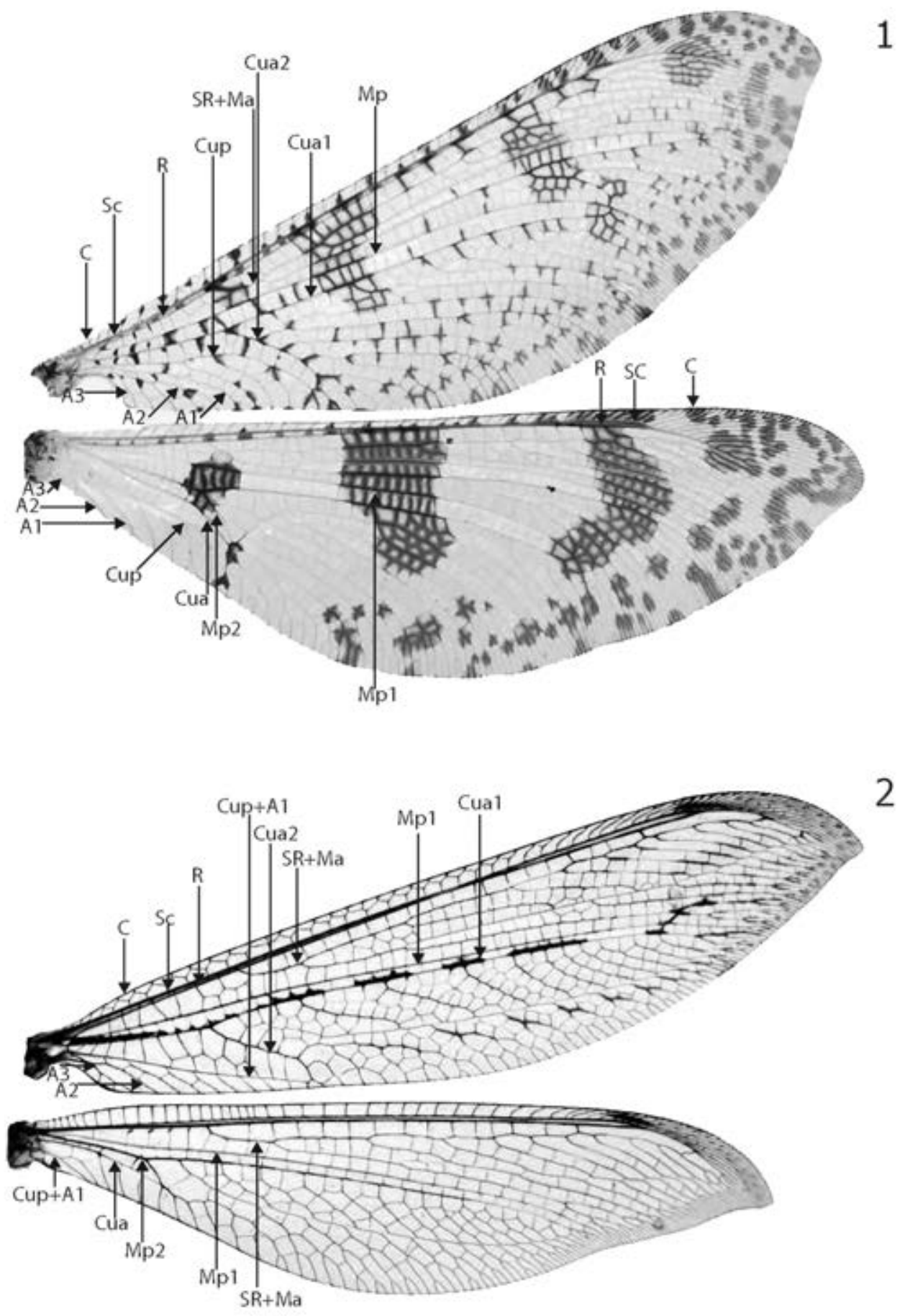

Figs. 1-2.- Alas de: 1) Palpares libelluloides, 2) Acanthaclisis occitanica. A diferentes escalas. A: Anal, C: Costal, Cu: Cubital, Cua: Cubital anterior, Cup: Cubital posterior, Ma: Mediana anterior, Mp: Mediana posterior, R: Radial, Sc: Subcostal, SR: Sector del Radio.

Figs. 1-2.- Wings of: 1) Palpares libelluloides, 2) Acanthaclisis occitanica. At different scales. A: Anal, C: Costal, Cu: Cubital, Cua: Cubital anterior, Cup: Cubital posterior, Ma: Median anterior, Mp: Median posterior, R: Radial, Sc: Subcostal, SR: Radial Sector. 
o praderas, y se han recolectado entre los meses de junio y agosto, y en altitudes que oscilan entre los 10 y los 1620 metros. Aspecto general de sus alas según figura 1. La biología de sus larvas es poco conocida, habitan en zonas pedregosas. Estadios larvarios en Brauer (1854); Hagen (1873); Redtenbcher (1884); Doflein (1921); Steffan (1975); Willmann (1977); Séméria \& Berland (1988); Hölzel \& Gepp (1989); Gepp (2010); Krivokhatsky (2011) y Badano \& Pantaleoni (2013).

NueVo MATERIAL ESTUDiADo: ESPAÑA: Granada, Orgiva, Valle de Guadalfeo, 29.VI.1968, 1 , , Sattler y Carter (NHM).

\section{Palpares hispanus Hagen, 1860}

Palpares hispanus Hagen, 1860a: 40, 1860b: 361; Pictet, 1865: 76, 110; Hagen, 1866a: 288, 1866b: 456, 1873: 255; McLachlan, 1873: 128; Brauer, 1876: 289; Bolívar, 1878: 63; Kolbe, 1884: 135; McLachlan, 1889: 344, 345, 346; Bolívar, 1890: 31; McLachlan, 1902a: 33, 1902b: 129; Navás, 1902b: 103, 1904a: 10, 1905c: 28, 1907b: 100, 1913d: 11, 1914a: 749, 1914f: 607, 1924a: 44, 1925b: 23; Morton, 1925: 405; Monserrat, 1978a: 59, 1979b: 410, 1982: 70, 1985d: 476; Monserrat \& Díaz-Aranda, 1987: 175; Díaz-Aranda \& Monserrat, 1988c: 215; Stange, 2004: 53; Monserrat \& Acevedo, 2011: 125; Ábrahám, 2012: 65, 86, 87, 92, 93, 96, 98; Monserrat \& Triviño, 2013: 19,106.

Palpares hispanicus (sic) Hagen, 1860: Esben-Petersen, 1931: 2; Mountfort, 1968: 191, 162.

Especie mediterránea conocida de la Península Ibérica, Marruecos, Argelia, Túnez, Libia y Egipto. En la Península Ibérica es conocida del centro y especialmente de sus zonas meridionales. Sus imagos habitan en medios abiertos y soleados, laderas pedregosas con gramíneas altas y prados agostados, y se han recolectado entre los meses de mayo y agosto, y en altitudes que oscilan entre los 10 y los 2000 metros. Aspecto general de sus alas según figura 3. La biología de sus larvas es desconocida, probablemente habiten en zonas pedregosas. La larva descrita por MacLachlan (1873) como perteneciente a Palpares hispanus, corresponde en realidad a Synclisis baetica.

Nuevo material estudiado: ESPAÑA: Cádiz, Bolonia, 21.VI.2012, 10", Jimena de la Frontera, 21.VI.2012, 3 우 우, Los Alcornocales, 21.VI.2012, $50^{\pi} 0^{\prime \prime}, 2$ 우. Málaga, Serranía de Ronda, Cartajima, Riscos, 30S3054057, 870 m, 3.VIII.2013, $10^{7}$, O. Gavira.

Acanthaclisinae Navás, 1912

Acanthaclisini Navás, 1912

Acanthaclisis occitanica (Villers, 1789)

Acanthaclisis occitanica (Villers, 1789): Pictet, 1865: 74, 110; Hagen, 1866a: 288, 1873: 262; Brauer, 1876: 289; Ventalló, 1904: 115; Navás, 1904a: 9, 1905c: 27, 1907b: 100, 1913d: 12, 1916d: 178, 1924a: 47, 1925b: 24; Vidal y López, 1943:
14; Steffan, 1975: 404; Marques \& Ormières, 1978: 160; Monserrat, 1979a: 19; Aspöck et al., 1980: 12; Monserrat, 1981: 152, 1984b: 110, 1985a: 476; Díaz-Aranda \& Monserrat, 1988c: 215; Navarro et al., 1988: 52; Gepp \& Hölzel, 1989: 13; Whittington, 2002: 381; González López, 2002: 203; Stange, 2004: 342; Monserrat, 2005: 80; Monserrat \& Acevedo, 2011: 125; Krivokhatsky, 2011: 287; Monserrat \& Triviño, 2013: 19, 95; Barreda, 2013: 78.

Myrmeleon occitanicus Villers, 1789: Walker, 1853: 316.

Especie holomediterránea expansiva extendida al Cáucaso, Irán, Afganistán, Pakistán y Kazajistán. Es conocida en la Península Ibérica y Mallorca en zonas de influencia mediterránea. Sus imagos habitan en medios abiertos, soleados y arenosos, se han recolectado entre los meses de junio y agosto, $y$ en altitudes que oscilan entre los 10 y los 1460 metros. Aspecto general de sus alas según figura 2. Las larvas habitan en zonas arenosas con abundantes restos vegetales. Estadios larvarios en Percheron (1833) (como Myrmeleon libelluloides); Brauer (1855); Hagen (1859, 1873); Redtenbacher (1884); Steffan (1975); Willmann (1977); Stange \& Miller (1985); Gepp \& Hölzel (1989); Gepp (2010), Krivokhatsky (2011) y Badano \& Pantaleoni (2013). Las descripciones dadas por Dufour (1854); Perris (1857); Ferrari (1864); Girard (1875) y Dubois (1899) de larvas asignadas a A. occitanica, corresponden en realidad a Synclisis baetica.

Nuevo material estudiado: ESPAÑA: Almería, Almería, 7.VI.1972, 1 우 , leg.? (MCNM). Ávila, San Martín del Pimpollar, 15.VIII.2007, 1 은. M. Portillo. Madrid, Cercedilla, 1.460 m, s.f., 1 ㅇ , J. Junco (MNCN), Cercedilla, El

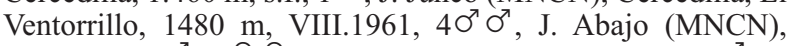
VIII.1962, $10^{\pi}, 5$ 우 우, J. Abajo (MNCN), VIII.1964, $10^{\pi}$, J. Abajo (MNCN), Cercedilla, Estación Alpina, VIII.1935, 10', M. Escalera (MNCN). Salamanca, La Alberca, Laguna de San Marcos, 12.VII.2011, 1 우, M. Portillo (US).

\section{Synclisis baetica (Rambur, 1842)}

Synclisis baetica (Rambur, 1842): Navás, 1922a: 7, 1922b: 18, 1924a: 48, 1924c: 120, 1925b: 25, 1928a: 92, 1932a: 287; Vidal y López, 1943: 14; Stange \& Miller, 1985: 38; Monserrat, 2005: 80.

Acanthaclisis baetica Rambur, 1842: Rambur, 1842: 379; Rosenhauer, 1856: 367; Hagen, 1860b: 362, 1863: 198; Pictet, 1865: 75, 110; Hagen, 1866a: 289, 1866b: 378; McLachlan, 1875: 175; Brauer, 1876: 289; McLachlan, 1884: 183; Navás, 1900a: 96, 1904a: 9, 1905c: 27, 1907b: 100; Andreu, 1909: 160; Okamoto, 1910: 276; Banks, 1911: 6; Navás, 1913d: 14, 1914a: 750, 1914d: 187, 1914f: 609, 1916b: 172; 1916d: 178; Esben-Petersen, 1918: 127; Navás, 1919b: 218; Auber, 1955a: 57, 1958: 39; Mândru, 1961: 333; Berland, 1962: 58; Steinmann, 1963: 215; Steffan, 1975: 402; Monserrat, 1977: 16, 42; Marques \& Ormières, 1978: 160; Insom et al., 1979: 40; Monserrat, 1979 a: 19, 1984 a: 170,1984 b: 110,1985 a: 477, 1985 c: 84; Tröger, 1988: 220, 221; Séméria \& Berland, 1988: 98; Whittington, 2002: 380; Stange, 2004: 358; Monserrat \& Acevedo, 2011: 125; Krivokhatsky, 2011: 293; Monserrat \& Triviño, 2013: 19, 95; Barreda, 2013: 78. Myrmeleon baeticus (Rambur, 1842): Walker, 1853: 316. 

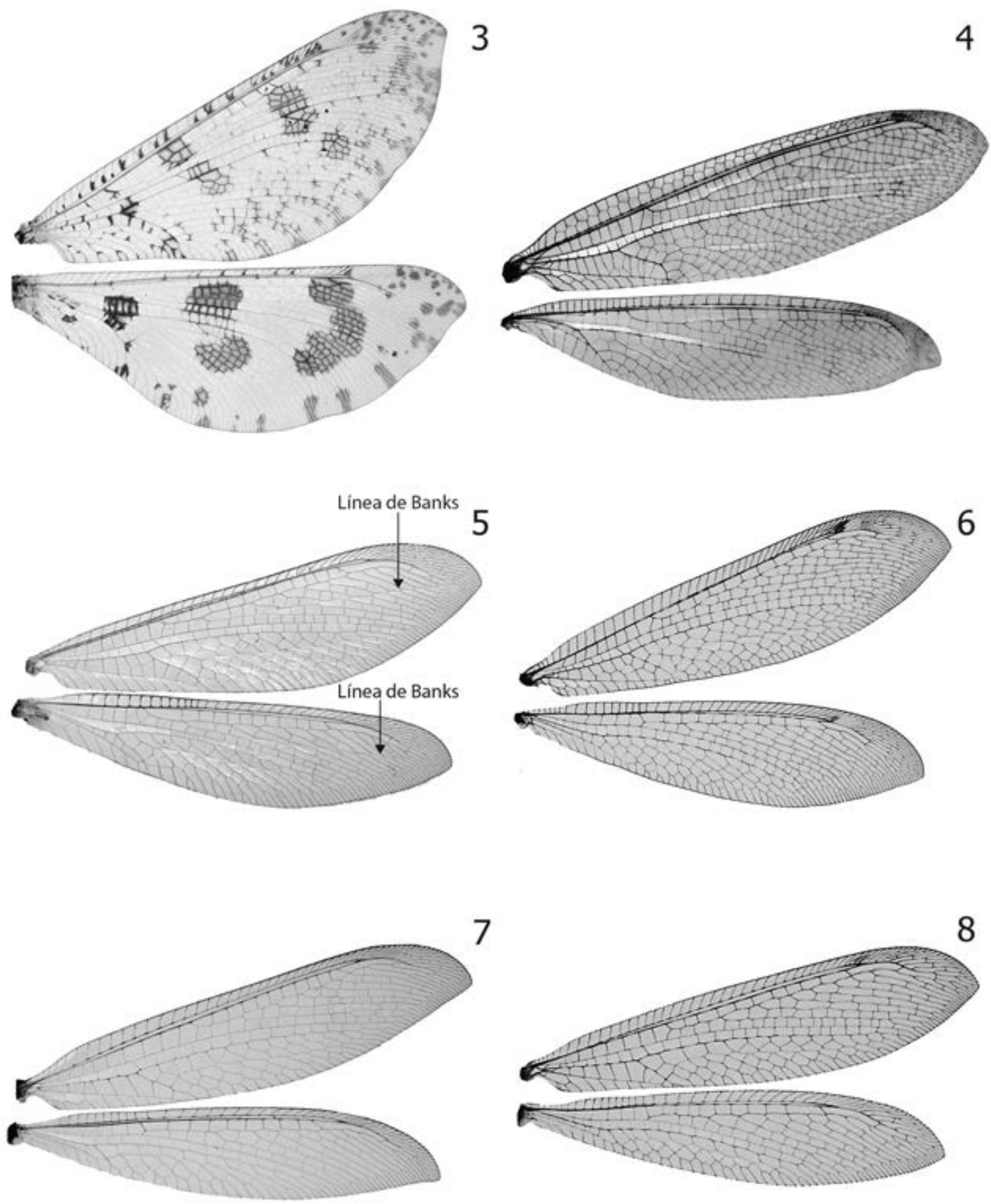

Figs. 3-8.- Alas de: 3) Palpares hispanus, 4) Synclisis baetica, 5) Myrmecaelurus trigrammus, 6) Myrmeleon formicarius, 7) Myrmeleon hyalinus, 8) Myrmeleon inconspicuus. A diferentes escalas.

Figs. 3-8.- Wings of: 3) Palpares hispanus, 4) Synclisis baetica, 5) Myrmecaelurus trigrammus, 6) Myrmeleon formicarius, 7) Myrmeleon hyalinus, 8) Myrmeleon inconspicuus. At different scales. 
Especie holomediterránea extendida hasta Anatolia e Irán. Es conocida en toda la Península Ibérica y Mallorca, especialmente en zonas costeras. Sus imagos habitan en medios abiertos, soleados y litorales, especialmente dunares, y se han recolectado entre los meses de mayo y octubre, y en altitudes que oscilan entre los 10 y los 1000 metros. Aspecto general de sus alas según figura 4. Las larvas habitan en zonas arenosas y dunas abiertas. Datos sobre sus estadios larvarios en MacLachlan (1873) (como Palpares hispanus); Redtenbacher (1884); Meinert (1899) (como Myrmeleon pallidipennis); Principi (1947); Richard \& Pons (1951); Richard (1952); Saffré (1957); Steffan (1975); Willmann (1977); Stange \& Miller (1985); Gepp \& Hölzel (1989); Gepp (2010); Krivokhatsky (2011) y Badano \& Pantaleoni (2013). Como se ha indicado, las descripciones dadas por Dufour (1854); Perris (1857); Ferrari (1864); Girard (1875) y Dubois (1899) de larvas asignadas a Acanthaclisis occitanica, corresponden en realidad a Synclisis baetica.

Nuevo material estudiado: ESPAÑA: Almería, Cabo de Gata, 14.VII.2012, larva L1 recolectada sin cono en la playa en base de planta, vivió hasta el 1.X.2012, Rambla del Retamar, 13.IX.2013, $10^{\top}$ sobre Retama. Cádiz, Barbate, 20.VI.2012, larva L1 recolectada sin cono en la playa en base de planta, vivió hasta el 1.X.2012. Madrid, Dehesa (de la Villa), 29.VIII.1935, $10^{\pi}$, M.Pujol (MNCN).

\section{Myrmecaelurinae Esben-Petersen, 1919}

Myrmecaelurini Esben-Petersen, 1919

\section{Myrmecaelurus trigrammus (Pallas, 1771)}

Myrmecaelurus trigrammus (Pallas, 1771): Hagen, 1866a: 290; Brauer, 1876: 289; Bolívar, 1878a: 63; McLachlan, 1889: 345; Bolívar, 1890: 31; Novak, 1891: 52; McLachlan, 1902b: 130; Navás, 1904b: 21, 1905a: 506, 1905c: 29, 1907b: 99; Andreu, 1909: 160; Cáceres, 1909: 291; Navás, 1909a: 375, 1912e: 176, 1913b: 76, 1913d: 20; Lacroix, 1913: 100; Navás, 1915: 47, 1925b: 30, 1932a: 288, 1932b: 13; Vidal y López, 1943: 15; Principi, 1952: 17; Mândru, 1961: 334; Steinmann, 1963: 213; Steffan, 1975: 386; Monserrat, 1977: 15, 42, 1978a: 59, 1979a: 19, 1981: 152, 1984b: 110, 1985a: 477, 1985c: 84, 1986: 97; Díaz-Aranda, Monserrat \& Marín, 1986a: 1125, 1986b: 1134; Monserrat, 1987a: 134; Monserrat \& Díaz-Aranda, 1987: 176; Díaz-Aranda \& Monserrat, 1988a: 114, 1988c: 215; Marín \& Monserrat, 1991: 180; Marín, 1994: 260; Marín \& Monserrat, 1995a: 39, 1995b: 112; Monserrat, 1996: 12; Whittington, 2002: 383; Stange, 2004: 275; Monserrat, 2005: 80; Monserrat \& Acevedo, 2011: 125; Krivokhatsky, 2011: 258; Monserrat \& Triviño, 2013: 19, 100; Monserrat et al., 2013: 5.

Myrmeleon trigrammus Pallas, 1771: Pictet, 1865: 78, 110; Monserrat, 1977: 43.

Myrmeleon flavus Rambur, 1842: Rambur, 1842: 398; Schneider, 1845: 341; Rosenhauer, 1856: 367.

Myrmecaelurus trigrammus flava Rambur, 1842: Navás, 1919d: 49, 1924a: 59, 1925b: 30, 1927b: 113, 1927c: 95, 1927d: 122; Vidal y López, 1943: 15; Compte, 1967: 133, 140.
Myrmecaelurus flavus (Rambur, 1842): Costa, 1855: 11. Myrmecaelurus trigrammus flavus Rambur, 1842: Capra, 1934: 97; Principi, 1952: 17; Monserrat, 1982: 71.

Especie holomediterránea extendida al Cáucaso, Irán, Kirguistán, Tayikistán y Kazajistán. Es conocida en la Península Ibérica y Mallorca en zonas de influencia mediterránea. Sus imagos habitan en medios abiertos y soleados, especialmente en praderas de gramíneas, estepas y cultivos de cereales agostados y zonas de mal país, y se han recolectado entre los meses de mayo y septiembre, y en altitudes que oscilan entre los 10 y los 1800 metros. Aspecto general de sus alas según figura 5. Sus larvas habitan en zonas abiertas, esteparias, de barbechos, eriales, etc. Estadios larvarios en Redtenbacher (1883, 1884a); Doflein (1921) (como Macronemurus appendiculatus y Megistopus flavicornis); Hölzel (1974) (como Myrmeleon gerlindae); Steffan (1975); Willman, (1977), Krivokhatsky (2011) y Devetak et al. (2013) y Badano \& Pantaleoni (2013).

Nuevo material estudiado: ESPAÑA: Almería, El Pozo de los Frailes, 5.VII.2013, $10^{\pi}$, Playa de los Genoveses, 14.VII.2012, $10^{\pi}$, 6.VII.2013, $20^{\top} \sigma^{\pi}, 4$ 우 우 (era extremadamente abundante), 19.VIII.2013, 1 ㅇ ex larva recolectada en cono el 16.VI.2013, pupó el 29.VII.2013, Playa de Mónsul, 28.VI.2011, $10^{\top}$, San José, 19.VII.2011, $10^{7}$, Tabernas, 18.VII.2011, 1 ㅇ. Granada, Cáñar, 18.VII.2011, $10^{7}, 1$ 우. Madrid, El Salitral, Chinchón, 11.VII.2009, 10", Hoyo de Manzanares, s.f., 2 우 우, leg.? (MCNM). Málaga, Marbella, 20.VIII.1985, 1 ㅇ , M. Candela (MCNM). Murcia, Jumilla, 1.VII.2000, 1 ㅇ, S. Collado.

Myrmeleontinae Latreille, 1802

Myrmeleontini Latreille, 1802

\section{Myrmeleon formicarius Linnaeus, 1767}

Myrmeleon formicarius Linnaeus, 1767: Hagen, 1873: 289; Brauer, 1876: 289; Redtenbacher, 1884: 363; Navás, 1900a: 96; McLachlan, 1902b: 130; Navás, 1904b: 22, 24, 1904c: 200, 1905b: 117, 125, 1905c: 30, 1905d: 46; Lucas, 1905: 297 , 298, 1906a: 53; Navás, 1907b: 94, 97, 1909b: 148, 1909c: 374; Andreu, 1909: 160; Navás, 1912a: 31, 1913a: 80, 1913d: 18, 1914c: 40, 1915: 470; Bosca Seytre, 1916: 48; Navás, 1918: 40, 1919a: 193, 1924a: 51, 1925b: 27, 1931a: 117; Vidal y López, 1943: 15; Principi, 1952: 16; Monserrat, 1977: 15, 44, 45; New, 1983: 282; Monserrat, 1984a: 169, 1984c: 156, 1984d: 46, 1996: 12; Letardi, 1998: 150; Stange, 2004: 326; Krivokhatsky, 2011: 202; Monserrat \& Triviño, 2013: 19, 101.

Myrmeleon formicarium (sic) Linnaeus, 1767: Dziedzielewicz, 1891: 96.

Myrmeleon (Myrmeleon) formicarius Linnaeus, 1767: Monserrat, 1984b: 111, 1985a: 477, 1986: 96; Díaz-Aranda \& Monserrat, 1988b: 219; Monserrat \& Díaz-Aranda, 1988: 89, 1989: 49; Marín \& Monserrat, 1989: 190; Monserrat, Marín \& Díaz-Aranda 1994: 44.

Myrmeleon formicalynx Brauer (sic): Hagen, 1866a: 290.

Especie palaeártica. En la Península Ibérica es conocida mayoritariamente de su tercio septentrional y en zonas 
montanas de latitudes más meridionales. Sus imagos habitan en medios montañosos, claros boscosos abiertos y no demasiado soleados, y se han recolectado entre los meses de mayo y agosto, y en altitudes que oscilan entre los 100 y los 2150 metros. Muchas de las citas de esta especie deberían tomarse con cautela, especialmente las dadas de zonas merionales, térmicas y/o de baja cota. Aspecto general de sus alas según figura 6. Sus larvas habitan en zonas montañosas y boscosas abiertas. Datos sobre sus estadios larvarios en Brauer (1853) (como Myrmecoleon formicalynx); Hagen (1873); Redtenbacher (1884); Doflein (1916); Eglin (1940); Friheden (1973); Steffan (1975); Eisenbeis \& Wichard (1987); Matsura (1987); Gepp \& Hölzel (1989); Gepp (2010); Krivokhatsky (2011) y Badano \& Pantaleoni (2013).

Nuevo material estudiado: ESPAÑA: Ávila, Abantos, Monte de San Juan, 6.VI.1987, 1 ㅇ J. Junoy, Hoyos del Espino, 9.VI.1951, 1 우, F. Ese (MCNM). Cuenca, Valdemela, 13.VII.2009, 1 ㅇ, P. Almagro. Huesca, Baños de Benasque, 27.VII.1983, 2 우 우 a la luz, E. Galante. Madrid, Cercedilla, s.f., 1 ㅇ, C.Bolívar (MCNM), VII.1914, 1 오, Arias (MCNM), 31.VI.1992, 1 ㅇ a la luz, R. Outerelo, Cercedilla, Estación Alpina, VI-VIII.1934-1935, 3 $3 \sigma^{\top} \sigma^{\top}, 4$ 우 우, M. Morales (MCNM), El Escorial, Abantos, Fuente del Cervunal,

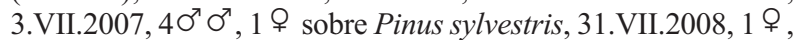
Montejo de la Sierra, VIII.1936, $10^{7}, 1$ ㅇ , leg.?, 14-22.VI.1948, 1 우, leg.? (MCNM), Puerto de Navacerrada, VIII.1932, 2 우 우, F. Marcet (MCNM), Sierra de Guadarrama, VIII.1927, 1 오, B. Uvarov (NHM). Segovia, San Ildefonso, VII.1902, $10^{7}$, Seebold (MCNM), VI-VIII.1906, $30^{\top} \sigma^{\pi}, 4$ 우 $ᄋ$ M. Escalera (MCNM, NHM), San Rafael, VII-VIII.1934-1935, 6 우 오, I. Bolívar (MCNM), Valsaín, 5.VIII.1993, $10^{7}$, leg.? Teruel, Fuente de la Señora, 13.VII.1990, 1 우. Toledo, La Sagra, s.f., 1 우, M. Escalera (MCNM). Zamora, Ribadelago, 26.VI.1978, 1 ㅇ ex larva recolectada el 10.VII.1977. PORTUGAL: Braga, Gerés, Vidoeiro, 31.VII.1987, 1 ㅇ , L. da Terra. Duoro Litoral, Ribeira do Ramalhoso, 9.VI.1986, 1 오 L. da Terra. Trás-os-Montes e Alto Douro, Serra da Estrela, S. Lorenzo, 24.VII.1988, $10^{7}$, E. Clemente. Dudamos de la correcta etiquetación de 1 Q recolectada por C. Bolívar, s.f. en Madrid, Montarco, (MCNM).

\section{Myrmeleon hyalinus Olivier, 1811}

Myrmeleon hyalinus Olivier, 1811: Navás, 1912b: 674, 1913d: 16, 1914d: 187, 1914e: 196, 1915: 47; Auber, 1955a: 56; Mândru, 1961: 333; Berland, 1962: 57; Steinmann, 1963: 220; Compte, 1968: 142; Monserrat, 1978a: 60, 1979a: 18, 1979b: 411, 1984d: 46; Séméria \& Berland, 1988: 101; Marín \& Monserrat, 1995a: 37; Monserrat, 1996: 12, 2005: 80; Monserrat \& Triviño, 2013: 19, 102.

Morter hyalinus (Olivier, 1811): Navás, 1914f: 613; EsbenPetersen, 1918: 125; Cervera, 1922: 148; Navás, 1922d: 148, 1924a: 53, 1925b: 28, 1928a: 93, 1929a: 39; Vidal y López, 1943: 15; Kimmins, 1950: 156; Auber, 1955b: 56; Compte, 1967: 134; Insom et al., 1979: 46.

Myrmeleon distinguendus Rambur, 1842: Rambur, 1842: 407; Schneider, 1845: 342; Walker, 1853: 372; Hagen, 1860b: 368; Pictet, 1865: 79; Hagen, 1866a: 290, 1866b: 437; McLachlan, 1882: 171, 1898: 157; Navás, 1904b: 24, 1905b: 127, 128, 1905c: 30, 1907b: 94, 96, 1909b: 148; Andreu, 1909: 160; Navás, 1912a: 31; Bosca Seytre, 1916: 48.

Myrmeleom distinguendus Rambur, 1842: Navás, 1910: 45; Vidal y López, 1943: 15.

Myrmecaelurus distinguendus (Rambur, 1842): Costa, 1855: 16; Hagen, 1866b: 432; Brauer, 1876: 289.

Myrmeleon (Morter) hyalinus Olivier, 1811: Aspöck et al., 1980: 10; Monserrat, 1984b: 95, 1985a: 477, 1985c: 84; Eglin, 1985: 323; Monserrat, 1986: 97, 1987: 134; Díaz-Aranda \& Monserrat, 1988c: 215; Monserrat \& Díaz-Aranda, 1988: 89, 1989: 49.

Myrmeleon cinereus Klug, 1834: Navás, 1913c: 99, 1913e: 114, 1914 a: 751.

Myrmeleon hyalinus distinguendus Rambur, 1842: Hölzel, 1987b: 81; Stange, 2004: 328.

Holomediterránea. Es conocida en la Península Ibérica y Baleares, mayoritariamente en zonas litorales de influencia mediterránea. Sus imagos habitan en medios abiertos y soleados, frecuente en cauces de ríos secos, ramblas, zonas arenosas y medios litorales y térmicos, y se han recolectado entre los meses de abril y septiembre, $\mathrm{y}$ en altitudes que oscilan entre los 10 y los 820 metros. Aspecto general de sus alas según figura 7. Sus larvas habitan en zonas arenosas, ramblas, rieras, riveras, dunas, etc. Estadios larvarios en Auber (1956b), Willmann (1977) y Badano \& Pantaleoni (2013). Probablemente a esta especie pertenezca la referencia a conos de caza a orillas del río Ebro que cita Marcet (1906: 138), y quizás también las que cita Navás (1905b: 123).

Nuevo material estudiado: ESPAÑA: Alicante, Campoamor, VII.1934, $10^{7}, 3$ 우 우, Andreu (MCNM), Orihuela, Puente Greda, VIII.1933, $10^{\top}$, Andreu, VI.1934, $20^{\top} \sigma^{\top}, 3$ 우 $ᄋ$, Andreu (MCNM), Torrevieja, 18.VIII.1981, 1 \& , S. Cano, Playa El Altet, 4.VII.1996, 1 ㅇ, V. Ortuño. Almería, Adra, VI.1942, $10^{7}$, R. Ajenjo (MCNM), Alhabia, Rambla de Andarax, 20.VII.1988, 1 ㅇ a la luz, Cabo de Gata, 20.VI.2012, 1 오, 12.VI.2013, 1 ㅇ ex larva recolectada en cono el 18.VI.2012, pupó el 22.IV.2013, M.A.Dionisio, Casillas de Atochares, 6.IX.2011, 1 ㅇ ex larva recolectada en cono el 7.V.2011, pupó el 12-16.VIII.2011, El Algarrobico, 25.VI.2012, $10^{7}$ ex 1. recolectada en cono bajo Tamarix el 20.VII.2011, pupó el 29.V.2012, 2.VII.2012, 1 ㅇ ex larva recolectada en cono bajo Tamarix el 20.VII.2011, pupó el 4.VI.2012, 23.VIII.2011, $10^{7}$ ex larva recolectada en cono el 20.VII.2011, pupó el 29.VII.2011, 29.VIII.2011, 1 ㅇ ex larva recolectada en cono bajo Ammophila arenaria el 20.VII.2011, pupó el 3.VIII.2011, 16.IX.2011, 1 ㅇ ex larva recolectada bajo Ononis natrix el 20.VII.2011, pupó el 18-22.VIII.2011, 5.IX.2011, 1 \& ex larva recolectada en cono bajo Tamarix sp. el 20.VII.2011, pupó el 5-8.VIII.2011, 13.VIII.2012, 1 ㅇ ex larva recolectada en cono el 14.VII.2012, pupó el 23.VII.2012, 16.VIII.2012, 1 ㅇ ex larva recolectada en cono el 17.VII.2012, pupó el 23.VII.2012, 29.V.2013, $10^{7}$ ex larva recolectada en cono el 7.VII.2012, 29.V.2013, $10^{\text {" }}$ ex larva recolectada en cono el 7.VII.2012, El Charcón, Rambla Morales, 23.VIII.2011, 1 우 ex larva, recolectada en cono bajo Ononis natrix el 20.VII.2011, pupó el 30.VII.2011, 23.VIII.2011, 1 우 ex larva, recolectada en cono bajo Lycium intricatum el 20.VII.2011, pupó el 29.VII.2011, Las Amoladeras, 14.VI.2012, $10^{7}, 1$ 우 , 23.VII.2012, 1 우 ex larva recolectada en cono en 
oquedad el 14.VI.2012, pupó el 25.VI.2012, 16.VIII.2012, 1 우 ex larva recolectada en cono el 14.VII.2012, pupó el 23.VII.2012, 12.VI.2013, 1 우 ex larva recolectada en cono el 3.XII.2012, pupó el 10.IV.2013, M.A.Dionisio, 14.VI.2013, $10^{7}$, 3 우 우, 16.VIII.2013, 1 우 ex larva recolectada en cono el 14.VI.2013, pupó el 19.VI.2013, 29.VIII.2013, $10^{\top}$ ex larva recolectada en cono el 6.VII.2013, pupó el 8.VIII.2013, 24.IX.2013, $10^{7}$ ex pupa recolectada el 14.IX.2013, Las Casillas de Atochares, Rambla del Artal, 4.VII.2011, $10^{7}$ ex larva recolectada en cono el 7.V.2011, pupó el 8-15.VI.2011, 29.VIII.2011, 1 우 ex larva recolectada en cono el 7.V.2011, pupó el 3.VIII.2011, 30.VIII.2011, 1 우 ex larva recolectada en cono el 7.V.2011, pupó el 5-8.VIII.2011, Las Negras, 2.VII.2007, 1 ㅇ ex larva recolectada en cono el 3.V.2007, 8.VII.2007, 1 우 ex larva recolectada en cono el 3.V.2007, Llano de Dalias 24.V.1942, $10^{7}$, R. Ajenjo (MCNM), Los Albaricoques, 26.VIII.2005 $10^{\prime \prime}$ ex larva recolectada en cono el 9.VII.2005, Níjar, 16.VIII.2011, $10^{7}$ ex larva recolectada en cono el 29.VI.2011, pupó el 26.VII.2011, Playa de los Genoveses, 16.VI.2003, $10^{\prime \prime}$ ex larva, recolectada el 25.VIII.2002, J.F.Gómez, 14.VI.2012, $10^{7}$, 13.VIII.2012, $10^{\pi}$ ex larva recolectada en cono el 14.VI.2012, pupó el 23.VII.2012, 3.IX.2012, 1 ㅇ ex larva recolectada en cono el 14.VI.2012, pupó el 7.VIII.2012, 13.IX.2012, $10^{7}$ ex larva recolectada en cono bajo Thymalea hirsuta el 14.VI.2012, pupó el 27.VIII.2012, 20.IX.2012, 1 ㅇ ex larva recolectada en cono el 14.VI.2012, pupó el 27.VIII.2012, 6.VII.2013, $10^{7}, 1$ ㅇ, 29.VII.2013, 1 우 ex larva recolectada en cono el 16.VI.2013, pupó el 9.VII.2013, 16.VIII.2013, 1 우 ex larva recolectada en cono el 6.VII.2013, pupó el 15.VII.2013, Playa de Mónsul, 25.VI.2012, 1 ㅇ ex larva recolectada en cono el 20.VII.2011, pupó el 28.V.2012, Rambla del Agua, 29.VI.2011, $10^{\prime \prime}, 3$ 우 우, 19.VII.2011, 1 우, 30.VIII.2011, 1 우 ex larva recolectada en cono el 19.VII.2011, pupó el 11.VIII.2011, Rambla de Morales, Cabo de Gata, 18.VII.1988, 1 우 a la luz, 15.VIII.1990, 1 우 ex larva recolectada en cono el 20.VI.1990, 14.X.1990, $10^{7}$ ex larva recolectada en cono el 20.VI.1990, 20.VIII.2007, 1 우 ex larva recolectada en cono el 15.VI.2007, pupó el 25.VII.2007, Retamar, Rambla del Retamar, 29.VIII.2011, $10^{\prime \prime}$ ex larva recolectada en cono bajo Ononis natrix el 19.VII.2011, pupó el 11.VIII.2011, 19.IX.2011, $1 \sigma^{7}$ ex larva recolectada en cono bajo Timalea hirsuta el 20.VII.2011, pupó el 23.VIII.2011, 14.VI.2012, $10^{7}, 14$. VI.2012, $10^{7}$ a la luz, 16.VIII.2012, $10^{7}$ ex larva recolectada en cono bajo Ononis natrix el 19.VII.2011, pupó el 23.VII.2012, 2.VII.2012, 1 ㅇ ex larva recolectada en cono bajo Ononis natrix el 19.VII.2011, pupó el 4.VI.2012, 13.IX.2013, 1 ㅇ , Retamar, Rambla de Torre García, 14.VI.2012, $10^{\pi}, 1$ ㅇ , 20.VIII.2012, $10^{\pi}$ ex larva recolectada en cono bajo Salsola sp. el 14.VI.2012, pupó el 30.VII.2012, 3.IX.2012, $10^{7}$ ex larva recolectada en cono bajo oquedad el 14.VI.2012, pupó el 12.VIII.2012, 3.IX.2012, $10^{7}$ ex larva recolectada en cono bajo Salsola sp. el 14.VI.2012, pupó el 13.VIII.2012, 22.VII.2013, $10^{7}$ ex larva recolectada en cono el 15.VI.2013, pupó el 30.VI.2013, San José, Cerro de Enmedio, 22.VI.1991, 2 우 우, San José, 25.V.2003, $20^{\pi} \sigma^{\pi}, 2$ 우 우 (TAMU), 2 우우, 9.VI.2003, $10^{7}$ ex pupa hallada en un talud, 27.VI-4.VIII. 2003, $70^{\top} \sigma^{7}, 2$ 우 우 ex larva recolectadas en cono el 25.V.2003 y pupadas entre 9.VI-23.VII.2003, San José, Playa de Mónsul, 16.VI.2011, 1 ㅇ ex larva recolectada en cono el 7.V.2011, pupó 16-24.V.2011, 28.VI.2011, $30^{\top} \sigma^{\top}, 1$ 우 우, 4.VII.2011, $10^{\pi}$ ex larva recolectada en cono el 7.V.2011, pupó el 8-15.VI.2011, 2.VIII.2011, $10^{7}$ ex larva recolectada en cono el 29.VI.2011, pupó el 7-15.VII.2011, 23.VIII.2011, 1 우 ex larva recolectada en cono el 7.V.2011, pupó el 26.VII.2011, 29.VIII.2011, $10^{\pi}$, 1 ㅇ ex larvas recolectadas en cono el 7.V.2011, puparon el 58.VIII.2011, 29.VIII.2011, 1 ㅇ ex larva recolectada en cono el 29.VI.2011, pupó el 2.VIII.2011, 30.VIII.2011, $10^{7}$ ex larva recolectada en cono el 7.V.2011, pupó el 9.VIII.2011, 13.IX.2011, 1 우 ex larva recolectada el 7.V.2011, pupó el 22.VIII.2011, 22.IX.2011, 1 ㅇ ex larva recolectada el 28.VI.2011, pupó el 18-22.VIII.2011, 13.VIII.2012, $10^{7}$ ex larva, recolectada en cono el 14.VI.2012, pupó el 23.VII.2012, 3.IX.2012, $10^{7}$ ex larva recolectada en cono el 14.VI.2012, pupó el 13.VIII.2012, Tabernas, 29.VIII.2011, 1 우, $10^{7}$ ex larvas recolectadas el 18.VII.2011, puparon el 11.VIII.2011, 5.IX.2011, 1 우 ex larva recolectada en cono el 18.VII.2011, pupó el 1216.VIII.2011, Vera, Rambla Río Antas, 10.VI.1983, 1 ○ ex larva recolectada en cono el 30.III.1983. Cádiz, Barbate, 20.VI.2012, 1 우 , Bolonia, 22.VI.2003, 1 우 ex larva recolectada el 16.IV.2003, pupó el 20.V.2003, Caños de Meca, 3.V.2002, 2 우 우, 11.VI.2002, 1 우, 8.VII.2002, 1 우, 15.VI.2004 $10^{\top}$ ex larva, 22.VI.2004, 1 우 ex larva recolectada en trampa de arena bajo Pinus el 22.V.2004, pupó el 3.VI.2004, 7.VII.2004 1 ㅇ ex larva recolectada en trampa de arena el 22.V.2004, pupó el 15.VI.2004, 10.VII.2004 1 Q ex larva, recolectada en trampa de arena el 22.V.2004, pupó el 15. VI. 2004, 17.VII.2004 1 Q ex larva recolectada en trampa de arena el 22.V.2004, pupó el 22.VI.2004, 19.VII.2004 1 ㅇ ex larva recolectada en trampa de arena el 22.V.2004, pupó el 22.VI.2004, 29.VII.2004 1 ㅇ ex larva recolectada en trampa de arena el 22.V.2004, pupó el 23.VII.2004, 10-24.VI.2005, 3 $\sigma^{7} \sigma^{7}, 4$ 우 우 ex larvas recolectada en trampa de arena el 1.V.2005, 17.VII.2012, 1 우 ex larva recolectada en cono el 24.V.2012, pupó el 3.VII.2012. Granada, La Herradura, 8. IX.2001, 1 ㅇ a la luz, Lobras, 4.IX.2011, 1 ㅇ ex larva recolectada en cono el 6.V.2011, pupó el 5-6.VIII.2011, San Lúcar de Barrameda, 5-11.VII.1967, $10^{\pi}$, S.V.Peris (MCNM). Huelva, Matalascañas, 18.VI.2012, 1 के ex larva recolectada en cono el 24.V.2012, pupó el 4.VI.2012, 2.VII.2012, 1 ㅇ ex larva recolectada en cono el 24.V.2012, pupó el 11.VII.2012, Punta Umbría, 20.VI.2012, 1 우, 25.VI.2012, 1 우 ex larva recolectada en cono el 24.V.2012, pupó el 4.II.2012, 13.VIII.2012, 1 우 ex larva recolectada en cono el 24.V.2012, pupó el 23.VII.2012. Madrid, Aranjuez, Mar de Ontígola, 24.VII.1979, $20^{\pi} \sigma^{\pi}, 1$ 우, Chinchón, 3.VII.1985, $10^{\pi}$ ex larva recolectada en cono el 19.IV.1985, pupó el 26.V.1985, L. M. Díaz Aranda, 8.VII.1985, $10^{7}$ ex larva recolectada en cono el 19.IV.1985, pupó el 12.V.1985, L. M. Díaz Aranda, 15.VII.1985, 1 o ex larva recolectada en cono el 19. IV.1985, pupó el 13.V.1985, L. M. Díaz Aranda, Rivas-Vaciamadrid, 22.VII.2005, 1 ㅇ , J. I. López-Colón. Murcia, Cabo de Palos, 25-31.VIII.1953, 1 우, leg.? (MCNM), Calblanque, 3.VII.1999, 1 ㅇ, 9.VI.2004, 1 오, ex larva recolectada andando en un talud arenoso el 4.IV.2004, 10.VI.2004, $10^{7}$, ex larva recolectada en cono el 4.IV.2004, 24.VI.2004, 1 우, ex larva recolectada en cono el 4.IV.2004, pupó el 22.V.2004, 27.VI.2004, $10^{7}$, ex larva recolectada en cono el 4.IV.2004, pupó el 5.VI.2004, 28.VI.2004, 1 오, ex larva recolectada en cono el 4.IV.2004, pupó el 20.VI.2004, 21.VII.2004 1 우, ex larva recolectada en cono el 4.IV.2004, pupó el 22.V.2004, 24.IX.2005, $10^{7}$, ex pupa recolectada en arena el 28.VIII.2005, 27.II.2006, 1 ㅇ , ex larva recolectada en cono el 28.VIII.2005, pupó del 13.XII.2005-13.I.2006, 1.III.2006, 1 우, ex larva recolectada en cono el 28.VIII.2005, pupó del 19.XII.2005-13.I.2006, 
23.III.2006, 1 Q , ex larva recolectada en cono el 28.VIII.2005, pupó del 13.I.2006-22.II.2006, 27.III.2006, 1 ㅇ , ex larva recolectada en cono el 28.VIII.2005, pupó del 13.I.2006-22.II.2006, 22.V.2006, 1 ㅇ, ex larva recolectada en cono el 30.VIII.2005, pupó del 15.III.2006-16.IV.2006, 23.V.2006, 1 우, ex larva recolectada en cono el 30.VIII.2005, pupó del 15.III.200616.IV.2006, 18.VII.2011, 1 우, 12.VI.2012, 1 우 ex larva recolectada en cono el 18.VIII.2011, pupó el 12.IV.2012, 14.VI.2012, $10^{\pi}$ ex larva recolectada en cono el 18.VIII.2011, pupó el 14.V.2012, 18.VI.2012, $10^{7}$ ex larva recolectada en cono el 18.VIII.2011, pupó el 21.V.2012, 18.VI.2012, $10^{\top}$ ex larva recolectada en cono el 18.VIII.2011, pupó el 21.V.2012, 18.VI.2012, 1 우 ex larva recolectada en cono el 18.VIII.2011, pupó el 21.V.2012, 25.VI.2012, $10^{7}$ ex larva recolectada en cono el 18.VIII.2011, pupó el 21.V.2012, 25.VI.2012, $10^{7}$ ex larva recolectada en cono el 18.VIII.2011, pupó el 21.V.2012, 10.IX.2012, 1 우 ex larva recolectada en cono el 18.VIII.2012, pupó el 13.VIII.2012, Mazarrón, 28.IV.1978, $10^{\top}$, M.L.M. (UCM), Playa de las Moreras, Mazarrón, 8.VII.2012, 1 ㅇ ex larva recolectada en cono el 19.VIII.2011, pupó el 11.VI.2012, 7.VIII.2012, $10^{7}$ ex larva recolectada en cono el 19.VIII.2011, pupó el 16.VII.2012, Puntas de Calnegre, 11.VI.2012, $10^{7}$ ex 1 recolectada en cono el 28.VIII.2011, pupó el 14.V.2012, 15.VI.2012, $10^{\pi}$ ex larva recolectada en cono el 20.VIII.2011, pupó el 21.V.2012, 18.VI.2012, $10^{7}$ ex larva recolectada en cono el 20.VIII.2011, pupó el 21.V.2012. Tarragona, La Cava, VII.1926, 107, 1 우, J. Gil (MCNM), San Jaume d'Enveja, 26.VI.1999, $10^{\pi}$, J. F. Gómez. Valencia, Bosca, s. f., 2 우 우 Bolívar (MCNM), Oliva, Platja les Devesas, 13.VII.2007, 1 우, J. I. López-Colón.

\section{Myrmeleon inconspicuus Rambur, 1842}

Myrmeleon inconspicuus Rambur, 1842: Navás, 1900b: 219, 1904b: 22, 24; Kempny, 1905: 673; Navás, 1905b: 112, 117, 128, 1905c: 30, 1907b: 94, 97; Pitarque, 1908: 22; Andreu, 1909: 160; Navás, 1909b: 148, 1909c: 176, 1911: 207, 1912a: 29, 31, 1912d: 162; Herrán, 1913: 110; Navás, 1913b: 67, 1913d: 17, 1913g: 48, 1914a: 752, 1914d: 187, 1914f: 612; Esben-Petersen, 1918: 125; Navás, 1924a: 52, 1925b: 28; Tjeder, 1954: 60; Auber, 1955a: 56, 1958: 36; Mândru, 1961: 333; Berland, 1962: 57; Steinmann, 1963: 219; Steffan, 1975: 389; Capra, 1976: 549; Monserrat, 1977: 44, 1978a: 60, 1979b: 411, 1982: 71, 1984d: 46; Díaz-Aranda \& Monserrat, 1988a: 114; Séméria \& Berland, 1988: 101; Marín \& Monserrat, 1995a: 37, 1995b: 112; Monserrat, 1996: 12; Whittington, 2002: 384; Stange, 2004: 330; Monserrat, 2005: 80; Krivokhatsky, 2011: 215; Monserrat \& Triviño, 2013: 19, 103; Monserrat et al., 2013: 5.

Grocus inconspicuus leonina Navás, 1912: Vidal y López, 1943: 15.

Myrmeleon (Morter) inconspicuus Rambur, 1842: Monserrat, 1984b: 111, 1985a: 478, 1986: 97; Díaz-Aranda \& Monserrat, 1988c: 216; Monserrat \& Díaz-Aranda, 1988: 89, 1989: 49.

Myrmeleon inconspicuum (sic) Rambur, 1842: Bosca Seytre, 1916: 48.

Myrmeleon inconspicuus leonina Navás, 1912: Navás, 1912a: 30; Lacroix, 1913: 100; Navás, 1913b: 76, 1913d: 18, 1913e: 115, 1914a: 752, 1914f: 612, 1915: 68; Cervera, 1922: 142; Navás, 1922d: 148, 1924a: 52, 1925b: 28, 1927b: 113, 1927d: 122, 1932b: 13.
La diferente morfología encontrada en algunos ejemplares del sud-oeste peninsular sugiere la posibilidad de estar tratando un taxón distinto al que ahora citamos, por lo que el criterio ahora anotado puede variar en el futuro. Hasta que se revise más profundamente esta cuestión, mantenemos de momento esta situación.

Holomediterránea. Es conocida en la Península Ibérica y Baleares, tanto en zonas de influencia eurosiberiana como mediterránea. Sus imagos habitan en medios abiertos y soleados, sean boscosos o litorales, también en ramblas, rieras y zonas costeras arenosas, y se han recolectado entre los meses de junio y septiembre, y en altitudes que oscilan entre los 10 y los 1315 metros. Aspecto general de sus alas según figura 8 . Sus larvas habitan en zonas arenosas de riveras, costeras y dunas. Estadios larvarios en Redtenbacher $(1883,1884)$ (como Myrmeleon erberi Brauer, 1868); Principi (1943); Graefe (1970); Steffan (1975); Hölzel \& Gepp (1979); Nicoli Aldini (2007); Gepp (2010); Krivokhatsky (2011) y Badano \& Pantaleoni (2013).

Nuevo material eStudiado: ESPAÑA: Almería, Rambla Roja, Tabernas, 16.VII.2012, $10^{7}$ ex larva recolectada en cono en oquedad el 13.VI.2012, pupó el 3.VII.2012, San José, Playa de los Genoveses, 22.IX.2002, 1 ㅇ ex larva, recolectada el 25.VIII.2002, J.F.Gómez. Asturias, Castrillón, VIII.1928, 2 우 오, F. de Córdoba (MNCN). Ávila, Pantano de San Juan, 26.VI.1993, $10^{7}$ ex larva larva recolectada en cono el 1.V.1993, pupó el 30.V.1993. Cádiz, Bolonia, 13.VIII.2012, $10^{7}$ ex larva recolectada en cono el 21.VI.2012, pupó el 30.VII.2012, 25.VIII.2012, $10^{7}$ ex larva recolectada en cono el 21.VI.2012, pupó el 7.VII.2012, Bonanza, 2.VII.2012, $10^{7}$ ex larva recolectada en cono el 24.V.2012, pupó el 11.VI.2012, 3.VII.2012, $10^{7}$ ex larva recolectada en cono el 24.V.2012, pupó el 11.VI.2012, 23.VII.2012, $10^{\text {T }}$ ex larva recolectada en cono el 24.VI.2012, pupó el 3.VII.2012, 13.VIII.2012, 1 \& ex larva recolectada en cono el 24.V.2012, pupó el 30.VII.2012, Caños de Meca, 22.VII.2005, $10^{7}$ ex larva recolectada en cono el 1.V.2005, pupó el 27.VI.2005, 23.VII.2012, $10^{7}$ ex larva recolectada en cono el 20.VI.2012, pupó el 3.VII.2012, 4.VIII.2012, $10^{7}$ ex larva recolectada en cono el 20.VI.2012, pupó el 16.VII.2012, Chiclana, 13.VIII.2012, $10^{\pi}$ ex larva recolectada en cono el 24.V.2012, pupó el 30.VII.2012, Playa de los Lances, 13.VIII.2012, $10^{\pi}$ ex larva recolectada en cono el 21.VI.2012, pupó el 30.VII.2012, 27.VIII.2012, 1 ㅇ ex larva recolectada en cono el 21.VI.2012, pupó el 7.VIII.2012. Ciudad Real, Parque Nacional de Cabañeros, Navas de Estena, 9.VII.2012, $10^{x}$ ex larva recolectada en cono el 8.VI.2012, pupó el 3.VII.2012, 9.VIII.2012, 1 ㅇ ex larva recolectada en cono el 8.VI.2012, pupó el 25.VI.2012. Cuenca, Valdemeca, 13.VII.2009, 1 ㅇ, P. Almagro, P. Granada, Lanjarón, VII.1945, 10 17 Zarco (MNCN). Guipúzcoa, Legazpi, 1 , I. Zabalegui. Huelva, Arroyo Julianejo, 25.VI.2012, 1 \% ex larva recolectada en cono en oquedad el 24.V.2012, pupó el 4.VI.2012, Punta Umbría, 16.VII.2012, 1 우 ex larva recolectada en cono el 24.V.2012, pupó el 3.VII.2012, 4.VIII.2012, 1 \% ex larva recolectada en cono el 24.V.2012, pupó el 18.VI.2012. Huesca, Mesón de Puértolas, 9.VIII.2009, 
$10^{7}$ ex larva, recolectada en cono el 19.VII.2009, 17.VIII.2009, $10^{7}$ ex larva, recolectada en cono el 19.VII.2009. Madrid, Alcalá de Henares, 24.VII.1985, 1 우 a la luz, Madrid, VII, 1 우, C. Bolívar (MNCN), VIII.1978, 1 우, leg.? (UCM). Málaga, Las Cañillas, 20.VIII.2012, 1 ㅇ ex larva recolectada en cono el 25.V.2012, pupó el 20.VII.2012. Santander, San Vicente de la Barquera, 16. VIII.1973, 1 우, M. San Román. Segovia, Chañe, 17.VII-1.VIII.2000, $10^{\text {' }}$ en Trampa de Malaise, J. F. Gómez. Vizcaya, Bilbao, s.f., $10^{7}$, 2 우 우, Seebold (MNCN). Toledo, Calalberche, 22.VII.2002, $10^{7}$ ex larva recolectada el 22.VI.2002, J. F. Gómez, 23.VII.2002, 1 우 ex 1 recolectada el 22.VI.2002, J. F. Gómez.

\section{Myrmeleon bore (Tjeder, 1941)}

Myrmeleon bore (Tjeder, 1941): Letardi, 1998: 150; Stange, 2004: 320; Monserrat \& Triviño, 2013: 19, 101.

Especie conocida de zonas paleárticas de carácter extramediterráneo, desde Francia a Japón. En la Península Ibérica está citada por Letardi (1998), junto a una imprecisa lista de especies recolectadas en la "Península Ibérica" (sin más datos), en base a un único ejemplar $\left(0^{7}\right)$ recolectado en Salamanca: Sequeros, Peña de Francia, y quien nos ha ratificado (com. per.) la identificación de este ejemplar, aunque en este mismo artículo indique: "Further researches in suitable biotopes like warm, sunny, sandy places, need in order to confirm the presence of this taxon in Iberian península". A parte de esta duda sugerida por parte del autor de esta cita, tenemos ciertas dudas en la correcta etiquetación de este ejemplar, ya que esta especie es marcadamente siberiana, extramediterránea y habitante de pinares, zonas arenosas y dunas costeras en zonas frescas y/o septentrionales, y es muy similar a la especie que citamos a continuación. Nos mantenemos pues a la espera de hallar nuevos ejemplares que confirmen definitivamente su presencia en la península. Sus imagos habitan en medios abiertos y soleados, y en Europa se han recolectado entre los meses de junio y agosto (el ejemplar citado en España carece de fecha de recolección, sugiriendo 1931 a tenor de otros ejemplares recolectados en la misma localidad y colección), y en altitudes que oscilan entre los 0 y los 400 metros (la cita en Sequeros correspondería a $920 \mathrm{~m}$ ). Merced a la amabilidad del Dr. R. Pantaleoni, utilizamos material no ibérico para ofrecer el aspecto general de su pronoto, según figura 39, y también utilizamos material no ibérico (Alemania) para sus alas (fig. 9). Sus larvas habitan en riveras arenosas, zonas costeras y dunas. Estadios larvarios en Friheden (1973); Matsura (1987); Gepp \& Hölzel (1989); Nicoli Aldini (2007); Gepp (2010); Krivokhatsky (2011) y Badano \& Pantaleoni (2013).

\section{Myrmeleon gerlindae Hölzel, 1974}

Myrmeleon gerlindae Hölzel, 1974: Hölzel, 1974: 81; Aspöck et al., 1980: 10, 12; Monserrat, 1984b: 111; Marín \& Monserrat, 1995b: 112: 113; Monserrat, 1996: 12; Stange, 2004: 327; Pantaleoni \& Badano, 2012: 139; Monserrat \& Triviño, 2013: 19, 102.

Myrmeleon (Myrmeleon) gerlindae Hölzel, 1974: Díaz-Aranda \& Monserrat, 1988c: 215; Marín \& Monserrat, 1990: 222.

Especie conocida de España, S. de Francia, Italia, Cerdeña y Marruecos. Es conocida en la Península Ibérica en zonas de influencia mediterránea. Sus imagos habitan en medios boscosos, abiertos y soleados, a veces en zonas marcadamente litorales o bien montanas, y se han recolectado entre los meses de junio y septiembre, y en altitudes que oscilan entre los 20 y los 1700 metros. Aspecto general de sus alas según figura 10. Sus larvas habitan en zonas arenosas de bosque con abundantes detritos vegetales. Estadios larvarios en Badano \& Pantaleoni (2013).

Nuevo material estudiado: ESPAÑa: Ávila, Avila, IX.1971, 1 9 , C.Iñigo (UCM), Piedralaves, VIII. 1934, 2 우, F. Bonet (MNCN). Gerona, La Escala, Cala Montgó, 21.VIII.2003 1 우 ex larva capturada en cono en pinar el 13.VII.2003, pupó el 20.VII.2003. Granada, La Herradura, Punta de la Mona, 19.IX.2013, $10^{7}$ a la luz. Guadalajara, Valhermoso, 16.VII.1995, 1 우. Huelva, Arroyo Julianejo, 25VI-2012, 19 ex larva obtenida en cono en oquedad el 24.V.2012, pupó el 11-VI-2012. Jaén, Collado Jardines, 16.VII.1988, $10^{7}$ a la luz, Jándula, VIIII.1930, $20^{7} 0^{7}, 1$ \% , G. Collado (MNCN), VII.1935, 10" , G. Collado (MNCN), Sierra

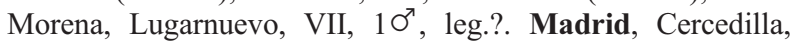
VII.1935, 1 O , M. Escalera (MNCN), 21.VII.1995, $20^{7} \sigma^{7}$ a la luz, R. Outerelo, Ciudad Universitaria, 16.VII.2010, $10^{7}$, Dehesa de la Villa, 29.VIII.1935, 10" , M. Pujol (MNCN), El Escorial, s.f., 1 옹 J. Lauffer (MNCN), El Escorial, Abantos, 7.VIII.2008, $10^{\text {t }}$ ex larva colectada en cono de arena el 17.VII.2008, pupó el 13.VII.2008, El Ventorrillo, VIII.1964, 1 ㅇ, Abajo (MNCN). Toledo, Los Navalmorales, 25.VI.2012, 1 ㅇ ex larva obtenida en cono bajo Quercus suber el 26.V.2011, pupó el 4.VI.2012, 2.VII.2012, 1 \% ex larva obtenida en cono bajo Quercus suber el 26.V.2011, pupó el 18.VI.2012. Zaragoza, Retuerta de Pina, 7.VI.1991, 1 ㅇ, 25.VIII.1991, $10^{7}, 12$.VIII.1992, $10^{7}, 10$. VIII.1993, 1 ㅇ a la luz y en Trampa de Malaise en bosque de Juniperus sabina, J. Blasco.

Euroleon nostras (Geoffroy en Fourcroy, 1785)

Euroleon nostras (Geoffroy en Fourcroy, 1785): Navás, 1924a: 55, 1925b: 29, 1927c: 95; Monserrat, 1977: 14, 43, 1981: 152, 1984a: 168, 1984d: 46, 1985a: 478; Díaz-Aranda et al., 1986a: 1125, 1986b: 1135; Monserrat \& Díaz-Aranda, 1987: 176; Díaz-Aranda \& Monserrat, 1988b: 219; Marín \& Monserrat, 1989: 290; Monserrat, 1996: 12; Stange, 2004: 304; Monserrat \& Acevedo, 2011: 126; Krivokhatsky, 2011: 228; Monserrat \& Triviño, 2013: 19, 98.

Euroleon nostras regia Navás, 1919: Navás, 1919b: 218, 1924a: 56, 1925b: 29; Monserrat, 1977: 14, 43.

Myrmeleon europaeum McLachlan, 1873: Brauer, 1876: 289; Dziedzielewicz, 1891: 97 

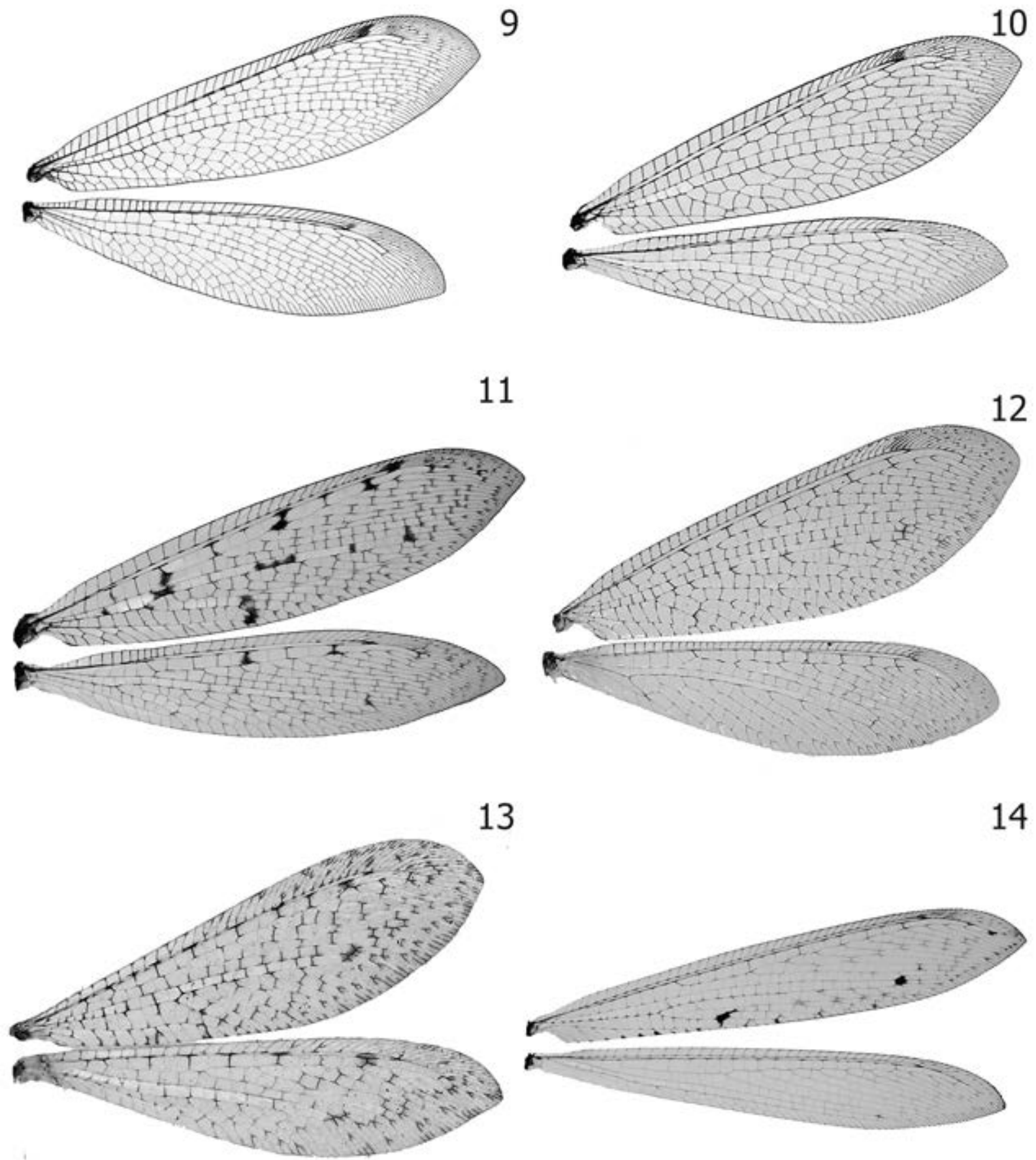

Figs. 9-14.- Alas de: 9) Myrmeleon bore, 10) Myrmeleon gerlindae; 11) Euroleon nostras, 12) Solter liber, 13) Tricholeon relictus, 14) Nemoleon notatus. A diferentes escalas.

Figs. 9-14.- Wings of: 9: Myrmeleon bore, 10: Myrmeleon gerlindae; 11: Euroleon nostras, 12: Solter liber, 13: Tricholeon relictus, 14: Nemoleon notatus. At different scales. 
Myrmeleon europaeus McLachlan, 1873: Redtenbacher, 1884: 361.

Myrmeleon nostras Geoffroy en Fourcroy, 1785: Navás, 1904b: 24, 25, 1905d: 46, 1907b: 96, 98, 1909b: 148, 1912a: 31, 1913a: 80, 1913d: 18; Monserrat, 1977: 14, 43.

Especie holomediterránea expansiva hacia Centroeuropa, Armenia, Azerbaiyán, Georgia y Cáucaso. Ampliamente distribuida en la Península Ibérica. Sus imagos habitan en zonas boscosas abiertas, sabinares/pinares, y se han recolectado entre los meses de junio y septiembre (Monserrat \& Acevedo, 2011 anotan de febrero un ejemplar ex.l. de Asturias, sin duda emergido en condiciones artificiales no espontáneas), y en altitudes que oscilan entre los 60 y los 1700 metros. Aspecto general de sus alas según figura 11. Sus larvas habitan en zonas arenosas protegidas, zonas rocosas, y pie de árboles, etc. Estadios larvarios en Réaumur (1742); Rösel von Rosenhof (1755); Brauer (1853, como Myrmecoleon formicarius; 1857, como Myrmeleon formicarium; Hagen (1873); Redtenbacher (1884); Eglin (1939, 1940); Principi (1943); Friheden (1973); Steffan (1975); Gepp \& Hölzel (1989); Krivokhatsky (1994b, 2011); Gepp (2010) y Badano \& Pantaleoni (2013).

\section{Gepini Mark1, 1954}

Solter liber Navás, 1912

Solter liber Navás, 1912: Navás, 1912a: 33, 1913d: 19; EsbenPetersen, 1918: 119; Navás, 1924a: 56, 1925b: 29; Morton, 1925: 410; Esben-Petersen, 1936: 73; Auber, 1955b: 56; Monserrat, 1985a: 477, 1986: 97; Díaz-Aranda \& Monserrat, 1988a: 115; Whittington, 2002: 385; Stange, 2004: 281; Monserrat, 2005: 80; Monserrat \& Acevedo, 2011: 126; Monserrat \& Triviño, 2013: 19, 107.

Formicaleo annulatus (Klug, 1834): Navás, 1906a: 140 (esta cita es posteriormente asignada a Solter liber por Navás, 1912 a: 34).

Especie saharo-eremial, conocida de Portugal, España, Marruecos, Túnez y Mauritania. En la Península Ibérica es conocida de su mitad meridional. Sus imagos habitan en medios secos, abiertos y soleados, más frecuentemente en zonas térmicas, xéricas y ramblas rocosas con abundancia de oquedades (por todo ello mantenemos nuestras reservas sobre la veracidad en los datos de captura del ejemplar tipo de esta especie en San Fiel, Portugal), y sus imagos se han recolectado entre los meses de julio y agosto, $y$ en altitudes que oscilan entre los 350 y los 940 metros. Aspecto general de sus alas según figura 12. Sus larvas son desconocidas, muy probablemente sus fases juveniles sean troglobias o cavernícolas, y deben habitar en pequeñas oquedades de ramblas en zonas donde se hallan los imagos.

Nuevo material estudiado: ESPAÑ̃: Almería, Tabernas, Rambla Roja, 18.VII.2011, 1 ㅇ. Granada, La Zubia, s.f., $10^{\pi}$, leg?
Dendroleontinae Banks, 1899

Dendroleontini Banks, 1899

Tricholeon relictus Hölzel \& Monserrat, 2002

Tricholeon relictus Hölzel \& Monserrat, 2002: Hölzel \& Monserrat, 2002: 1151; Fernández, 2003: 117; Monserrat, 2010: 20; Monserrat \& Acevedo, 2011: 130; Monserrat \& Triviño, 2013: 19, 108.

Especie muy poco conocida, endémica de la Península Ibérica y citada de dos únicas localidades (España, sur de la provincia de Granada), de la que aportamos ahora nuevos datos. Sus imagos habitan en medios costeros, rocosos y soleados, y se han recolectado mayoritariamente en el interior de viviendas (aunque los imagos no acuden a la luz artificial), entre finales de julio a principios de septiembre, y en altitudes que oscilan entre los 10 y los 200 metros. Muy probablemente sus fases juveniles sean troglobias o cavernícolas. Aspecto general de sus alas según figura 13.

Nuevo MATERIAL ESTUdiado: ESPAÑA: Granada, La Herradura, Cerro Gordo, 17.VIII.2013, $10^{\top}, 31$. VIII.2013, 1 우, La Herradura, Punta de la Mona, 8.VIII.2011, $10^{7}$,

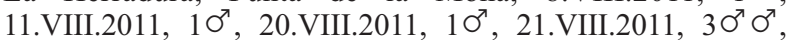
22.VIII.2011 (un ejemplar visto y no recolectado), 23.VIII.2011, 1 우, 24.VIII.2011, $10^{7}$ (BM), 24.VIII.2011, 1 우 (BM), 3.VIII.2012, $10^{\pi}$, 4.VIII.2012, $10^{7}, 6$. VIII. 2012, $1 \sigma^{7}$, 8.VIII.2012, $10^{\pi}, 13$. VIII.2012, $20^{\pi} \sigma^{\pi}$, 14.VIII.2012, $10^{\pi}$, 15.VIII.2012，10", 16.VIII.2012，10", 23.VIII.2012, $1 \sigma^{\pi,}$, 25.VIII.2012, $10^{7}, 27$. VIII.2012, $10^{7}, 1$.VIII.2013, $10^{7}, 1$ 우, 10.VIII.2013, 1 우, 11.VIII.2013, $1 \sigma^{\pi}, 1$ 우, 14.VIII.2013, 1 우, 15.VIII.2013, 1 우 (MCNM), 16.VIII.2013, $10^{\top}$ (MCNM), 1 우, 18.VIII.2013, $10^{7}, 23$. VIII.2013, $10^{7}, 25$. VIII.2013, $10^{7}$ (NHMW), 26.VIII.2013, $10^{7}$, 28.VIII.2013, 1 ㅇ , 29.VIII.2013, 1 ㅇ (NHMW), todos estos ejemplares observados con actividad de vuelo en las primeras horas tras el atardecer o recolectados en el interior de viviendas (casa, garaje o sótano), sin sentirse atraídos por la luz artificial, hecho ya anotado para esta especie, La Herradura (pueblo), 14.VIII.2012, $10^{7}$ volando al atardecer a nivel del mar. Algunos de estos ejemplares mantenidos en cautividad se mantuvieron con vida, sin alimento, hasta 10-12 días.

Nemoleontinae Banks, 1911

Nemoleontini Banks, 1911

Nemoleon notatus (Rambur, 1842)

Nemoleon notatus (Rambur, 1842): Navás, 1909b: 147, 1912a: 30, 1913d: 34, 1913e: 116, 1914a: 763, 1914d: 187, 1914f: 631, 1916e: 18; Esben-Petersen, 1918: 108; Navás, 1924a: 65, 1925b: 34, 1929a: 39; Kimmins, 1939: 108; Vidal y López, 1943: 16; Handschin \& Mark1, 1955: 81; Aspöck et al., 1980: 12; Monserrat, 1983: 126, 1984b: 96, 1985a: 481; Díaz-Aranda \& Monserrat, 1988c: 216; Monserrat \& DíazAranda, 1988: 89, 1989: 49; Stange, 2004: 119; Monserrat, 2005: 81; Monserrat \& Triviño, 2013: 19, 103.

Myrmeleon notatus Rambur, 1842: Rambur, 1842: 402; Walker, 1853: 369; Rosenhauer, 1856: 367; Hagen, 1860 b: 367; Pictet, 1865: 79, 110; Hagen, 1866a: 290, 1866b: 445; 
McLachlan, 1873: 137; Brauer, 1876: 290; Navás, 1904b: 24, 25, 1907b: 96, 97; Andreu, 1909: 160.

Myrmeleon innotatus (sic) Rambur, 1842: Navás, 1900a: 96.

Especie eremial circumsahariana. Es conocida en la Península Ibérica y Mallorca, mayoritariamente en zonas litorales de influencia mediterránea. Sus imagos habitan en medios subdesérticos, abiertos, térmicos, xéricos, pedregosos y soleados, y se han recolectado entre los meses de junio y septiembre, y en altitudes que oscilan entre los 10 y los 1300 metros. Aspecto general de sus alas según figura 14. Sus larvas deben habitar en medios similares a los imagos, son descritas por Badano \& Pantaleoni (2013).

Nuevo material estudiado: ESPAÑA: Almería, Castillo de Baños, 28.VI.2011, 1 우, Rambla Retamar, Retamar, 18.VI.2012, $10^{\circ}$. Granada, La Herradura, Playa de Cantarriján, 12.VI.2012, 1 우, F. (Fuente?) de la Greda, 22.IX.1935, 1 ㅇ , M. Burr.

\section{Creoleontini Markl, 1954}

\section{Creoleon aegyptiacus (Rambur, 1842)}

Creoleon aegyptiacus (Rambur, 1842): Auber, 1955a: 54; Berland, 1962: 55; Hölzel, 1976: 35; Monserrat, 1977: 14, 57, 62, 1979a: 19, 1984b: 111, 1985a: 483, 1985c: 85, 1986: 98; Séméria \& Berland, 1988: 91; Marín \& Monserrat, 1995b: 112: 113; Monserrat, 1996: 12; Whittington, 2002: 381; Stange, 2004: 135; Monserrat, 2005: 81; Monserrat \& Acevedo, 2011: 129; Monserrat \& Triviño, 2013: 19, 96

Creagris plumbeus nigrum (Rambur, 1842): Bolívar, 1890: 31.

Creagris submaculosa (Rambur, 1842): Esben-Petersen, 1918: 116.

Creagris submaculosus (Rambur, 1842): Hagen, 1866a: 290, 1866b: 402; Brauer, 1876: 289.

Creagris v-nigrum (Rambur, 1842): Hagen, 1866a: 290, 1866b: 402; Brauer, 1876: 289; McLachlan, 1889: 345; Navás, 1904b: 20, 1905c: 28, 1907b: 99; Morton, 1907: 2; Andreu, 1909: 160; Navás, 1913d: 22, 1914a: 755, 1914d: 188, 1914f: 618, 1916b: 172; Esben-Petersen, 1918: 116; Compte, 1968: 143.

Creoleon submaculosus (Rambur, 1842): Monserrat, 1977: 62. Creoleon v-nigrum (Rambur, 1842): McLachlan, 1873: 135; Navás, 1919b: 221, 1924a: 80, 1924b: 7, 1925b: 40, 1931a: 117; Vidal y López, 1943: 17; Auber, 1955a: 54; Berland, 1962: 55; Monserrat, 1977: 62, 1978a: 61, 1984 b: 111, 1986: 98; Séméria \& Berland, 1988: 91.

Creoleon v-nigrun (Rambur, 1842): Navás, 1928a: 96.

Creoleon v-nigrum collina Navás, 1919: Navás, 1919b: 220, 1924a: 80, 1925b: 40; Compte, 1967: 132.

Creoleon v-nigrum submaculosa (Rambur, 1842): Navás, 1919b: 219, 1924a: 80, 1925b: 40; Compte, 1967: 132.

Creoleon v-nigrum submaculosus (Rambur, 1842): Navás, 1927c: 95; Capra, 1937: 57, 1976: 553.

Myrmeleon submaculosus Rambur, 1842: Rambur, 1842: 396; Walker, 1853: 352; Rosenhauer, 1856: 367; Hagen, 1860b: 364; Pictet, 1865: 77, 110; McLachlan, 1873: 136.

Myrmeleon v-nigrum Rambur, 1842: Rambur, 1842: 394; Rosenhauer, 1856: 367; Hagen, 1860b: 364; Pictet, 1865: 76, 110; McLachlan, 1873: 136.
Especie holomediterránea expansiva, conocida de Egipto, Argelia, Túnez, Marruecos, España, Italia (Sicilia), Israel, Irak, Irán y Afganistán. La reciente revisión de las especies europeas del género Creoleon (Hölzel, 1976) dista de ser satisfactoria desde nuestro punto de vista, especialmente en lo que respecta a la identidad de Creoleon aegyptiacus (Rambur, 1842) respecto a Creoleon v-nigrum (Rambur, 1842), que quizás pueda tratarse de una especie válida, por lo que el criterio ahora anotado puede variar en el futuro.

Es una especie conocida de la Península Ibérica y Baleares en zonas de influencia mediterránea. Sus imagos habitan en medios térmicos, áridos, abiertos y soleados, praderas agostadas, ramblas y zonas de mal país, y se han recolectado entre los meses de mayo y septiembre, y en altitudes que oscilan entre los 10 y los 2000 metros. Aspecto general de sus alas según figura 15. Sus larvas son desconocidas, deben habitar en la base de matorrales de zonas arenosas y dunas interiores entre restos vegetales.

Nuevo material estudiado: ESPAÑA: Almería, Bella Vista, 28.VI.2011, 2 ㅇ 우, Rambla de Retamar, Cabo de Gata, 20.VII.2011, 1 ㅇ, 18.VI.2012, 1 ㅇ, El Alquián, 7.VII.2012, 1 운, Rambla Retamar, Retamar, 14.VI.2012, $20^{7} 0^{7}$, 18.VI.2012, 1 우 14.VI.2013, $30^{7} 0^{7}, 2$ 우 우, Rambla de Torre García, Retamar, 14.VI.2012, 1 우, San José, Cerro de Enmedio, 29.VI.2011，10 , Tabernas, 18.VII.2011, 1 ㅇ. Baleares, Mallorca, Sa Roca, Parc Natural de s'Albufera, 3.IX.2012, $10^{\text {", }}$ M.R. Honey (MRH). Cádiz, Facinas, 3.VII.2012, 1 ㅇ, ex larva ecolectada bajo Olea euopaea el 25.V.2012, pupó el 18.VI.2012, Jándula, VIII.1930, 1 ㅇ, G. Collado (MCNM), Playa de los Lances, 26.VII.2012, 1 , , ex larva recolectada bajo Retama sp. el 21.VI.2012, pupó el 9.VII.2012. Granada, Sierra Nevada, VIII.1966, 1 ㅇ, R. A. Broad, Ugijar, 24.VII.1985, 1 오, F. J. Alba. Huelva, Matalascañas, 20.VI.2012, $10^{7}$. Teruel, Teruel, 935 m, VIII.1928, 1 ej. B.Muñoz (MCNM).

\section{Creoleon lugdunensis (Villers, 1789)}

Creoleon lugdunensis (Villers, 1789): Steffan, 1975: 397; Hölzel, 1976: 37; Monserrat, 1977: 14, 57, 58, 1978a: 61, 1978b: 173; Insom et al., 1979: 41; Monserrat, 1979a: 19, 1979b: 411, 1980a: 173, 1980b: 183; Aspöck et al., 1980: 10, 12; Monserrat, 1982: 72, 1984a: 169, 1984b: 97, 1984c: 156, 1984d: 32, 1985a: 481, 1985c: 85, 1986: 98; DíazAranda, Monserrat \& Marín, 1986a: 1125, 1986b: 1135; Monserrat \& Díaz-Aranda, 1987: 176, 1988: 89; DíazAranda \& Monserrat, 1988a: 115, 1988b: 220, 1988c: 216; Monserrat \& Díaz-Aranda, 1989: 50; Marín \& Monserrat, 1990: 223, 1991: 180; Marín, 1994: 260; Monserrat et al., 1994: 45; Marín \& Monserrat, 1995a: 39, 1995b: 112: 113; Monserrat, 1996: 12; Whittington, 2002: 381; Stange, 2004: 141; Monserrat, 2005: 81, 2011: 162; Monserrat \& Acevedo, 2011: 129; Krivokhatsky, 2011: 179; Monserrat \& Triviño, 2013: 19, 97; Monserrat et al., 2013: 5.

Creagris plumbea (Olivier, 1811): Navás, 1913d: 21, 1914c: 40, 1914d: 188, 1914g: 212; Gil, 1915: 26; Navás, 1915: 28, 1916b: 172, 1917: 86 . 
Creagris plumbeus (Olivier, 1811): Hagen, 1866a: 289; Bolívar, 1878: 62; Cuní y Martorell, 1880: 242; MacLachlan, 1889: 344, 345; Bolívar, 1890: 31; Cuní y Martorell, 1897: 324; Navás, 1900a: 95, 1902b: 102; MacLachlan, 1902a: 33, 1902b: 130; Ventalló, 1904: 115; Navás, 1904b: 19, 1904d: 143, 1904e: 128, 1905a: 506, 1905b: 111, 116, 125, 128; Lucas, 1906b: 277; Navás, 1907b: 98; Andreu, 1909: 160; Cáceres, 1909: 291; Navás, 1909a: 376, 1909c: 176, 1910: 45, 1913a: 81, 1913b: 67, 1913c: 99; Compte, 1968: 143; Monserrat, 1977: 61.

Creoleon lugdunense (Villers, 1789): Mândru, 1961: 332; Berland, 1962: 55; Steinmann, 1963: 224; Compte, 1967: 132; Monserrat, 1981: 153, 1987a: 135; Séméria \& Berland, 1988: 90.

Creoleon plumbens (sic) (Olivier, 1811): Navás, 1922a: 7, 1927d: 122.

Creoleon plumbeus (Olivier, 1811): MacLachlan, 1903: 225; Navás, 1904c: 200, 1905c: 28, 1913f: 11, 1919a: 194, 1922d: 148; Cervera, 1922: 148; Navás, 1923: 167, 1924a: 78, 1924b: 7, 1924c: 123, 1925b: 39, 1927b: 113, 1928a: 96, 1928c: 43, 1932b: 13; Vidal y López, 1943: 17; Monserrat, 1977: 61, 62; Whittington, 2002: 381; Monserrat, 2011: 162.

Creoleon plumbeus maculosa Navás, 1927: Navás, 1927e: 80; Monserrat, 1977: 61

Myrmecaelurus pallidipennis (Rambur, 1842): Costa, 1855: 17. Myrmeleon pallidipennis Rambur, 1842: Rambur, 1842: 395; Schneider, 1845: 341; Walker, 1853: 352; Rosenhauer, 1856: 367; Cuni y Martorell, 1897: 324; Navás, 1900a: 95.

Myrmeleon plumbens (sic) Olivier, 1811: Hagen, 1858: 126; Bosca Seytre, 1916: 48; Navarro et al., 1988a: 53.

Myrmeleon plumbeus Olivier, 1811: Pictet, 1865: 77.

Especie mediterránea occidental, conocida de Croacia, Suiza, Italia, Malta, Francia, España, Portugal, Marruecos y Túnez. En la zona de estudio ha sido erróneamente citada con frecuencia como Creoleon plumbeus (Olivier, 1811), incluso recientemente. Monserrat (2011) comenta y corrige estas citas. Como citábamos en el caso de la especie anterior, la situación de esta especie mediterránea occidental no la consideramos definitivamente resuelta, y dada la variabilidad de tamaño y coloración hallada dentro de los ejemplares ibéricos de esta especie (especialmente en las poblaciones litorales) nos sugiere que probablemente en el futuro puedan desglosarse distintos taxa respecto a lo que ahora se considera.

Es conocida en la Península Ibérica y Baleares en zonas de influencia mediterránea. Sus imagos son frecuentes en medios secos, abiertos y soleados carentes de vegetación arbórea, estepas y praderas agostadas, claros de bosques y zonas litorales térmicas y áridas, y se han recolectado entre los meses de marzo y octubre, y en altitudes que oscilan entre los 10 y los 2250 metros. Aspecto general de sus alas según figura 16. A pesar de la abundancia de imagos, la biología de sus larvas es muy poco conocida. Nosotros las hemos encontrado en pie de árboles, entre restos vegetales. Estadios larvarios en Steffan $(1965,1975)$ y Badano \& Pantaleoni (2013).

NueVo Material estudiado: ESPAÑA: Albacete, Castala, 11.VII.1985, 1 웅 Molinicos, 20.VI.1986, 1 웅 Ríopar,
31.VII.1984, 1 우, leg.?. Alicante, Alicante Ciudad, 12.VI.1977, 1 옹. M. A. Herrera (UCM). Almería, Bella Vista, 28.VI.2011, 2 mm, Cabo de Gata, 18.VI.2012, $20^{\top} \sigma^{\prime \prime}$, Castala, 11.VII.1985, 1 우, El Ejido, Rambla del Tuerto, 19.VII.2011, $10^{7}$, El Toyo, 6.V.2011, $10^{7}, 1$ 을, Guardias Viejas, 11.VII.1985, $10^{7}$, Las Amoladeras, 14.VI.2013, $3 \sigma^{\top} \sigma^{\top}$, Playa de El Ejido, 19.VI.1990, $10^{\top}$, Playa de Mónsul, 28.VI.2011, 1 우, 20.VII.2011, 1 우, Punta del Sabinar, 10.VII.1985, $10^{\top}, 1$ 오 , Rambla de Retamar, Cabo de Gata, 20.VII.2011, 1 ㅇ , 14.VI.2012, 1 ㅇ, 18.VI.2012, 2 우, 12.VII.2012, $10^{\top}, 1$ 우 a la luz, Rambla de Torre García, Retamar, 12.VII.2012, $20^{7} \sigma^{7}, 1$ 우, Rambla Morales, 20.VI.1990, 1 우, Rambla de Tabernas, 17.VI.1989, 1 ㅇ, Roquetas, 20.IV.1942, $10^{\prime \prime}$, R. Agenjo (MCNM), Roquetas, Las Marinas, 10.VIII.1971, 1 우, L. Subías, 14.VIII.1971, $10^{7}$, L. Subías, 10.VII.1985, $20^{7} \sigma^{7}, 1$ 우, San José, 12.IX.1991, $10^{7}$, V. Ortuño, San José, Playa de los Genoveses, 23.VIII.1991, 1 우, 25.V.2003, 3 우 우, 14.VI.2012, $40^{7} \sigma^{\pi}$, 26.VI.2012, $20^{7} \sigma^{\pi}, 2$ 우 우, San José, Playa de Mónsul, $12 \sigma^{7} \sigma^{7}, 28$. VI.2011, $10^{7}, 14$. VI.2012, $10^{7}, 1$ 우, Tabernas, 18.VII.2011, 2 우 우, Tabernas, Rambla Roja, 14.VI.2012, $10^{\circ}$, Vícar, 14.IX.2013, 1 ㅇ a la luz, F. Rodríguez Luque. Ávila, Ávila Ciudad, 2.VIII.1973, 1 오, M. J. Puche, Casillas, VI.1987, $10^{7}$, A. Galiano (UCM), Navacepeda de Tormes, 12.VIII.1989, $10^{7}$, E. S. L. (UCM), Navalperal de Pinares, 28.VII.2007, 2 우 ㅇ (TAMU), Navas del Marqués, 19.VI.1983, 1 오 A. Roldán (UCM), 11.VII.1985, 1 ㅇ A. Riza (UCM), Once Castaños, 17.VII.1988, 1 오, E. Clemente, San Esteban del Valle, 25.VII.1978, 1 오, J. M. Barrasa. Badajoz, Montemolín, 15.VI.1985, $10^{7}$, Oliva, Río Ardila, 21.VI.1985, 1 ㅇ, E. Clemente, Valle de Matamoros, 20.VI.1985, 1 오 , E. Clemente. Cádiz, Bolonia, 21.VI.2012, $10^{\prime}$, 23.VII.2012, 1 우 , ex larva recolectada bajo palmito sin cono el 21.VI.2012, pupó el 4.VII.12, Estación de La Almoraima, 25.V.2012, 2 우, Facinas, 20.VI.2012, 1 우, La Línea, 3.VI.1978, 1 오, J. L. Torres, La Zarzuela, 25.V.2012, $20^{\pi} \sigma^{\pi}$, 2 우 우, Los Ángeles, 21.VI.2012, $10^{\top}, 1$ 우, Pinar de San Roque, 1.VI.1996, 1 \& , J. Ramírez (MCNM), Puerto de Santa María, 15.VI.1984, 1 우, J. Nieto, Venta del Retín, 27.V.1987, 1 우. Ciudad Real, Alcázar, 5.VI.1990, $10^{7}$, M. J. Arroyo (UCM), Parque Nacional de Cabañeros, Navas de Estena, 7.VI.2012, 10", 8.VI.2012,

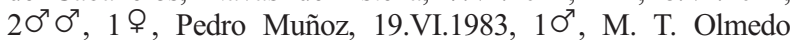
(UCM). Cuenca, Cañada del Hoyo, 8.VII.1987, 1 우, E. Soteras (MCNM). Granada, Cáñar, 27.VI.2011, $20^{7} 0^{\pi}, 3$ 우 우, 18.VII.2011, 2 우 우, Capilleira, 5.VIII.1984, 10", A. Compte (MCNM), Dehesa del Camarate, 19.VII.2011, $20^{7} \sigma^{7}, 1$ 우, Gualchos, 28.VI.2011, 1 우, Soportújar, 27.VI.2011, $2 \sigma^{\top} \sigma^{\top}, 4$ ff, 18.VII.2011, $10^{\top}, 1$ 우. Huelva, El Rocío, 9.VIII.1991, 1 우, A. Arillo, Niebla, 8.VIII.1991, 1 우, A. Arillo. Jaén, Despeñaperros, 9.VI.1923, $20^{7} \sigma^{7}, 2$ 우 우, A Codina (MB), Santiago de la Espada, 7.VI.1986, $10^{\nearrow}$. La Coruña, Muros, 10.III.1990, 1 ㅇ, M. J. Pintado (UCM). Madrid, Abantos, 4.VII.2012, 3 우 우, Algete, 17.VI.1983, 1 ㅇ A. González (UCM), Aranjuez, 13.VI.1974, $50^{7} \sigma^{7}, 7$ 우 우, 20.VI.1983, $10^{\circ}$, A. Jacoste (UCM), Batán, 19.VI.1972, $10^{7}, 1$ ㅇ , Brunete, Cienvallejos, VI.1927, $10^{\circ}$, C.Bolívar (MCNM), Campo Real, 25.VI.1987, 1 온.Izquind (MCNM), Buitrago, s.f., 1 웅, Arroyo (MCNM), Casa de Campo, 2.VI.1983, $10^{7}$, F.J.Palacios (UCM), Castillo de Viñuelas, 24.VI.1982, 1 ᄋ , R. Outerelo, Cercedilla, 2.VI.1990, $10^{7}$, G. Morales (UCM), 7.VIII.1992, 1 ㅇ, V. Ortuño, Cervera de Buitrago, 6.VI.2007, 1 우, M. Costas, Chinchón, 18.V.1987, $10^{7}$, G. Marcano (UCM), Ciudad Universitaria, 1.VI.1973, $10^{\sigma}$, Colmenar Viejo, 20.VI.1987, 1 올. E. García (UCM), Cubas, 3.VII.1971, $10^{7}$, J. A. de la Fuente, El Escorial, Cerro Cabezuelo, 
26.VII.1977, 1 우, R. Outerelo, El Pardo, 26.VI.1983, 1 오, V. Málida (UCM), 20.VI.1985, 1 \& , J. Guerra (UCM), 5.VI.1987, 1 , A. Escudero (UCM), 15.VI.1987, 1 ㅇ, A. Escudero (UCM), Galapagar, 20.VI.1983, 1 오, I. Martínez (UCM), 28.V.1988, 1 옹, R. R. (UCM), Getafe, VII.1946, 1 우, S. V. Peris, 17.V.1986, 1 우, M. Torrero (UCM), 13.VI.1987, 1 ㅇ, M. Gorroño (UCM), Hortaleza, 24.VI.1986, 1 오 F. López (UCM), Hoyo de Manzanares, 15.VII.1979, 1 우, 23.VI.1980, 2 우 우, 11.VII.1980, $30^{7} \sigma^{7}, 1$ ᄋ , 28.VI.1992, 10", 26.VI.2004, 10", La Pedriza, 11.VI.1981, $10^{\pi}, 1$ \& , R. Outerelo (UCM), Las Rozas, 11.III.1977, $10^{7}$, P. Villanueva, Leganés, 12.VI.1980, 10", A. Espuela (UCM), Madrid Ciudad, VII.1941, $20^{\top} \sigma^{\top}$, leg.? (MCNM), V.1945, 1 ej. Gómez Menor (MCNM), VII.1980, 1 오, M. T. Boquete (UCM), 2.VI.1983, 10 $0^{\pi}$, E. Lobo (UCM), 5.VI.1985, $10^{7}$, S. López (UCM), 13.VI.1986, 1 우, P. Molina (UCM), 16.VII.2000, 10', J. F. Gómez, Majadahonda, 1.VI.1986, 1 ㅇ, F. Navarro (UCM), Mejorada 18.VI.1978, 10', F. E., 21.VI.1981, $10^{7}$, A. Mateo (UCM), Montarco, Rivasvaciamadrid, 17.VI.1993, 1 ㅇ , J. L. López-Colón, 3.VII.1993, $10^{7}$, J. L. LópezColón, 27.VI.2007, 10", J. L. López-Colón, Móstoles, V.1987, $10^{7}$, R. Almarza (UCM), 20.VI.1987, 1 우, R. Aguado (UCM), Navaluenga, VII.1980, 1 우, P. Pajuelo (UCM), Parquelagos, 21.VI.1978, $10^{\pi}$, leg.?, Pelayos, 19.VI.1986, 1 우, A. Tonda (UCM), Prádena del Rincón, 10.VI.1980, $10^{\top}$, E. Plaza (MCNM), Ribas Vaciamadrid, Cerro del Telégrafo, 23-24.V.1997, $10^{7}, 1$ 우, J.L.López-Colón, Río Cofio, 11.VII.1980, $10^{7}$, San Fernando de Henares, 26.VI.2010, 1 ㅇ, 29.VI.2010, 1 ㅇ , 13.VI.2012, $10^{7}$, J. I. López-Colón, Santa Eugenia, 20.VI.1978, $20^{7} \sigma^{7}$, Allac, Somontes, 28.V.1987, 1 우, M. Candela (MCNM), Talamanca del Jarama, 2.VI.1983, $10^{\top}$, J. Calle (UCM), Valdemoro, 2.VI.1974, $190^{7} 0^{\prime}, 11$ 우 우, Villa del Prado, 28.VIII.1991, $10^{\pi}, \mathrm{M} . \mathrm{V}$. Peinado, Villalba, 13.VI.1983, $10^{7}$, F. Pérez (UCM), Villalbilla, 12.VIII.1984, $10^{7}, 1$ 우, F. Marín, 21.VI. 1985, 1 우, F. Marín, Villanueva de Perales, 6.V.2009, 10', Villaviciosa de Odón, 5.VI.1987, 1 옹. J. Alonso (UCM). Málaga, Los Teatinos, 20.VI.1923, 1 ㅇ, A. Codina (MB), Málaga, 1.VIII.1986, $10^{\top}$, A. Zarazaga, Puerto de Montejaque, 22.VI.2012, $20^{7} \sigma^{\top}, 2$ 우 ㅇ․ Murcia, Águilas, 28.V.1977, $10^{7}$, C. Rey (MCNM), Calblanque, 18.VII.2011, 1 울, Cartagena, 13.V.1986, 1 우, B. Álvarez (UCM). Pontevedra, Hío, Playa de Barra, 17.VII.1993, 1 ㅇ. Salamanca, El Tejado de Béjar, 14.V.1984, 10', M.Ga. París (MCNM), Salamanca, VII, 10, 2 우 우, F. de Alonso (MCNM). Toledo, Cedillo del Condado, 28.V.1988, $10^{7}$, M. Ramírez (UCM), Lillo, Laguna del Altillo, 9.VI.1986, $10^{\top}, 1$ 우, Orgaz, 18.VI.1988, 1 우, J. Guzmán (UCM). Valencia, Rocafort, 30.VIII.1960, $10^{\pi}, 1$ 우, S. V. Peris, Sagunto, Playa de la Malvarrosa, 28.VIII.2004, $10^{\pi}$, J. I. López-Colón. Valladolid, Fuente el Sol, 29.VI.1994, 1 오, C. Ornosa.

\section{Distoleontini Tillyard, 1916}

\section{Distoleon tetragrammicus (Fabricius, 1798)}

Distoleon tetragrammicus (Fabricius, 1798): Steffan, 1975: 399; Monserrat, 1981: 153, 1984d: 46, 1985a: 480; DíazAranda et al., 1986b: 1135; Díaz-Aranda \& Monserrat, 1988b: 219; Gepp \& Hölzel, 1989: 13; Marín \& Monserrat, 1989: 290, 1990: 233; Monserrat et al., 1994: 44; Monserrat, 1996: 12; Stange, 2004: 163; Monserrat \& Acevedo, 2011: 128; Krivokhatsky, 2011: 134; Monserrat \& Triviño, 2013: 19, 98; Monserrat et al., 2013: 5.
Formicaleo tetragrammicus (Fabricius, 1798): Hagen, 1866a: 290; Navás, 1904c: 200, 1904d: 143, 1913d: 36, 1913f: 11, 1914a: 764, 1914f: 633, 1914g: 212, 1914h: 32, 1916b: 172, 1916e: 82; Esben-Petersen, 1918: 110; Navás, 1919a: 193, 1921a: 150, 1924a: 75, 1924c: 123, 1925b: 38, 1927b: 113, 1927d: 122, 1929b: 32, 1931a: 117; Vidal y López, 1943: 17; Auber, 1955a: 51, 1958: 28; Mândru, 1961: 331; Steinmann, 1963: 221; Capra, 1976: 549; Monserrat, 1980a: 171.

Formicaleon tetragrammicus (Fabricius, 1798): Navás, 1921b: 63; Monserrat, 1977: 14, 48.

Formicaleo tetragrammicus (Pallas, 1798) (sic): Navás, 1904b: 19, 1905c: 28, 1907b: 98, 1909a: 376, 1909c: 176, 1913a: 81, 1932a: 288.

Especie holomediterránea expansiva hacia el Cáucaso, Armenia, Georgia, Siria, Irak e Irán. Es conocida en toda la Península Ibérica, donde sus imagos habitan en medios boscosos y arbolados, a veces cerrados y marcadamente húmedos, y se han recolectado entre los meses de mayo y septiembre, y en altitudes que oscilan entre los 10 y los 2250 metros. Aspecto general de sus alas según figura 17. Sus larvas habitan en zonas de bosque mediterráneo. Estadios larvarios en Bonnet (1780); Réaumur (1742); Brauer (1854); Hagen (1873); Redtenbacher (1884); Steffan (1975); Gepp \& Hölzel (1989); Satar et al. (2006); Gepp (2010); Krivokhatsky (2011); Acevedo et al. (2013) y Badano \& Pantaleoni (2013).

Nuevo material estudiado: ESPAÑA: Cádiz, Huerta Grande Pelayo, 21.VI.1912, 10 $0^{x}$. Cuenca, Valdemeca, 13.VII.2009, $10^{\prime \prime}$ a la luz, P. Almagro. Gerona, Lloret de Mar, 5.VII.1978, $10^{7}$, C. Rey (MCNM). Granada, Dúdar, 14.VI.2012, 1 \% , A. Tinaud. Lérida, Ponts, San Pere, 15.VII.2009, 1 ㅇ․

\section{Distoleon annulatus (Klug, 1834)}

Distoleon annulatus (Klug, 1834): Aspöck et al., 1980: 10, 12; Monserrat, 1984b: 111, 1985a: 481, 1987a: 135; Díaz-Aranda \& Monserrat, 1988c: 216; Stange, 2004: 149; Monserrat \& Acevedo, 2011: 129; Monserrat \& Triviño, 2013: 19, 97.

Formicaleo annulatus (Klug, 1834): Hagen, 1866a: 290, 1866b: 404; Brauer, 1876: 289; MacLachlan, 1889: 347; Navás, 1904b: 19, 1906a: 140, 1907b: 98; Andreu, 1909: 160; Navás, 1912a: 34, 1913d: 37, 1914a: 764, 1914f: 633, 1915: 68, 1916e: 82; Coma, 1918: 152; Esben-Petersen, 1918: 111; Cervera, 1922: 148; Navás, 1922d: 148, 1924a: 76, 1925b: 39, 1927b: 113, 1927c: 95, 1927d: 122, 1928a: 95, 1929b: 32; Vidal y López, 1943: 17; Monserrat, 1979a: 19, 1980a: 171.

Myrmeleon annulatus Klug, 1834: Rambur, 1842: 389; Walker, 1853: 334; Rosenhauer, 1856: 367; Pictet, 1865: 76, 110; McLachlan, 1873: 134; Bosca Seytre, 1916: 48.

Especie afro-irano-eremial, conocida de España, Portugal, Grecia, Italia, Malta, Canarias (Fuerteventura), norte de África (Marruecos, Argelia, Egipto), Chipre, Israel, Irán e Irak. Es conocida en la Península Ibérica en zonas de influencia mediterránea. Sus imagos habitan en medios térmicos, secos y soleados, a veces boscosos, ramblas y zonas rocosas, y se han recolectado entre los 

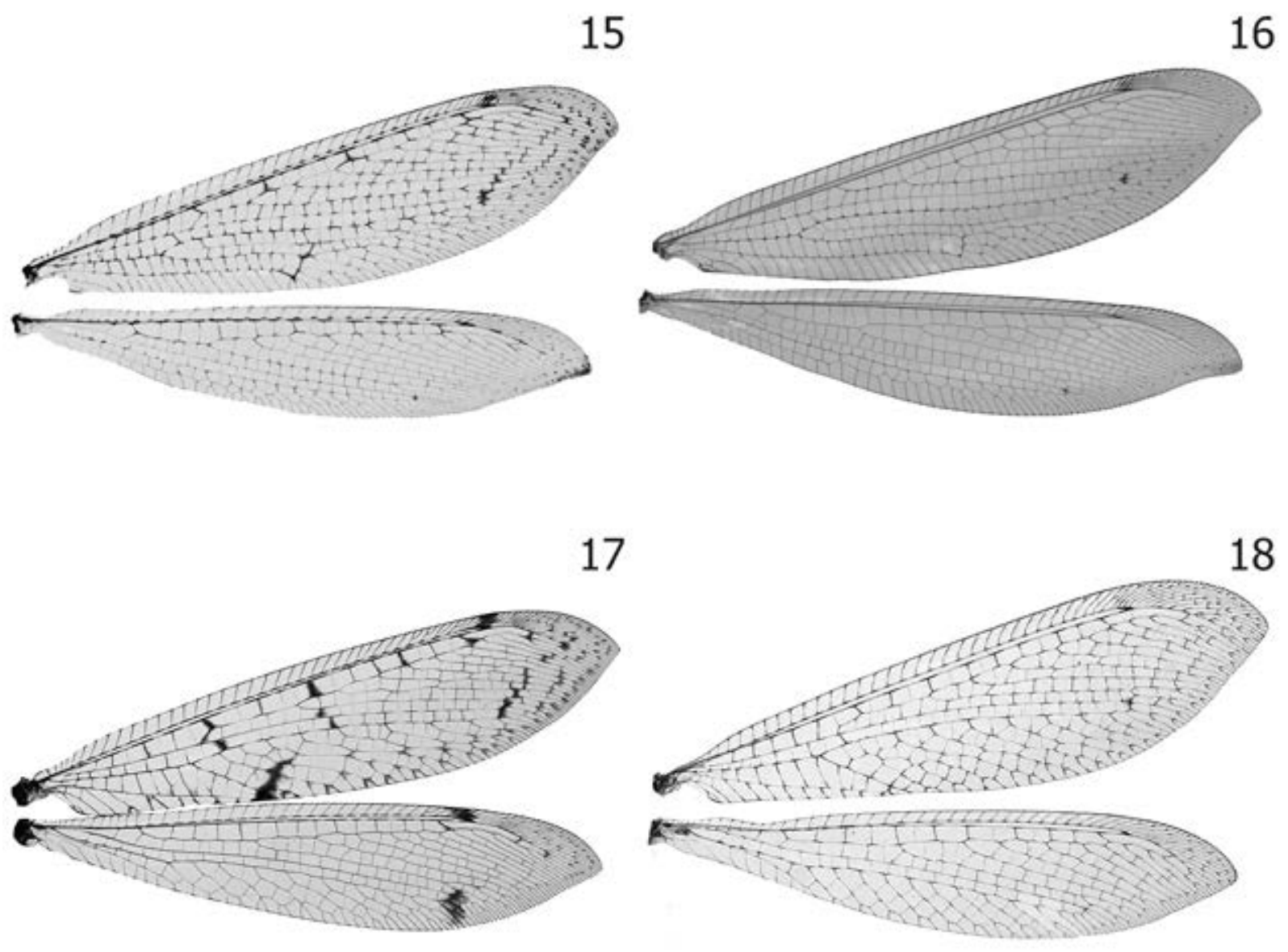

19

20
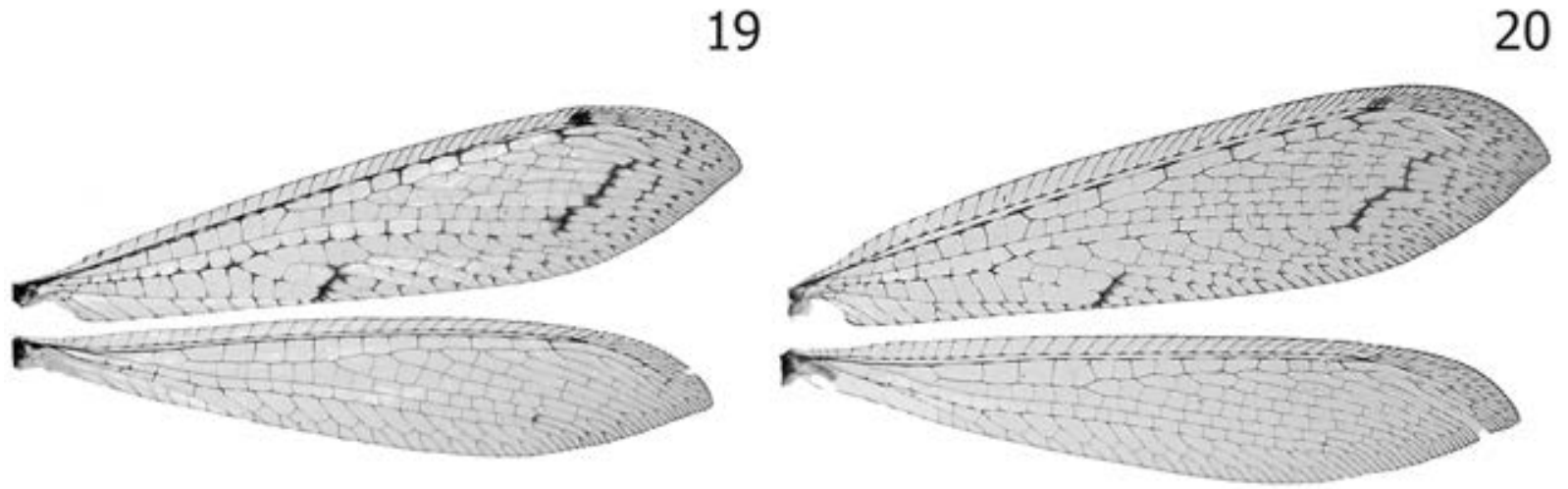

Figs. 15-20.- Alas de: 15) Creoleon aegyptiacus, 16) Creoleon lugdunensis, 17) Distoleon tetragrammicus, 18) Distoleon annulatus, 19) Neuroleon nemausiensis, 20) Neuroleon distichus. A diferentes escalas.

Figs. 15-20.- Wings of: 15) Creoleon aegyptiacus, 16) Creoleon lugdunensis, 17) Distoleon tetragrammicus, 18) Distoleon annulatus, 19) Neuroleon nemausiensis, 20) Neuroleon distichus. At different scales. 
meses de mayo y octubre, y en altitudes que oscilan entre los 10 y los 1900 metros. Aspecto general de sus alas según figura 18. Sus larvas habitan en oquedades y sotobosques mediterráneos. Estadios larvarios en Acevedo et al. (2013); lo descrito para esta especie por Willmann (1977) corresponde a Gymnocnemia variegata.

Nuevo material estudiado: ESPAÑA: Almería, Casillas de Atochares 30.VIII.2011, $10^{\pi}$ ex larva recolectada en oquedad de rambla el 7.V.2011, pupó el 12-16.VIII.2011, Rambla del Agua, 5.IX.2011, $10^{7}$ ex larva recolectada en oquedad de rambla el 29.VI.2011, pupó el 12-16.VIII.2011, Rambla del Retamar, 13.IX.2013, 40 $\sigma^{\pi}, 2$ 우 우 volando al atardecer, San José, 25.VIII.2002, $10^{\pi}, 1$ 운 25.VIII.2002, $10^{\pi}, 1$ 우, 29.VIII.2002, $10^{\top}$ (TAMU), Viator, 20.X.2011, 1 으, a la luz, M. A. Dionisio. Granada, Cenes de la Vega, s.f., G. Collado, Cerro Gordo, La Herradura, 24.VIII.2011, $10^{\prime \prime}, 2$ 우 우, a la luz, Sierra de Alfacar, 13.IX.1972, 1 ㅇ, K. Sattler (NHM).

\section{Neuroleontini Navás, 1912}

\section{Neuroleon nemausiensis (Borkhausen, 1791)}

Neuroleon nemausiensis (Borkhausen, 1791): Morton, 1925: 407; Auber, 1955a: 53, 1956a: 95, 1958: 29; Constantin, 1961: 56; Mândru, 1961: 332; Steinmann, 1963: 223; Compte, 1967: 130; Monserrat, 1977: 16, 53, 55; Insom et al., 1979: 47; Monserrat, 1979a: 19, 1980a: 171, 1982: 73, 1984a: 169, 1984b: 111, 1984c: 156, 1984d: 33, 1985a: 479, 1985c: 84, 1986: 97; Aspöck et al., 1980: 10; Díaz-Aranda \& Monserrat, 1988b: 219, 1988c: 216; Monserrat \& Díaz-Aranda, 1989: 49; Marín, 1994: 260; Monserrat et al., 1994: 44; Monserrat, 1996: 12; Stange, 2004: 207; Monserrat, 2005: 81, 2011: 162; Krivokhatsky, 2011: 146; Monserrat \& Triviño, 2013: 19, 105. Myrmeleon laufferi Navás, 1909: Navás, 1909a: 374.

Myrmeleon nemausiensis Borkhausen, 1791: McLachlan, 1889: 345; Bolívar, 1890: 31; Navás, 1902b: 102; McLachlan, 1902b: 130; Ventalló, 1904: 115; Navás, 1904b: 23, 25, 1904c: 191, 200, 1904d: 143, 1904e: 128, 1905c: 29 , 1905e: 14, 18, 1907b: 96, 97, 1909a: 374, 1909b: 148; Andreu, 1909: 160; Navás, 1910: 41, 49, 74, 1913a: 81; Monserrat, 1977: 56.

Myrmeleon nemausiensis liturata Navás, 1913: Navás, 1913a: 81; Monserrat, 1977: 56, 2011: 161.

Nelees nemausiensis (Borkhausen, 1791): Navás, 1912a: 32, 1913c: 99, 1913d: 30, 1914a: 726, 1914b: 175, 1914d: 187, 1914f: 630, 1914g: 212, 1914h: 32, 1915: 55, 1916b: 172, 1916e: 17; Esben-Petersen, 1918: 112; Navás, 1918: 40, 1919a: 193, 1921b: 63; Cervera, 1922: 148; Navás, 1922d: 148, 1923: 167, 1924a: 71, 1924c: 123, 1925b: 37, 1927c: 95, 1930b: 160, 1931a: 117; Vidal y López, 1943: 17; Compte, 1968: 143; Monserrat, 1981: 153.

Nelees nemausiensis fortunyi Navás, 1919: Navás, 1919a: 193, 1924a: 72, 1925b: 37, 1931 b: 237.

Nelees nemausiensis liturata Navás, 1913: Navás, 1913a: 81, 1913d: 31, 1914a: 762, 1914f: 630, 1916e: 18, 1924a: 72, 1925b: 37.

Neleoma nemausiense (Borkhausen, 1791): Capra, 1976: 551.

Neuroleon laufferi (Navás, 1909): Navás, 1912a: 31, 1913d: 28, 1914a: 760, 1914f: 628, 1916e: 12, 14; Esben-Petersen, 1918: 112; Navás. 1924a: 69, 1925b: 35; Constantin, 1961: 56; Steffan, 1971: 836; Monserrat, 1977: 16, 52, 54; Aspöck et al., 1980: 410, 2001: 323; Stange, 2004: 204; Monserrat, 2011: 161
Neuroleon nemausiensis fortunyi Navás, 1919: Compte, 1967: 130.

Neuroleon nemausiensis liturata Navás, 1913: Compte, 1967: 130.

Especie Holomediterránea expansiva hacia Crimea, Cáucaso y Asia central. Es conocida en la Península Ibérica, Mallorca, Menorca y Formentera, mayoritariamente en zonas de influencia mediterránea. Sus imagos habitan en medios abiertos y soleados, cauces de ríos secos y ramblas, y se han recolectado entre los meses de junio y septiembre, y en altitudes que oscilan entre los 20 y los 2250 metros. Aspecto general de sus alas según figura 19. Sus larvas habitan en bosquetes abiertos. Estadios larvarios en Auber (1956a), Steffan (1975), Krivokhatsky (2011) y Badano \& Pantaleoni (2013). La descripción de la larva dada por Steffan (1965) como $N$. nemausiensis corresponde a $N$. egenus.

NuEVo MATERIAl ESTUdiado: ESPAÑa: Álava, Iruña, Oka, Las Campas de Gabo, 7.VIII.2011, $10^{7}$ sobre Quercus ilex bellota, S. Pagola. Almería: Tabernas, Rambla Roja, 13.VI.2012, 1 ㅇ a la luz. Granada, La Herradura, Punta de la Mona, 19.VIII.2013, 1 우.

\section{Neuroleon distichus (Navás, 1903)}

Neuroleon distichus (Navás, 1903): Navás, 1909b: 148; Constantin, 1961: 56; Monserrat, 1977: 15, 52, 54, 1985a: 479, 1996: 12; Stange, 2004: 200; Monserrat, 2011: 162; Monserrat \& Acevedo, 2011: 128; Monserrat \& Triviño, 2013: 19, 104.

Myrmeleon distichus Navás, 1903: Navás, 1903: 106, 1904b: 24, 25, 1904d: 140, 143, 1907b: 96, 97.

Nelees distichus (Navás, 1903): Navás, 1912a: 32, 1913d: 33, 1914a: 762, 1914f: 630, 1914g: 212, 1916e: 18, 1924a: 72, 1925b: 37; Esben-Petersen, 1918: 114.

Especie atlantomediterránea, citada de España, Francia y Marruecos. Es conocida de la zona central de la Península Ibérica, donde sus imagos habitan en medios abiertos y soleados, cauces de ríos secos y ramblas, y se han recolectado entre los meses de julio y septiembre, y en altitudes que oscilan entre los 270 y 2250 metros. Aspecto general de sus alas según figura 20. Sus larvas son desconocidas, deben habitar en bosquetes abiertos.

Nuevo material estudiado: ESPAÑA: Madrid, Beacos, 30.VII. 19351 우, M. Pujol (MCNM).

\section{Neuroleon ocreatus (Navás, 1904)}

Neuroleon ocreatus (Navás, 1904): Navás, 1909b: 148, 1913b: 67, 1913d: 27, 1914a: 760, 1914b: 175, 1914d: 187, 1914f: 628, 1915: 73, 1916e: 14; Esben-Petersen, 1918: 112; Navás, 1918: 40, 1919a: 193; Cervera, 1922: 148; Navás, 1922a: 5, 7, 1922d: 148, 1923: 167, 1924a: 68, 1925b: 35; Vidal y López, 1943: 17; Auber, 1955a: 52, 1956a: 95, 1958: 30; Berland, 1962: 53; Compte, 1967: 131; Steffan, 1971: 816; Aspöck et 
al., 1980: 10; Monserrat, 1982: 73, 1984a: 169, 1984d: 46, 1985a: 480, 1986: 97; Monserrat \& Díaz-Aranda, 1988: 89; Séméria \& Berland, 1988: 95; Díaz-Aranda \& Monserrat, 1988a: 115; Monserrat \& Díaz-Aranda, 1989: 49; Marín \& Monserrat, 1995b: 113; Monserrat, 1996: 12; Whittington, 2002: 384; Stange, 2004: 208; Monserrat, 2005: 81; Monserrat \& Acevedo, 2011: 128; Monserrat \& Triviño, 2013: 19, 106.

Myrmeleon ochreatus (sic) Navás, 1904: Navás, 1904b: 23, 25 , 1904d: fig. 2.

Myrmeleon ocreatus Navás, 1904: Navás, 1905b: 112, 1905c: 29, 1907b: 95, 97.

Especie atlantomediterránea, conocida de España, Francia, Italia y Portugal. Es conocida en la Península Ibérica, Mallorca e Ibiza mayoritariamente en zonas de influencia mediterránea. Sus imagos habitan en medios abiertos y soleados, cauces de ríos secos y ramblas, y se han recolectado entre los meses de junio y agosto, y en altitudes que oscilan entre los 10 y los 1020 metros. Aspecto general de sus alas según figura 21. Sus larvas habitan en zonas arenosas y dunas. Estadios larvarios en Steffan $(1965,1975)$.

Nuevo material estudiado: ESPAÑA: Alicante, El Pinet, 29.VII.2013, $10^{\pi}$ ex pupa recolectada el 18.VII.2013 bajo tronco caido, 9.IX.2013, $10^{7}$ ex larva recolectada el 18.VII.2013, pupó el 24.VIII.2013. Almería, Rambla Retamar, Retamar, 14.VI.2012, 1 ․ Madrid, Beacos, 6.VII.1935, 1 ㅇ, M. Pujol (MCNM). Málaga, El Madroñal, Embalse del Río Guadaiza, 13.VI.2013, 10", Estepona, S ${ }^{\mathrm{a}}$. Bermeja, Río Padrón, 12.VI.2013, $10^{7}$. Toledo, Carranque, 8.VII.2002, $10^{7}$, M. Moreno, Calalberche, 24.VII.2002, $10^{\prime}$ ex larva recolectada el 22.VI.2002, J. F. Gómez.

\section{Neuroleon arenarius (Navás, 1904)}

Neuroleon arenarius (Navás, 1904): Navás, 1909b: 148, 1912a: 31, 1913b: 67, 76, 1913d: 26, 1914a: 759, 1914b: 175, 1914g: 212, 1915: 76, 78, 1916e: 13, 1917: 86; EsbenPetersen, 1918: 111; Coma, 1918: 152; Navás, 1919a: 193, 1922a: 5, 7, 1922d: 148; Cervera, 1922: 148; Navás, 1923: 167, 1924a: 67, 1925b: 35; Morton, 1925: 407; Navás, 1927c: 95; Vidal y López, 1943: 16; Auber, 1955a: 52, 1956a: 96, 1958: 31; Constantin, 1961: 56; Compte, 1967: 131; Steffan, 1971: 824; Monserrat, 1978a: 60; Aspöck et al., 1980: 10; Monserrat, 1980a: 171, 1982: 73, 1984a: 169, 1984b: 96, 1984d: 33, 1985a: 480, 1985c: 84, 1986: 97; Díaz-Aranda et al., 1986b: 1135; Monserrat \& Díaz-Aranda, 1987: 176; Monserrat, 1987a: 135; Díaz-Aranda \& Monserrat, 1988a: 115, 1988b: 219, 1988c: 216; Monserrat \& Díaz-Aranda, 1988: 89, 1989: 49; Marín, 1994: 260; Marín \& Monserrat, 1995b: 113; Monserrat, 1996: 12; ; Monserrat et al., 1999: 39, 42; Whittington, 2002: 384; Stange, 2004: 198; Monserrat, 2005: 81; Monserrat \& Acevedo, 2011: 128; Monserrat \& Triviño, 2013: 19, 104; Monserrat et al., 2013: 5.

Myrmeleon arenarius Navás, 1904: Navás, 1904b: 22, 24, 1904d: 140; Ventalló, 1904: 115; Navás, 1905b: 111, 1905c: 30, 1907b: 95, 97; Andreu, 1909: 160; Navás 1914f: 625.

Especie holomediterránea, conocida de España, Francia, Italia, Malta, Grecia, Argelia y Marruecos. Es conocida en la Península Ibérica e Ibiza en zonas de influencia mediterránea. Sus imagos habitan en medios abiertos y soleados especialmente térmicos y xéricos, cauces de ríos secos y ramblas, a veces en medios urbanos, y se han recolectado entre los meses de mayo y octubre, y en altitudes que oscilan entre los 10 y los 2250 metros. Aspecto general de sus alas según figura 22. Sus larvas habitan en zonas arenosas de riveras, rieras y dunas. Estadíos larvarios en Badano \& Pantaleoni (2013).

Nuevo material estudiado: ESPAÑa: Almería, Almería, Base Militar, 18.VII.2011, 10", 1 우, a la luz, Bella Vista, 28.VI.2011, $40^{7} \sigma^{7}, 2$ ㅇ 9 , El Toyo, 28. VI.2011, $20^{7} \sigma^{7}$, Níjar, 29.VI.2011, $20^{7} 0^{7}$, Las Amoladeras, 14.VI.2012, $10^{7}$, Rambla de Retamar, 20.VII.2011, 10", 1 ㅇ, 14.VI.2012, $20^{\pi} 0^{\pi}$, 14.VI.2012, $10^{\pi}$ a la luz, 18.VI.2012, 1 \% , 12.VII.2012, $30^{7} 0^{7}$, 14.VI.2013, Rambla Roja, Tabernas, 18.VII.2011, 1 ㅇ , 19.VII.2011, $10^{\pi}$, Rambla de Torre García, Retamar, 14.VI.2012, $10^{7}$, Tabernas, 18.VII.2011, $10^{7}, 2$ 우 우. Cádiz, Facinas, 20.VI.2012, $10^{\pi}$, 1 ㅇ a la luz, Pinar del Hierro, 20.VI.2012, 2 우 . Granada, Almuñécar, 2.VIII.1983, 1 운, M. González, 25.VIII.1983, 1 우, M. González, 4.VIII.1984, $10^{7}$, L. Subías, Calahonda, 19.VI.1990, 10 $0^{7}$, Castel de Ferro, 28.VI.2011, $10^{7}$, La Herradura, Cerro Gordo, 17.VIII.2013, $10^{7}$, La Herradura, Punta de la Mona, 8.IX.2001, 1 우, 28.VII.2011, 1 우 a la luz, 13.VIII.2011, 1 우 a la luz, vivió hasta el 19.VIII.2011, 20.VIII.2011, 1 a la luz, vivió hasta el 31.VIII.2011, 19.IX.2013, $10^{\prime \prime}$ a la luz, La Zubia, s.f., 2 우 우, Z. Hernández, Orgiva, Río Guadalfeo, 7.VII.1991, 1 \% , Sierra Nevada, Barranco de San Juan, 6.VIII.1983, 1 ㅇ, M. González, Madrid, El Salitral, Chinchón, 11.VII.2009, 2 우 ㅇ.

\section{Neuroleon egenus (Navás, 1915)}

Neuroleon egenus (Navás, 1915): Steffan, 1971: 835; Monserrat, 1977: 16, 53, 56, 1978a: 61, 1982: 73, 1984b: 96, 1984d: 33, 1985a: 480, 1985c: 84; Séméria \& Berland, 1988: 96; Marín \& Monserrat, 1995b: 113; Monserrat, 1996: 12; Monserrat et al., 1999: 39, 42; Whittington, 2002: 384; González López, 2002: 203; Stange, 2004: 202; Monserrat, 2005: 81, 2011: 162; Monserrat \& Acevedo, 2011: 128; Monserrat \& Triviño, 2013: 19, 105; Barreda, 2013: 79.

Myrmeleon stictichus (sic) Navás, 1903: Navás, 1903: 107.

Myrmeleon sticticus Navás, 1903: Navás, 1903: 107, 1904b: 23, 25, 1905c: 29, 1907b: 96, 97; Andreu, 1909: 160; Monserrat, 1977: 16, 56.

Nelees sticticus (Navás, 1903): Navás, 1912a: 32, 1913d: 32, 1914a: 762, 1914d: 187, 1914f: 630, 1916e: 17; EsbenPetersen, 1918: 114; Navás, 1924a: 73, 1925b: 38; Vidal y López, 1943: 17; Monserrat, 1977: 56.

Neuroleon sticticus (Navás, 1903): Navás, 1909b: 148, 1922e: 253; Constantin, 1961: 56.

Especie holomediterránea, conocida de España, Francia, Italia, Croacia, Grecia, Malta, Marruecos, Túnez, Argelia, Israel, Siria, Anatolia y Chipre. Es conocida en la Península Ibérica, Mallorca y Formentera en zonas de influencia mediterránea. Sus imagos habitan en medios abiertos y soleados, cauces de ríos secos y ramblas, a veces en medios urbanos, y se 

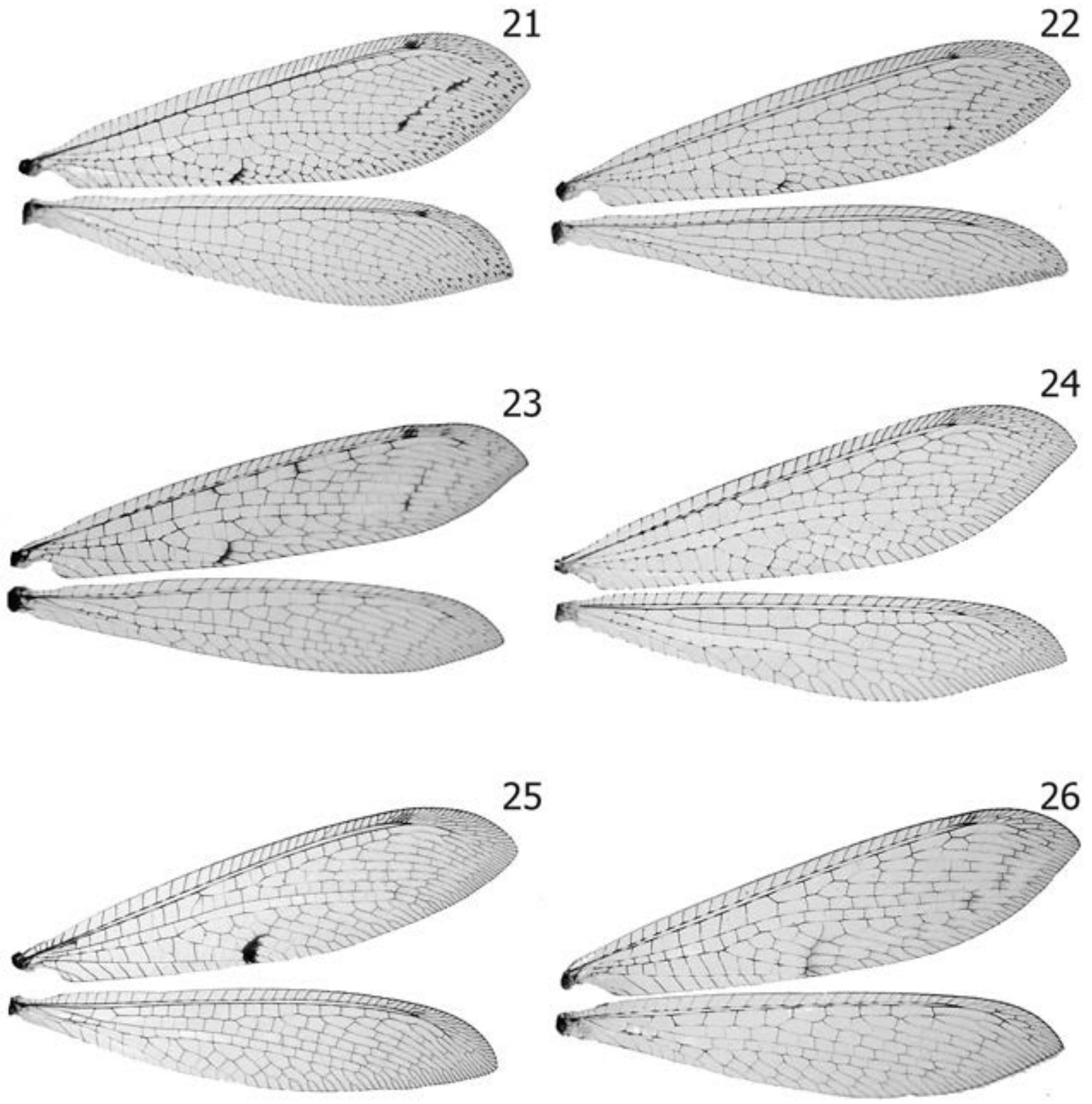

Figs. 21-26.- Alas de: 21) Neuroleon ocreatus, 22) Neuroleon arenarius, 23) Neuroleon egenus, 24) Macronemurus appendiculatus, 25) Megistopus flavicornis, 26) Gymnocnemia variegata. A diferentes escalas.

Figs. 21-26.- Wings of: 21) Neuroleon ocreatus, 22) Neuroleon arenarius, 23) Neuroleon egenus, 24) Macronemurus appendiculatus, 25) Megistopus flavicornis, 26) Gymnocnemia variegata. At different scales. 
han recolectado entre los meses de junio y septiembre, y en altitudes que oscilan entre los 10 y los 1300 metros. Aspecto general de sus alas según figura 23. Sus larvas habitan en pies de árboles y matorrales. Estadios larvarios en Steffan (1965) (descrita como N. nemausiensis), Steffan $(1971,1975)$ y Badano \& Pantaleoni (2013).

Nuevo material estudiado: ESPAÑA: Badajoz, Fregenal de la Sierra, 29.VII.2012, $10^{7}$ ex larva recolectada sin cono bajo Quercus ilex ballota el 19.VI.2012, pupó el 23.VII.2012, 12.VI.2013, $10^{2}$ ex larva recolectada sin cono bajo Quercus ilex ballota el 19.VI.2012, pupó el 22.IV.2013, Río Sillo, 2.VII.2013, $10^{7}$ ex larva recolectada sin cono bajo Quercus ilex ballota el 19.VI.2012, pupó entre el 1517.VI.2013, Santa Marta de los Barros, 23.VII.2012, $10^{7}$ ex larva recolectada sin cono bajo Quercus ilex ballota el 19.VI.2012, pupó el 9.VII.2012. Cádiz, Los Alcornocales, 16.VII.2012, 1 ㅇ ex larva recolectada sin cono bajo Quercus suber el 21.VI.2012, pupó el 9.VII.2012, 13.VI.2013, 1 우 ex larva recolectada sin cono bajo Quercus suber el 21.VI.2012, pupó el 14.V.2013, Los Algodonales, 2.VII.2012, 1 ○ ex larva recolectada sin cono bajo Quercus ilex ballota el 26.V.2012, pupó el 18.VI.2012, Pinsapar de Grazalema, 20.VIII.2012, 1 우 ex larva recolectada sin cono bajo Quercus faginea el 22.VI.2012, pupó el 12.VIII.2012, 16.VII.2012, $10^{\prime}$ ex larva recolectada sin cono bajo Quercus ilex ballota el 22.VI.2012, pupó el 8.VII.2012. Ciudad Real, Parque Nacional de Cabañeros, Navas de Estena, 2.VII.2012, 1 우 ex larva recolectada sin cono bajo Quercus ilex ballota el 8.VI.2012, pupó el 25.VI.2012, 9.VII.2012, 1 울 larva recolectada sin cono bajo Quercus ilex ballota el 8.VI.2012, pupó el 25.VI.2012, 9.VII.2012, $10^{7}$ ex larva recolectada sin cono bajo Quercus ilex ballota el 8.VI.2012, pupó el 25.VI.2012. Granada, Sierra de Guadalix, 27.VIII.1986, 1 ㅇ , L. Polo. Huelva, La Corte, 31.VIII.2012, 1 우 ex larva recolectada sin cono bajo Quercus ilex ballota el 19.VI.2012, pupó el 20.VIII.2012. Madrid, Boadilla del Monte, 18.VII.2008, 1 우, Ciudad Universitaria, s.f., P. Cabrero, Dehesa de la Villa, 8.VII.2009, 1 우 a la luz, J. P. Zaballos, San Fernando de Henares, 1.IX.2011, 1 우, J. I. López-Colón.

\section{Macronemurini Esben-Petersen, 1919}

\section{Macronemurus appendiculatus (Latreille, 1807)}

Macronemurus appendiculatus (Latreille, 1807): Costa, 1855: 9; Hagen, 1866a: 290; Brauer, 1876: 289; Bolívar, 1878: 62, 63; Cuní y Martorell, 1880: 221, 1882: 89, 1888: 163, 1897: 324; McLachlan, 1889: 346; Bolívar, 1890: 31; Novak, 1891: 52; Cuní y Martorell, 1899: 12; Navás, 1900a: 95; McLachlan, 1902b: 130; Navás, 1902a: 116, 1902b: 102, 1902c: 46; McLachlan, 1903: 225; Ventalló, 1904: 115; Navás, 1904b: 20, 1904c: 200, 1904d: 143, 1904e: 128, 1905a: 506, 1905b: 111, 117, 125, 128, 1905c: 29, 1905e: 18, 1907b: 99; Cáceres, 1909: 291; Andreu, 1909: 160; Navás, 1909a: 376, 1909c: 176, 1910: 36, 45, 46, 49, 52, 1913b: 67, 76, 1913c: 99, 1913d: 35, 1914a: 763, 1914b: 175, 1914d: 187, 1914f: 632, 1914g: 212, 1915: 50, 68, 73, 76; Gil, 1915: 26; Navás, 1916a: 154, 1916e: 79, 1917: 86; Vidal \& López, 1917: 32; Navás, 1919a: 193, 1919c: 42, 1921a: 150, 1921b: 63, 1922a: 7, 1922c: 108, 1922d: 148; Cervera, 1922: 148; Navás, 1923: 167, 1924a: 63, 1924b: 7, 1925b: 33, 1925c:
135, 1927b: 113, 1927c: 95, 1927d: 122, 1928a: 93, 1928b: 165, 1928c: 43, 1929a: 39, 1930a: 51, 1930b: 161; Morton, 1930: 4; Navás, 1932a: 288; Capra, 1934: 96; Vidal y López, 1943: 16; Compte, 1967: 133, 1968a: 142; Steffan, 1975: 400; Capra, 1976: 550; Monserrat, 1977: 15, 49, 1978a: 60, 1978b: 172; Aspöck et al., 1980: 10, 12; Morgan, 1980: 119; Monserrat, 1980a: 172, 1980b: 183, 1981: 153, 1982: 71, 1984a: 169, 1984b: 95, 1984c: 154, 1984d: 32, 1985a: 478, 1985b: 90, 1985c: 84, 1986: 97; Díaz-Aranda et al., 1986a: 1125, 1986b: 1135; Monserrat, 1986: 97, 1987a: 134; Hölzel, 1987a: 377; Marín \& Monserrat, 1987: 350-359; Monserrat \& Díaz-Aranda, 1987: 176; Díaz-Aranda \& Monserrat, 1988a: 114, 1988b: 219, 1988c: 206; Monserrat \& DíazAranda, 1988: 89, 1989: 49; Marín \& Monserrat, 1990: 223, 1991: 180; Marín, 1994: 260; Monserrat, Marín \& DíazAranda, 1994: 44; Marín \& Monserrat, 1995a: 39, 1995b: 113; Monserrat, 1996: 12; Whittington, 2002: 383; Stange, 2004: 184; Monserrat, 2005: 80; Monserrat \& Triviño, 2013: 19, 99; Barreda, 2013: 79; Monserrat et al., 2013: 5.

Macroneumurus appendiculatus (Latreille, 1807) (sic): Bosca Seytre, 1916: 48.

Myrmeleon appendiculatus Latreille, 1807: Rambur, 1842: 397; Walker, 1853: 356; Rosenhauer, 1856: 367; Pictet, 1865: 78, 110; Monserrat, 1977: 51.

Holomediterránea. Es conocida en la Península Ibérica y Baleares en zonas de influencia mediterránea. Sus imagos habitan en medios abiertos y soleados, especialmente en zonas de gramíneas sin o con escasa vegetación arbórea, áreas esteparias, pedregosas de mal país y cultivos cerealistas agostados o abandonados, y se han recolectado entre los meses de junio y noviembre, y en altitudes que oscilan entre los 10 y los 2250 metros. Aspecto general de sus alas según figura 24. A pesar de su frecuencia como imagos, sus larvas son de biología casi desconocida. Estadios larvarios en Insom et al. (1985) y Badano \& Pantaleoni (2013). La larva descrita por Doflein (1921) como perteneciente a esta especie corresponde a Myrmecaelurus trigrammus. Las citas de Macroneumurus sp. dadas por McLachlan, 1889: 345 y Bolívar, 1890: 31 de Gibraltar, corresponden sin duda a la especie que tratamos.

NuEVO MATERIAL ESTUdiAdo: ESPAÑA: Alicante, Abanilla, VI.1934, $20^{\top} \sigma^{7}, 1$ \% , Andreu (MCNM), Alicante VII.1902, $10^{\prime \prime}$, 2 우, J. Sanz (MCNM), Orihuela, Pte. Greda, VII.1933, 2 우 우, Andreu (MCNM). Almería, Alcolea, 24.VII.1985, $10^{7}$, J. Alba, Almería, Base Militar, 18.VII.2011, 1 우 a la luz, Bella Vista, 28.VI.2011, $30^{7} \sigma^{7}, 5$, $\$$, Cuevas de las Medinas, 20.VII.2011, $10^{\prime \prime}$, Dalías, 19.VII.2011, $20^{7} \sigma^{\prime \prime}, 6$ 우 ㅇ, El Ejido, Rambla del Tuerto, 19.VII.2011, $10^{\pi}, 1$ 우 , El Molino de La Serena, Bédar, 16.VII.2007, 2 우 ㅇ la luz, 17.VII.2007, $10^{7}, 2$ 우 으, El Pozo de los Frailes, 3.VII.2013, 2 우 으, El Toyo, 28.VI.2011, $10^{\prime \prime}, 7$ 웅, Espeliz, 13.VII.2012, 1 우, Las Amoladeras, 22.VII.2013, $10^{\top \mathrm{T}} \mathrm{ex}$ larva recolectada el 15.VI.2013, pupó el 30.VI.2013, Los Albaricoques, 9.VII.2005, $20^{x} \sigma^{x}, 1$, , Lucainena de las Torres, 29.VI.2011, $20^{\top} \sigma^{\top}, 3$ ㅇ ㅇ, Níjar, 29.VI.2011, 1 , San José, Cerro de Enmedio, 22.VII.1991, 1 \% , Rambla del Agua, 19.VII.2011, 1 옹 Rambla de las Higueruelas, 20.VII.2011, 2 o $ᄋ$, Rambla de Retamar, Cabo de Gata, 20. VI. 1990, $20^{7} 0^{\prime \prime}$, 20.VII.2011, 1 우, 14.VI.2012, $3 \sigma^{7} \sigma^{7}$, 5 웅, Rambla de Tabernas, 25.VII.1991, 1 ㅇ a la luz, Río Chico, 21.VII.1991, $10^{7}$, 
Salinas de Cabo de Gata, 16.VI.2013, $10^{7}$, San José, La Torta, 5.VII.2013, 2 우 우, 14.IX.2013, $10^{\prime}$ a la luz, San Roque, 21.VII.1991, 2 우 우, Sopalmo, 12.VII.1985, $10^{\text {T }}$, Tabernas, 18.VII.2011, $10^{\top}, 2$ 우 우, Tabernas, Rambla Roja, 18.VII.2011, 1 우 , 15.VI.2013, $10^{7}$ a la luz, 7.VII.2013, 3 우 우 a la luz. Ávila, Bihoyo, 30.VII.2008, 10, 1 웅. M. Portillo, Casillas, 10.VIII.1989, $10^{7}$, F. López (UCM), Castañar de El Tiemblo, 28.VII.2008, 1 우, M. Portillo, Fuente de la Joya, 8.VII.2009, 1 우, M. Portillo, Garganta Domingo Fernando, 8.VII.2009, 1 \& , M. Portillo, Los Guijuelos, 30.VII.2008, $10^{7}, 1$ 오 , M. Portillo, Nava del Barco, 30.VII.2008, 1 우, M. Portillo, Nogal del Barranco, 23.VII.2007, 10", 30.VIII.2007, 1 우, M. Portillo, Piedrahita, VIII.1981, 1 오, J. Blázquez (UCM), Piedralaves VIII.1934, 2 우 오, F. Bonet (MCNM), Pinar de Hoyo Casero Claro, 28.VII.2008 $20^{\pi} \sigma^{\pi}, 1$ ㅇ , 13.VII.2009, $1 \sigma^{\pi}, 1$ 오, M. Portillo, Pozo de las Nieves, 22.VIII.2007, 3 우 우, Puente Río Alberche, Hoyocasero Claro, 28.VII.2008, 1 \& , M. Portillo, Puerto de Casillas, 22.VIII.2007, 1 \& , M. Portillo, Ramacastañas, 26.VII.1984, 1 오․ M. A. Vázquez, 30.VI.1990, 1 오. M. Costas, Villaviciosa, 28.VII.2007, 1 ㅇ. Badajoz, Burguillos del Cerro, 14.VII.2001, 1 옹. Hoyo de Santa María, 24.VI.1985, $10^{7}$, E. Clemente, Río Sillo, 19.VI.2012, $4 \sigma^{7} \sigma^{\top}$, Santa Marta de los Barros, 19.VI.2012, $10^{7}, 1$ 오 . Barcelona, Bellaterra, 15.VII.1973, 10 $10^{7}, 1$, J. A. Barrientos (UAB), Sierra de Collserola, s.f., 107, R. Carbonell. Cáceres, Almaraz, 8.VII.2008, 3 우 우, Casas de Miravete, 17.VIII.1991, 1 우, M. Costas, Jarandilla de la Vera, 18.VI.1990, 107, C. Ornosa, Torrequemada, VII-VIII.1932, 1 오, J. Gil (MCNM). Cádiz, Barbate, 20.VI.2012, $10^{\pi}$, Chiclana, observado un ejemplar transportado por un asílido (Diptera: Asylidae) el 20.VI.2012, Estación de la Almoraima, 21.VI.2012, $10^{\pi}, 1$ 우, Gimena de la Frontera, 21.VI.2012, $10^{7}$, Parque Natural del Estrecho, 20.VI.2012, 2 우 우, Pinsapar de Grazalema, 22.VI.2012, $10^{\circ}$, Puerto del Boyar, 22.VI.2012, $10^{\pi}, 1$ ㅇ, San Roque 7.VIII, $10^{\sigma}$, Walter (NHM). Castellón, Vinaroz, 24.VIII.2006, 1 ㅇ. . Ciudad Real, Pozuelo, 1900, 1 ㅇ , leg.? (MCNM). Córdoba, Arroyo Don Lucas, 10.VIII.1984, 1 을. M. Baena. Cuenca, El Chantre, 15.VIII.1977, 1 우, P. Alonso, 1 우 (UCM), Tragacete, s.f., 1 우, McLachlan, Valdemeca, 13.VII.2009, 2 우, P. Almagro. Granada, Almuñécar, 25.VIII.1983, $20^{\prime \prime} \sigma^{\prime \prime}$, M. González, Cáñar, 18.VII.2011, $10^{\pi}, 3$ 우 우, Castel de Ferro, 28.VI.2011, $10^{\pi}, 1$ 우, Castillo de Baños, 28.VI.2011, $20^{\pi} \sigma^{\pi}, 2$ 우 우, 19.VII.2011, $10^{\pi}$, 2 우 우, Dúdar, VII-VIII.2005, $10^{\top}, 1$ 오, A. Tinaut, Gualchos, 28.VI.2011, $10^{\top}, 1$ 우, Güejar, Embalse de Canales, 30.VII.2009,

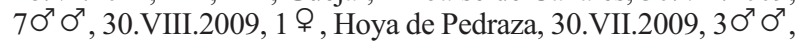
La Herradura, 8.IX.2001, 1 우 a la luz, 8.VII.2013, 1 ㅇ a la luz, 9.VII.2013, 2 우 우 a la luz, La Herradura, Cerro Gordo, 27.VII.2010, 2 우 우, Lanjarón, 23.VI.2009, 1 우, Pitres, 23.VI.2009, $10^{\pi}$, Sierra Nevada, VIII.1966, 1 우, R.A. Broad, Soportújar, 18.VII.2011, $10^{7}, 1$ 우, Torrequemada, VII.1932, 1 옹, J. Gil., Valle del Guadalfeo, Orgiva, 3.VII.1969, $10^{7}, 2$ 우 우, 5.VII.1969, $10^{7}, 4$ 우 우. Guadalajara, Tamajón, 6.VIII.1985, 1 오. F. Marín. Huelva, Matalascañas, 9.VIII.1991, $10^{7}, 3$ 우 우, A. Arillo, 20.VI.2012, $10^{7}$, Marismas del Odiel, Isla de Saltes, 8.VIII.1991, 1 ㅇ, A. Arillo, Patrás, 19.VI.2012, $30^{7} \sigma^{7}$. Huesca, Guara, 29.VII.1983, 2 우 우, E. Galante, Huesca 15.VII.1909, $10^{\prime \prime}$, Arias (MCNM). Lérida, Carminiu, 15.VII.2009, 2 ○ ᄋ . Madrid, Alcalá de Henares, VI.1985, $10^{7}$, J. M. Alonso (UCM), Algete, 7.VII.1984, 1 오 E. de Castro, Alpedrete, 29.VII.1975, $10^{7}, 21$. VII.1977, $10^{7}$ a la luz, Beacos, 14.VIII.1934, 1 ᄋ, 30.VII.1935, 10', M. Pujol (MCNM), Brunete, Cienvallejos,
VIII.1927, $20^{\top} \sigma^{\top}, 1$ 오, M. Escalera (MCNM), Casa de Campo 19.VII.1941, $10^{\top}$, M. Pujol (MCNM), Canillejas, IX.1972, 1 우, Sagastume (UCM), Cercedilla, 7.VIII.1992, $20^{7} \sigma^{7}$, V. Ortuño, Madrid, El Escorial, Abantos, Fuente del Cervunal, 24.VII.2007, $50^{7} 0^{7}, 4$ 우 우 (TAMU), El Goloso, 17-23.VII.1991, 2 우 우, 2431.VII. 1991, 1 ㅇ , 9-16.VII.1992, 1 웅, todos en Trampa de Malaise, Nieves \& Rey (MNCN), El Pardo, s.f., 1 ㅇ, A. Compte (MCNM), El Salitral, Chinchón, 11.VII.2009, 10 , 2 우 우, El Ventorrillo, VIII, $80^{7} \sigma^{x}, 13$ 우 우, J. Abajo (MCNM), VIII.1965, 2 우 우, leg.? (MCNM), Fuentidueña de Tajo, IX.1959, 1 오, P. Ceballos (MCNM), Guadalix de la S ${ }^{a}$., 1.VIII.1993, 1 \& , F. del Águila (UCM), Hoyo de Manzanares, s.f., 10 $10^{T}, 1$ 오, leg.? (MCNM), 15-27.VII.1979, $12 \sigma^{7} \sigma^{7}, 5$ 우 9 , 13.VII.1989, $2 \sigma^{7} \sigma^{\prime \prime}$, 1 우 a la luz, 31.VII.1990, 1우, 11.VII.2002, 1 오, Leganés, 8.VII.1980, 1 우, J.Carballo (UCM), Madrid, VI.1978, 1 ㅇ, J. Templado (MCNM), Madrid, Moncloa, 5-13.VIII.1940, $3 \sigma^{\top} \sigma^{\prime \prime}$, 5 우 우, M. Pujol (MCNM), Montarco, Rivas-Vaciamadrid, 8.VII.2007, 1 \& , J. I. López-Colón, 24.VII.2007, $10^{7}$, J. I. LópezColón, 18.VII.2007, 1 ㅇ , J. I. López-Colón, Pelayos, 24.VI.1983, $10^{7}$, M.J.García (UCM), Peña Grande 8.VII.1934, $10^{7}$, M. Pujol (MCNM), Puerto de la Morcuera, 13.VII.1986, 1 ㅇ, M.Santos (UCM), San Fernando de Henares, 24.VII.2011, 2우 우, J. I. López-Colón, San Martín de Valdeiglesias, 21.VII.1978, 1 우, Sierra de Guadarrama, VIII.1927, 2 우, B. Uvarov (NHM), Torrelodones, 25.VIII.1989, 1 ㅇ, A. Vives (MCNM), Vallecas, 9.VI.1990, 10", G.R. (UCM), Villaconejos, 24.VII.1977, 1 ㅇ, M.A.Vázquez (UCM), Villa del Prado, 28.VIII.1991, 1 ㅇ, M. V. Peinado, Villalbilla, 31.VII.1984, 1 o , F. Marín, 2.VIII.1984, 2 우 오, F. Marín, 12.VIII.1984, $10^{\top}$, F. Marín, 3.VIII.1985, 1 우, F. Marín, Villarejo de Salvanés, 21.VII.1970, 1 오, R. Navarro (UCM). Málaga, Estepona, $\mathrm{S}^{\mathrm{a}}$. Bermeja, Río Padrón, 12.VI.2013, $10^{7}$, Marbella, 10.VIII.1985, 10, 2 우 우, M. Candela (MCNM), 20.VIII.1985, 1 오. M. Candela (MCNM). Murcia, Calblanque, 18.VII.2011, $10^{\Upsilon 1}, 1$ ㅇ. Segovia, Prádena, VIII.1982, 1 우 , leg.? (MCNM), San Rafael VIII.1933, 1 오, I. Bolívar (MCNM). Teruel, Albarracín s. f., 1 ㅇ, McLachlan (NHM), VII.1906, $2 \sigma^{7} \sigma^{7}$, Arias (MCNM), Albarracín, Fuente de la Señora, 30.VI.1990, $10^{7}, 14$.VII. 1990, $20^{7} \sigma^{7}, 4$ 우 우 a la luz, Alcolea del Cinca, 13.VII.1904, 1 ㅇ, N. (NHM), Pto. Losilla, s. f., 2 우 우, Mc Lachlan (NHM), VII.1929, $10^{7}, 2$ 우 우, M. Escalera (MCNM), Teruel, 25.VII.1933, 10, 1 우, B. Muñoz (MCNM). Zaragoza, Retuerta de Pina, 25. VII.1991, 1 ㅇ en Trampa de Malaise en bosque de Juniperus sabina, J. Blasco.

Glenurinae Banks, 1927

Glenurini Banks, 1927

\section{Megistopus flavicornis (Rossi, 1790)}

Megistopus flavicornis (Rossi, 1790): Navás, 1904a: 10, 1905c: 28, 1907b: 94; Andreu, 1909: 160; Navás, 1909a: 376, 1909c: 176, 1913d: 24, 1914a: 757, 1914d: 188, 1914f: 622; Esben-Petersen 1918a: 115; Navás, 1919a: 193, 1924a: 61, 1925a: 91, 1925b: 32, 1927b: 113, 1927d: 122, 1928a: 95, 1929a: 39, 1932a: 288, 1932b: 13; Zacwilichowski, 1938: 437; Vidal y López, 1943: 16; Auber, 1955a: 53, 1958: 32; Mândru, 1961: 332; Berland, 1962: 54; Steinmann, 1963: 224; Eglin, 1967: 53; Steffan, 1975: 394; Monserrat, 1977: 47, 1978b: 172, 1979a: 19; Insom et al., 1979: 44; Monserrat, 1984a: 170, 1984b: 111, 1984d: 46, 1985a: 483; 


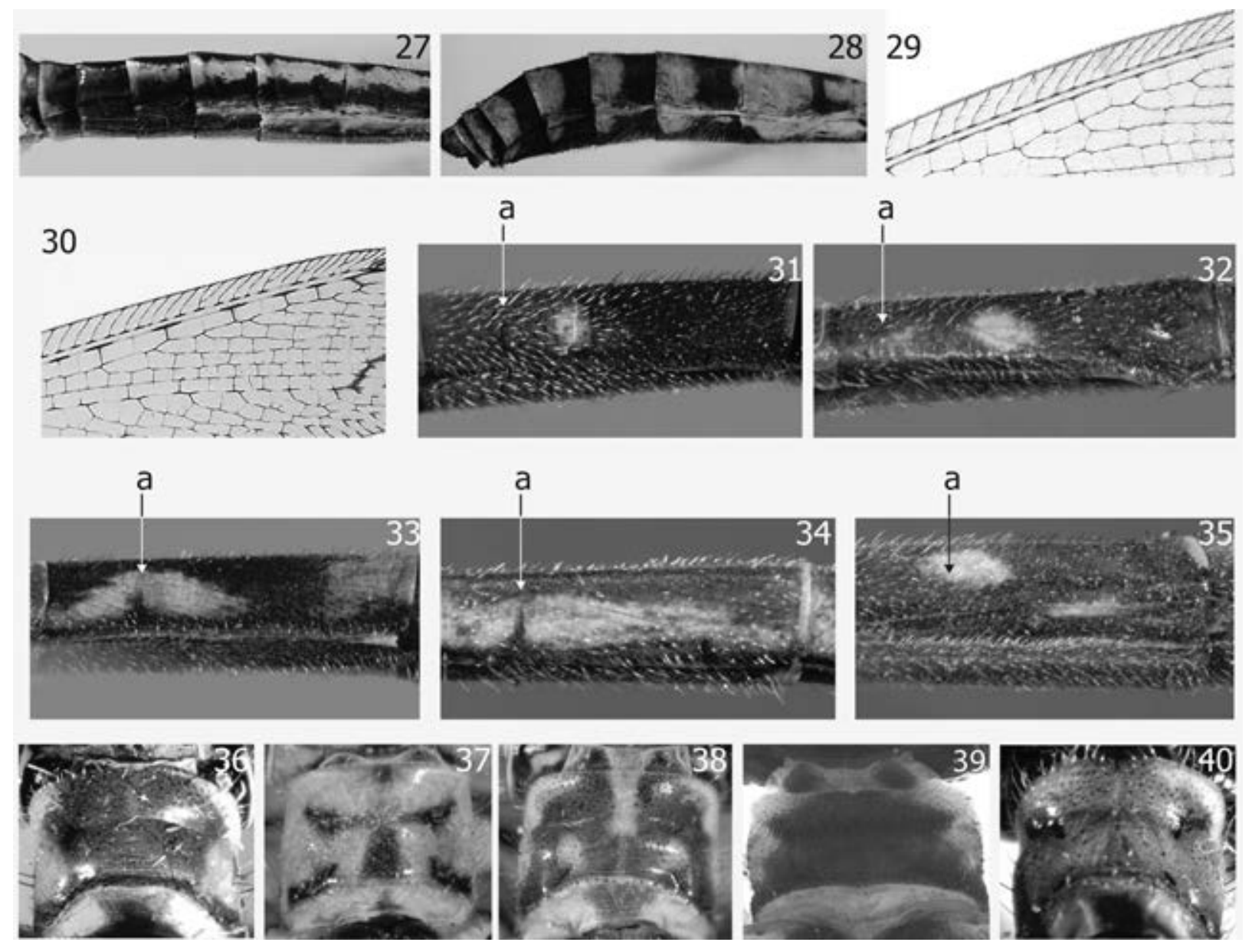

Figs. 27-40.- Abdomen, lateral de: 27) Palpares libelluloides, 28) Palpares hispanus. Región costal del ala anterior de: 29) Neuroleon arenarius, 30) Neuroleon ocreatus. Abdomen, lateral de: 31) Neuroleon nemausiensis, 32) Neuroleon distichus, 33) Neuroleon ocreatus, 34) Neuroleon arenarius, 35) Neuroleon egenus. Pronoto de: 36) Myrmeleon formicarius, 37) Myrmeleon hyalinus, 38) Myrmeleon inconspicuus, 39) Myrmeleon bore, 40) Myrmeleon gerlindae. (a: antecosta). A diferentes escalas.

Figs. 27-40.- Abdomen, lateral of: 27) Palpares libelluloides, 28) Palpares hispanus. Costal area of fore wings of: 29) Neuroleon arenarius, 30) Neuroleon ocreatus. Abdomen, lateral of: 31) Neuroleon nemausiensis, 32) Neuroleon distichus, 33) Neuroleon ocreatus, 34) Neuroleon arenarius, 35) Neuroleon egenus. Pronota of: 36) Myrmeleon formicarius, 37) Myrmeleon hyalinus, 38) Myrmeleon inconspicuus, 39) Myrmeleon bore, 40) Myrmeleon gerlindae. (a: antecosta). At different scales.

Monserrat \& Díaz-Aranda, 1987: 177; Monserrat, 1987a: 135; Séméria \& Berland, 1988: 91; Monserrat, 1996: 12; Stange, 2004: 189; Monserrat, 2005: 82; Monserrat \& Acevedo, 2011: 130; Krivokhatsky, 2011: 116; Monserrat \& Triviño, 2013: 19, 100.

Especie holomediterránea expansiva hasta el Cáucaso, Georgia, Anatolia, Armenia, Azerbaiyán, Irán y Turkmenistán. Es conocida en la Península Ibérica y Mallorca mayoritariamente en zonas de influencia mediterránea. Sus imagos habitan en medios tanto boscosos, como abiertos y soleados con vegetación arbórea, cauces de ríos y bosquetes de zonas litorales, y se han recolectado entre los meses de mayo y agosto, y en altitudes que oscilan entre los 10 y los 1250 metros. Aspecto general de sus alas según figura 25. Sus larvas habitan en zonas arenosas de rieras y ramblas y en dunas interiores. Estadios larvarios en Steffan (1965, 1968, 1975); Gepp \& Hölzel (1989); Gepp (2010); 
Cesaroni et al. (2010); Krivokhatsky (2011) y Badano \& Pantaleoni (2013). La larva descrita por Doflein (1921) como perteneciente a esta especie corresponde a Myrmecaelurus trigrammus.

Nuevo material estudiado: ESPAÑA: Ciudad Real, Navas de Estena, Parque Nacional de Cabañeros, 18.VI.2012, $10^{7}$. Toledo, Carranque, 23.VI.2002, 1 우, M. Moreno.

Gymnocnemini Navás, 1912

Gymnocnemia variegata (Schneider, 1845)

Gymnocnemia variegata (Schneider, 1845): Navás, 1904a: 9, 1907b: 93, 1909a: 376, 1913d: 23, 1914d: 188, 1914f: 619; Esben-Petersen, 1918: 115; Navás, 1918: 40, 1919a: 194, 1924a: 59, 1925b: 31; Vidal y López, 1943: 16; Auber, 1955a: 53; Berland, 1962: 54; Steffan, 1975: 395; Monserrat, 1977: 14, 46, 1985a: 483, 1985c: 84, 1996: 12; Stange, 2004: 180; Monserrat, 2005: 82; Monserrat \& Acevedo, 2011: 130; Monserrat \& Triviño, 2013: 19, 99. Myrmeleon variegatus Klug (sic): Navás, 1902b: 103.

Especie holomediterránea expansiva hacia Siria, Turkmenistán y Tayikistán. Es conocida en la Península Ibérica y Mallorca en zonas de influencia mediterránea. Sus imagos habitan en medios abiertos y soleados, frecuentemente en zonas kársticas y rocosas con oquedades y vegetación arbórea dispersa, y se han recolectado entre los meses de julio y septiembre, y en altitudes que oscilan entre los 25 y los 2000 metros. Aspecto general de sus alas según figura 26. Sus larvas habitan en zonas arenosas, oquedades y pequeñas cuevas. Estadios larvarios en Willmann (1977) (como Distoleon annulatus); Insom et al. (1985); Stange \& Miller (1990); Stange (2004); Cesaroni et al. (2010); Monserrat \& Acevedo (2011) y Badano \& Pantaleoni (2013).

NuEvo MATERIAl EStudiado: ESPAÑA: Granada, La Herradura, Cerro Gordo, 21.VI.2011, $10^{\pi}$ ex larva hallada en hoquedad rocosa el 21.IV.2011, pupó a finales de V.2011, 21.IV.2011, 1 larva recolectada sin cono en oquedad rocosa, vivió hasta el 1.X.2012 (como larvas fueron citadas por Monserrat \& Acevedo, 2011).

\section{Especies citadas como probables en la Península Ibérica}

\section{Dendroleon pantherinus (Fabricius, 1787)}

Especie eurosiberiana extendida al Cáucaso, Georgia, Anatolia, Azerbaiyán y China, no citada en la fauna ibérica. Navás (1904b: 21) la cita como probable en ella. Dada su distribución geográfica, mantenemos esta opinión y no es improbable que pueda habitar en zonas boscosas del tercio norte peninsular, aunque aún no ha sido hallada.

\section{Especies citadas en la Península Ibérica que requieren confirmación}

Neuroleon tenellus (Klug, 1834)

Se trata de una especie afro-iraní distribuida por Grecia (Creta y Naxos), norte de África (Túnez, Libia, Egipto, Sudán) y Asia (Anatolia, Israel, Líbano, Irak, Irán, Arabia, Omán, Turkmenistán y Afganistán), citada de "España" por Kimmins (1950: 154) y Auber (1955b: 54). Muy probablemente estas referencias pertenezcan y se correspondan con Neuroleon ocreatus (Navás, 1904), ya que es cierto que algunos ejemplares ibéricos de esta especie poseen manchas en el abdomen similares a las citadas para $N$. tenellus, pero otros caracteres de sus tarsos, pigmentación de pronoto y genitalia no son coincidentes. En cualquier caso dejamos estas citas a la espera de poder estudiar los correspondientes ejemplares.

\section{Especies incorrectamente citadas en la Península Ibérica}

Baliga asakurae (Okamoto, 1910)

Especie oriental conocida de Formosa. Como Baliga asakurai Okamoto, 1910, cita Navás (1927a: 31) un ejemplar erróneamente rotulado de Murcia. Posteriormente Monserrat (1985c: 92, 2011: 163) comenta este hecho.

\section{Baliga pupillatus (Navás, 1905)}

Especie oriental conocida de la India. Navás (1927a: 31) cita un ejemplar erróneamente rotulado de Murcia. Posteriormente Monserrat (1985c: 92, 2011: 163) comenta este hecho.

\section{Formicaleo formosanus Okamoto, 1910}

Especie oriental conocida de Formosa. Navás (1927a: 33) cita un ejemplar erróneamente rotulado de Murcia. Posteriormente Monserrat (1985c: 92) comenta este hecho.

\section{Macronemurus ibericus Navás, 1927}

Especie descrita por Navás (1927e: 78) de Portugal. Más tarde Hölzel (1972: 44) sinonimiza esta especie a Macronemurus linearis (Klug, 1834), especie conocida de Siria, Líbano e Israel, y sugiere un evidente error de etiquetación. Posteriormente Hölzel (1987a: 379), Aspöck et al. (1980: 411) y Monserrat (2011: 163) comentan este hecho.

\section{Myrmecaelurus atrifrons (Hölzel, 1970)}

Especie conocida de Mongolia, China, Irán y Turquía, que fue erróneamente citada de España por Whittington 
(2002: 384) como Nohoveus atrifrons (Hölzel, 1970). Posteriormente Monserrat (2011: 163) detecta y corrige el error de interpretación en los datos de captura (Burujón, Toledo, España por Burlan, Ararat, Turquía).

Neuroleon aguilari Navás, 1930

Especie de Sri Lanka descrita e inadecuadamente listada entre las especies recolectadas en Ribera de Cardós (Lérida) por Navás (1930a: 50). Posteriormente Aspöck et al. (1980: 411) cita y subsana esta confusión, y Monserrat (2011: 163) comenta este hecho.

\section{Agradecimientos}

Esta contribución forma parte del Proyecto coordinado de I+D+i Fauna Ibérica (Neuroptera) CGL2010-22267-C07-05. Deseamos agradecer a los museos e instituciones citadas el habernos permitido estudiar ejemplares de sus colecciones, y a los autores y compañeros citados en el material estudiado por el envío de ejemplares de sus colecciones particulares o de sus centros de investigación. También deseamos manifestar nuestro sincero agradecimiento a las autoridades de las diferentes Comunidades Autónomas por facilitarnos los correspondientes permisos de muestreos para la toma de datos en los espacios protegidos visitados, a Davide Badano por sus valiosos comentarios, a Víctor Triviño y Miguel Ángel Dionisio por su ayuda en los últimos muestreos realizados, y a Alex Fernández y Miguel Villatoro por su colaboración en la realización de las fotografías. También deseamos manifestar nuestro agradecimiento a Vitali Sobolev por su ayuda en la traducción de algunos textos.

\section{Referencias}

Ábrahám, L., 2012. "On the other hand, what is this Eastern aeschnoides?" (Morton 1926) - an undescribed Palpares species from the Eastern Mediterranean (Neuroptera: Myrmeleontidae). Natura Somogyiensis, 22: $65-102$.

Acevedo, F., Monserrat, V. J. \& Badano D., 2013. The larvae of the two European species of genus Distoleon: D. annulatus (Klug, 1834) and D. tetragrammicus (Fabricius, 1798). A comparative description (Insecta, Neuroptera: Myrmeleontidae). Zootaxa, 3721(5): 488-494.

Albertus Magnus, 1478. De Animalibus Libri. Edición de Venecia (1519). Disponible on line: http: //babel.hathitrust.org/cgi/pt?id=ucm.5323777796;vie $\mathrm{w}=1$ up;seq $=4$

Andreu, J., 1909. Datos para la fauna de la provincia de Alicante. Neuropteros de los alrededores de Orihuela. Actas y Memorias Primer Congreso Naturaleza España, Zaragoza, 1908: 159-162.

Aspöck, H., Aspöck, U. \& Hölzel, H., 1980. Die Neuropteren Europas, 2 vols. Goecke \& Evers. Krefeld, t. I, 495 pp, t. II, 355 pp.
Aspöck, H., Hölzel, H. \& Aspöck, U., 2001. Kommentierter Katalog der Neuropterida (Insecta: Raphidioptera, Megaloptera, Neuroptera) der Westpaläarktis. Denisia, 2: 1-606.

Auber, J., 1955a. Les Myrmeleonidae de France. L'Entomologiste, 11: 48-58.

Auber, J., 1955b. Liste des Névroptères planipennes du Sahara nord occidental. Revue Française d'Entomologie, 22: 53-58.

Auber, J., 1956a. Les espèces françaises du genre Neuroleon (Névropt. Planipennes). Vie et Milieu, 7: 95-100.

Auber, J., 1956b. Au sujet de la larve du Myrmeleon hyalinus Olivier. L'Entomologiste, 12: 69-71.

Auber, J., 1958. Névroptéroides. Faune terrestre et d'eau douce des Pyrénées Orientales. Vie et Milieu, 9(suppl. 3): 1-42.

Badano, D. \& Pantaleoni, R. A., 2013. The larvae of European Myrmeleontidae (Neuroptera). Zootaxa (in press.).

Banks, N., 1911. Notes on African myrmeleonidae. Annals of the Entomological Society of America, 4(1): 1-29, 2 pl.

Barreda, J. M., 2013. Nuevos registros de Chrysopidae y Myrmeleontidae para la provincia de Sevilla (Andalucía, España) (Neuroptera, Planipennia). Boletín de la Sociedad Aragonesa de Entomología, 21: 77-81.

Berland, L., 1962. Atlas des Névroptères de France, Belgique, Suisse. Mégaloptères, Raphidioptères, Névroptères Planipennes, Mécoptères, Trichoptères. N. Boubée \& Cie. Paris. 158 pp.

Bolívar, I., 1878. Nota: insectos colectados por M. Cuní y Martorell en las cercanías de Barcelona. Actas de la Sociedad Española de Historia Natural, 7: 61-64.

Bolívar, I., 1890. Nota. Actas de la Sociedad Española de Historia Natural, 19: 31.

Bonnet, C., 1780. Oeuvres d'histoire naturelle et de philosophie. Vol. 2. Marc-Michel Rey. Amsterdam. [iv] $+\mathrm{ii}+524 \mathrm{pp}$.

Bosca Seytre, A., 1916. Fauna Valenciana. In: F. Carreras y Candi. Geografía general del Reino de Valencia. Valencia: 48.

Brauer, F., 1853. Vergleichende Beschreibung der Larven des Myrmecoleon formicarius L. und M. formicalynx T. Verhandlungen des ZoologischBotanischen Vereins in Wien, 3: 144-145.

Brauer, F., 1854. Beiträge zur Kenntniss des inneren Baues und der Verwandlung der Neuropteren. Verhandlungen des Zoologisch-Botanischen Vereins in Wien, 4: 463-472.

Brauer, F., 1855. Beiträge zur Kenntniss der Verwandlung der Neuropteren. Verhandlungen des Zoologische-Botanischen Vereins in Wien, 5: 479484, 777-786. 
Brauer, F., 1876. Die Neuropteren Europas und insbesondere österreichs mit Rücksicht auf ihre geographische Verbreitung. Festschrift zur Feier des fünfundzwanzigjährigen Bestehen Kaiserlich-Koniglichen Zoologisch-Botanischen Gesellschaft, Wien, 1(38): 263-300.

Brauer, F., 1857. Neuroptera austriaca. Die im Erzherzogthum Oesterreich bis jetzt aufgefundenen Neuropteren nach der analytischen Methode zusammengestellt, nebst einer kurzen Charakteristik aller europäischen Neuropteren-Gattungen. C. Gerold's Sohn. Wien. xxiii +80 pp.

Cáceres, J., 1909. Neuropteros cogidos en Cartagena. Actas de la Sociedad Española Historia Natural, 29: 291.

Cammaerts, R., 1967. Kommt Palpares libelluloides im Schwarzwald vor? (Planipennia, Myrmeleonidae). Entomologische Zeitschrift, 77: 184.

Capra, F., 1934. Su alcuni odonati e Mirmeleonidi di Sicilia. Annali del Museo Civico di Storia Naturale di Genova, LVII: 92-97.

Capra, F., 1937. Raccolte entomologiche nell'Isola di Capraia fatte de C. Mancini e F. Capra (1927-1931). VI. Odonati e Neurotteri con note sulla memoria. Bolletino della Societá Entomologica Italiana, 69, 4: 50-58.

Capra, F., 1976. Quanto si sa sugli Odonati e Neurotteri dell'Archipelago Toscano (Studi sulla Riserva Naturalle dell'Isola di Montecristo, XIII). Lavori della Societè Italiana di Biogeografia N.S., V (1976): 540-560.

Cervera, F., 1922. Algunos insectos recogidos por D. Fermin Cervera en la provincia de Tarragona, Castellón y Valencia. Boletín de la Sociedad Entomológica Española, 5: 147-148.

Cesaroni, C., Nicoli Aldini, R. \& Pantaleoni, R. A., 2010. The larvae of Gymnocnemia variegata (Schneider, 1845) and Megistopus flavicornis (Rossi, 1790) (Neuroptera: Myrmeleontidae): a comparative description. In: D. Devetak, S. Lipov?ek \& A. E. Arnett (eds.). Proceedings of the $10^{\text {th }}$ International Symposium on Neuropterology (22-25 June 2008, Piran, Slovenia). University of Maribor. Maribor: 135-144.

Coma, P., 1918. Neurópteros de Murcia. Boletín de la Sociedad Entomológica Española, 1(7): 152.

Compte, A., 1967. Resultados de una expedición Zoologica a las Islas Pitiusa. III Neurópteros y Odonatos. Graellsia, 23: 127-142.

Compte, A., 1968. Síntesis de la fauna de Menorca, su naturaleza y un ensayo acerca de su origen. Revista de Menorca, $\mathrm{n}^{\circ}$ extraordinario: 1-212.

Constantin, M., 1961. Neuroleon (Nelees) nemauriensis Borkh (Neuroptera Myrmeleonidae) neu für Fauna Rumäniensis. Fragmenta Balcanica, (4), 7(91): 1-56.
Costa, A., 1855. Fauna del Regno di Napoli. Ossia enumerazione di tutti gli animali che abitano le diverse regioni di questo regno e le acque che le bagnano $e$ descrizione de'nuovi o poco esattamente conosciuticon figure ricavate da originali viventi e dipinte al naturale. Nevrotteri. Stamperia di Antonio Cons. Napoli (1860-1870) (diferente paginación y años de publicación según familias: Famiglia de'Formica-leonidei, pp. [1]-20, 3/4 Diciembre de 1855, para otros años de publicación ver: Sherborn, 1937 y Pantaleoni, 1999).

Cuní y Martorell, M., 1880. Excursión entomológica y botánica a San Miguel de Fay. Anales de la Sociedad Española Historia Natural, 9: 204-242.

Cuní y Martorell, M., 1882. Resultado de una exploración entomológica y botánica por el término de $\mathrm{La}$ Garriga (Cataluña). Anales de la Sociedad Española Historia Natural, 11: 83-101.

Cuní y Martorell, M., 1888. Insectos observados en los alrededores de Barcelona. Anales de la Sociedad Española Historia Natural, 17: 133-191.

Cuní y Martorell, M., 1897. Fauna entomológica de la villa de Calella (Cataluña, Provincia de Barcelona). Anales de la Sociedad Española Historia Natural, 26: 281-339.

Cuní y Martorell, M., 1899. Recorts d'una exploració entomológica en Arbucias. L'art del Pads, 23: 5-29.

Devetak, D., Klokocovnik, V., Lipovsek, S., Bock, E. \& Leitinger, G., 2013. Larval morphology of the antlion Myrmecaelurus trigrammus (Pallas, 1771) (Neuroptera, Myrmeleontidae), with notes on larval biology. Zootaxa, 3641(4): 491-500.

Díaz Aranda, L. M. \& Monserrat, V. J., 1988a. Contribución al conocimiento de los neurópteros de Jaén (Insecta, Neuropteroidea). Boletín de la Asociación Española Entomología, 12: 111-123.

Díaz Aranda, L. M. \& Monserrat, V. J., 1988b. Contribución al conocimiento de los neurópteros de Teruel (Insecta, Neuropteroidea). Boletín de la Asociación Española Entomología, 12: 215-231.

Díaz Aranda, L. M. \& Monserrat, V. J., 1988c. Contribución al conocimiento de los Neurópteros de Granada (Insecta, Neuropteroiea). Actas III Congreso Ibérico de Entomología, Granada: 211-227.

Díaz Aranda, L. M., Monserrat, V. J. \& Marín, F., 1986a. Composición biogeográfica de los neurópteros de Guadalajara (Insecta, Neuropteroidea: Planipennia). Actas VIII Jornadas de la Asociación Española de Entomología, Sevilla: 1121-1130.

Díaz Aranda, L. M., Monserrat, V. J. \& Marín, F., $1986 b$. Contribución al conocimiento de los neurópteros de Guadalajara (Insecta, Neuropteroidea). Actas VIII Jornadas de la Asociación Española de Entomologia, Sevilla: 1131-1141.

Doflein, F., 1916. Der Ameisenlöwe. Eine biologische, tierpsychologische und reflexbiologische Untersuchung. G. Fischer. Jena. 138 pp. 
Doflein, F., 1921. Mazedonien: erlebnisse und beobachtungen eines naturforschers imgefolge des deutschen heeres. G. Fischer. Jena. 592 pp.

Druce, G. C., 1923. An Account of the Myrmekoleon or ant-lion. The Antiquaries Journal, 3(4): 347-364.

DuBois, E. R., 1899. Notes sur l'habitat des pseudo-névroptères et névroptères de la Gironde. Feuille des Jeunes Naturalistes, 29: 50-53.

Dufour, L., 1854. Excursion entomologique aux dunes de Biscarosse et d'Arcachon. Actes de la Société Linnéenne de Bordeaux, 19: 283-317.

Dziedzielewicz, J., 1891. Przeglad fauny krajowej Owadow Siatkoskrzydlych (Neuroptera, Pseudoneuroptera). Sprawozdanie Komisyi fizyograficznéj, 26: 26-150.

Eglin, W., 1939. Zur Biologie und Morphologie der Raphidien und Myrmeleoniden (Neuropteroidea) von Basel und Umgebung. Verhandlungen der Naturforschenden Gesellschaft in Basel, 1: 163-220.

Eglin, W., 1940. Die Neuropteren der Umgebung von Basel. Revue Suisse de Zoologie, 47: 243-358.

Eglin, W., 1967. Die Mecopteren und Neuropteren des Kantans Tessin, Süd Schweiz. Mitteilungen der Entomologischen Gesellschaft Basel, 17: 41-58.

Eglin, W., 1985. Zwei mediterrane Netzflügler neu für die Schweiz: Myrmeleon (Morter) hyalinus Olivier und Semidalis pseudouncinata Meinander (Neuroptera: Myrmeleonidae). Mitteilungen der Schweizerischen Entomologischen Gesellschaft, 58: 323-324.

Eisenbeis, G. \& Wichard W., 1987. Atlas on the Biology of Soil Arthropods. Antlions (Myrmeleonidae), Springer. Berlin und München: 278-283.

Esben-Petersen, P., 1918. Help-notes towards the determination and the classification on the Myrmeleonidae. Entomologiske meddelelser, 12: 1-31.

Esben-Petersen, P., 1931, Inveta entomologica itineris Hispanici et Maroccani quod a.1926 ferunt Harald et Hakan Lindberg. VIII. Neuroptera. Commentationes Biologicae Societas Scientiarum Fennicae, 3(13): 1-6.

Esben-Petersen, P., 1936. Missioni scientifiche del Prof. Edoardo Zavattari nel Sahara italiano (1933-1934) Neuroptera. Bollettino della Società Entomologica Italiana, 68(5-6): 71-74.

Fernández, J., 2003. Noticia de nuevos táxones para la ciencia en el ámbito íbero-balear y macaronésico. Graellsia, 59(1): 101- 130.

Ferrari, J. A. G., 1864. Kleiner Beitrag zur Käferfauna Venedigs und des Lido, mitgetheilt von einem süddeutschen Entomologen. Wiener Entomologische Monatsschrift, 8: 105-113.

Friheden, J., 1973. Morphological characteristics of North-European myrmeleontid larvae (Neuroptera). Entomologica Scandinavica, 4: 30-34.

Gardiner, J. S., 1932. Demons of the Dust: a Study in Insect behavior. Nature, 129: 39-40.
Gepp, J., 2010. Ameisenlöwen und Ameisenjungfern. Myrmeleontidae. Eine weltweite Betrachtung unter besonderer Berücksichtigung Mitteleuropas. 3., neubearbeitete Auflage. Die Neue Brehm-Bücherei 589. Westarp Wissenschaften. Hohenwarsleben. 168 $\mathrm{pp}$.

Gepp, J. \& Hölzel, H., 1989. Ameiselöwen und ameisenjungfern. Die Neue Brchm-Bücheri. A. Ziemsen. Wittenberg Lutherstadt. $108 \mathrm{pp}$.

Gerhardt, M. I., 1965. The ant-lion. Nature study and the interpretation of a biblical text, from the Physiologus to Albert the Great. Vivarium, 3: 1-23.

Gil, C., 1915. Excursiones por Benanarre (Huesca). Boletín de la Sociedad Aragonesa de Ciencias Naturales, XIV: 24-26.

Girard, M., 1875. Myrméléontides du sud-ouest de la France. Bulletin de la Société Entomologique de France, (5), 5: ccxxi-ccxxii.

González López, A. E., 2002. Neurópteros nuevos para Aragón o sus provincias. Boletín de la Sociedad Entomológica Aragonesa, 30: 203.

Graefe, G., 1970. Grocus inconspicuus (Rambur, 1842) (Neuroptera, Myrmeleonidae) im Neusiedlerseegebiet. Entomologisches Nachrichtenblatt, 17: 60-61.

Hagen, H. A., 1859. Ueber das Vorkommen von Palingenia longicauda und Acanthaclisis occitanica in Preussen. Stettiner Entomologische Zeitung, 20: 431-432.

Hagen, H. A., 1860a. Neuroptera Neapolitana von A. Costa, nebst Synopsis der Ascalaphen Europas. Stettiner Entomologische Zeitung, 21: 38-56.

Hagen, H. A., 1860b. Beitrag zur kenntniss der Myrmeleon-Arten. Stettiner Entomologische Zeitung, 21: 359-369.

Hagen, H. A., 1863. Die Odonaten und Neuropteren-Fauna Syriens und Klein-Asiens. Wiener Entomologische Monatschrift, 7: 193-199.

Hagen, H. A., 1866a. Die Neuropteren Spaniens nach Ed. Pictet's Synopsis des Néuroptères d'Espagne. Genève 1865. 8. tab. 14 col. und Dr. Staudingers Mittheilungen. Stettiner Entomologische Zeitung, 27: 281-302.

Hagen, H. A., 1866b. Hemerobidarum Synopsis Synonymica. Stettiner Entomologische Zeitung, 27: $369-462$.

Hagen, H. A., 1873. Die Larven von Myrmeleon. Stettiner Entomologische Zeitung, 34: 249-295, 377-398.

Hagen, H. A., 1858. Russlands Neuropteren. Stettiner Entomologische Zeitung, 19(1-3): 110-134.

Handschin, E. \& Markl, W., 1955. Neuropteren aud Angola. Publicações Culturais da Companhia de Diamantes de Angola, 27: 67-82, 11 fig.

Herrán, P., 1913. Excursiones científicas por las orillas del Ebro. Boletín de la Sociedad Aragonesa de Ciencias Naturales, 12: 109-111. 
Hölzel, H., 1972. Die Neuropteren Vorderasiens IV. Myrmeleonidae. Beiträge zur Naturkundlichen Forschung in Südwestdeutschland, Beiheft, 1: 3-103.

Hölzel, H., 1974. Ein neuer trichterbauender Ameisenlöwe aus Südwesteuropa (Planipennia). Nachrichtenblatt der Bayerischen Entomologen, 23(5): 81-85.

Hölzel, H., 1976. Revision der europäischen Creoleon Arten (Planipennia, Myrmeleonidae). Zeitschrift der Arbeitsgemeinschaft Österreichischer Entomologen, 28(1-3): 33-38.

Hölzel, H., 1987a. Revision der Distoleonini I. Die Genera Macronemurus Costa, Geyria EsbenPetersen und Mesonemurus Navás (Planipennia, Myrmeleonidae). Entomofauna, 8(27): 369-410.

Hölzel, H., 1987b. Myrmeleon hyalinus Olivier. Eine chorologisch-taxonomische Analyse (Neuropteroidea: Planipennia: Myrmeleonidae). Zeitschrift der Arbeitsgemeinschaft Österreich Entomologen, 38(3/4): 78-88.

Hölzel, H. \& Monserrat, V. J., 2002. Tricholeon relictus nov. sp.- ein neuer europäischer Ameisenlöwe (Neuropterida: Neuroptera: Myrmeleontidae). Linzer Biologische Beitraege, 34(2): 1151-1154.

Insom, E., Centina, P. del \& Carfi, S., 1979. Alcuni neurotteri planipenni italiani (Osmilidae, Ascalaphidae, Myrmeleonidae). Redia, 62: 35-52.

Insom, E., Centina, P. del \& Carfì, S., 1985. II Contributo alla conoscenza della fauna Neurotterologica italiana (Neuroptera: Raphidioptera, Planipennia). Redia, 65(3): 105-121.

Kempny, P., 1905. Beitrag zur Neuropterenfauna Roumäniens. Buletinul Societatii de Stiinte din Bucuresti, 14: 665-674.

Kevan, D. K. McE., 1992. Antlion ante Linné: Mvpunkolewv to Myrmeleon (Insecta: Neuroptera: Myrmeleonidae). In: M. Canard, H. Aspöck \& M. W. Mansell (eds.) Proceedings $4^{\text {th }}$ International Symposium on Neuropterology, Toulouse: 203-232.

Kimmins, D. E., 1939. 5. Ephemeroptera and Neuroptera. Ruwenzori Expedition, 1934-5, vol. 3. British Museum (Natural History). London: 107-115.

Kimmins, D. E., 1950. Results of the Amstrong College expedition to Siwa Oasis (Libyan Desert), 1935 under the Leadership of Prof. J.Omer Cooper. Bulletin de la Société Fouad ler d'entomologie, 34: 151-157.

Kolbe, H. J., 1884. Neuroptera aus Marocco gesammelt von Quendenfeldt. Berliner entomologische Zeitschrift, 28: 132-136.

Krivokhatsky, V. A., 1990. [A New Ant-Lion Species (Neuroptera, Myrmeleonidae) from Middle Asia.] Novosti faunistiki i sistematiki: 61-63 (en ruso).

Krivokhatsky, V. A., 1992a. New taxa of Asiatic antlions (Neuroptera, Myrmeleontidae). Entomologiceskoe Obozrenie, 71(2): 405-413.
Krivokhatsky, V. A., 1992b. A new ant-lion from Turkmenia, Middle Asia (Insecta, Neuroptera: Myrmeleonidae). Reichenbachia, 29(1): 77-80.

Krivokhatsky, V. A., 1992c. Revision of the Genus Lopezus Navás, 1913 (Neuroptera, Myrmeleonidae). Entomological Review, 70(5): 90-102.

Krivokhatsky, V. A., 1994a. Ant-lions (Neuroptera, Myrmeleontidae) in Turkmenistan. In: V. Fet \& K. I. Atamuradov (eds.). Biogeography and Ecology of Turkmenistan. Kluwer Academic. Dordrecht: 495-498.

Krivokhatsky, V. A. 1994b. [Antlion larvae of the genus Euroleon E.-P. (Neuroptera, Myrmeleontidae).] Kharkov Entomological Society Gazette, 2: 49-61. (en ruso).

Krivokhatsky, V. A., 1995. New Taxa of Asiatic Ant Lions (Neuroptera, Myrmeleontidae). Entomological Review, 74(5): 33-42.

Krivokhatsky, V. A., 1996 a. Antlions of the subgenus Ganussa (Genus Neuroleon) from Middle Asia (Neuroptera: Myrmeleontidae). Zoosystematica Rossica, 4: 301-306.

Krivokhatsky, V. A., 1996b. [Two new species of palearctic antlions (Neuroptera, Myrmeleontidae).] Entomologiceskoe Obozrenie, 75(3): 643-648 (en ruso).

Krivokhatsky, V. A., 2011. [Antlions (Neuroptera, Myrmeleontidae) of Russian.] Russian Academy of Sciences, Zoological Institute. St. Petersburg. 334 pp. (en ruso).

Krivokhatsky, V. A. \& Zakaharenko A. V., 1994. [AntLions of the genera Euroleon Esben-Petersen, 1918 and Kirghizoleon gen. n. (Neuroptera, Myrmeleontidae) of Palaearctic.] Entomologiceskoe Obozrenie, 73(3): 690699 (en ruso).

Lacroix, J. L., 1913. Contribution à létude des Névroptères de France. Feuille des jeunes naturalistes, 43: 98-103.

Letardi, A., 1998. Myrmeleon bore (Tjeder, 1941) new to Spain (Neuroptera Myrmeleontidae). Frustula entomologia, 20(33): 150-151.

Lucas, W. J., 1905. Neuroptera collected by Dr. T.A. Chapman in France and Spain 1904. The Entomologist, 38: 296-298.

Lucas, W. J., 1906a. On the emergence of Myrmeleon fornicarius from the pupa. Transactions of the Entomological Society of London, 1906: 53-57.

Lucas, W. J., 1906b. Neuroptera and Trichoptera taken by Dr. T.A. Chapman in Spain, 1906. The Entomologist, 39: 276-277.

Lucas, W. J., 1922. Notes. The Entomologist, 55: 263.

Mândru, C., 1961. Revizuirea sistematica a familiei Myrmeleonidae din R.P.R. Analele Stiintifice ale Universitatii "Al. I. Cuza" din lasi. Sectiunea II. Sttinte Naturale, 2(7): 329-336.

Mansell, M. W., 1996. Predation strategies and evolution in antlions (Insecta: Neuroptera: Myrmeleontidae). In: Pure and Applied research in Neuropterology. 
Proceedings of the Fifth International Symposium on Neuropterology, Toulouse: 161-169.

Mansell, M. W., 1999. Evolution and success of antlions (Neuropterida: Neuroptera: Myrmeleontidae). Stapfia, 60: 49-58.

Marcet, A. F., 1906. Una excursión a orillas del Ebro. Boletín de la Sociedad Aragonesa de Ciencias Naturales, 5(1/2): 137-141.

Marín, F., 1994. Las comunidades de neurópteros de la provincia de Albacete (Insecta: Neuropteroidea). AlBasit, Estudios albacetenses, 34: 247-304.

Marín, F. \& Monserrat V. J., 1987. Los neurópteros del encinar ibérico (Insecta, Neuropteroidea). Boletín de sanidad vegetal. Plagas, 13: 347-359.

Marín, F. \& Monserrat, V. J., 1989. Contribución al conocimiento de los neurópteros de Cantabria (Insecta, Neuropteroidea). Boletín de la Asociación Española de Entomología, 13: 287-298.

Marín, F. \& Monserrat, V. J., 1990. Contribución al conocimiento de los Neurópteros de Soria (Insecta, Neuropteroidea). Boletín de la Asociación Española de Entomología, 14: 219-230.

Marín, F. \& Monserrat, V. J., 1991. Contribución al conocimiento de los neurópteros de Albacete (Insecta, Planipennia). Jornadas sobre el Medio Natural Albacetense 1990, Albacete: 179-184.

Marín, F. \& Monserrat, V. J., 1995a. Contribución al conocimiento de los neurópteros de Valencia (Insecta, Neuroptera). Boletín de la Asociación Española de Entomología, 19(3-4): 35-49.

Marín, F. \& Monserrat, V. J., 1995b. Contribución al conocimiento de los neurópteros de Zaragoza (Insecta, Neuropteroidea). Zapateri Revista aragonesa de entomología, 5: 109-126.

Marques, A. \& Ormières, R., 1978. Actinocephalus acanthaclisis n. sp., Eugregarine parasite of the Acanthaclisis larva. Zeitschrift für Parasitenkunde 56: 159-166.

Matsura, T., 1987. Nomenclature of the Japanese pitbuilding antlions (Neuroptera, Myrmeleontidae). Kontyû, 55: 543-548.

McLachlan, R., 1873. Notes sur les Myrmeleontides décrits par le Docteur Rambur. Annales de la Société entomologique belge, 16: 127-141.

McLachlan, R., 1875. A sketch of our present knowledge of the neuropterous fauna of Japan (excluding Odonata and Trichoptera). Transactions of the Entomological Society of London, 1875: 167-190.

McLachlan, R., 1882. The Neuroptera of Madeira and the Canary Islands. Journal of the Linnean Society of London (Zoology), 16: 149-183.

McLachlan, R., 1884. Acanthaclisis occitanica and baetica, a differential essay. Entomologist's Monthly Magazine, 20: 181-184.
McLachlan, R., 1889. Neuroptera collected by Mr. J.J. Walker, R.N. on both sides of the Straits of Gibraltar. Entomologist's Monthly Magazine, 25: 344-349.

McLachlan, R. 1898. Neuroptera-Planipennia collected in Algeria by the Rev. A. E. Eaton. Transactions of the Entomological Society of London, 1898: 151168.

McLachlan, R., 1902a. Trichoptera, Planipennia and Odonata collected by Lord Walsingham in the vicinit of Granada (Spain) in 1901. Entomologist's Monthly Magazine, 13: 33-34.

McLachlan, R., 1902b. An annotated list of NeuropteraPlanipennia collected in central Spain by Dr.T.A.Chapman and Mr. G.C. Champion in July and August 1901. Entomologist's Monthly Magazine, 13: 129-131.

McLachlan, R., 1903. An annotated list of Neuroptera Planipennia collected in Central Spain by Dr. T.A. Chapman and Mr. G.C. Champion in June and July 1902. Entomologist's Monthly Magazine, 14: 224225.

Meinert, F., 1889. Contribution à l'anatomie de Fourmilions. Oversigt over det Kongelige Danske Videnskabernes Selskabs Forhandlinger, 1889: 43-66.

Monserrat, V. J., 1977. Los Neurópteros del Guadarrama. Trabajos de la Cátedra Artrópodos, Facultad de Biología, Universidad Complutense de Madrid, 19: 1-202.

Monserrat, V. J., 1978a. Primera contribución al conocimiento de los Neurópteros de Cádiz (Insecta, Neuroptera, Planipennia). Boletín de la Real Sociedad Española de Historia Natural (Sección Biológica), 76: 57-70.

Monserrat, V. J., 1978b. Contribución al conocimiento de los Neurópteros de Orense (Neu. Planipennia). Boletín de la Asociación Española de Entomología, 2: 169-184.

Monserrat, V. J., 1979a. Sobre los Neurópteros Ibéricos (II) (Neuroptera, Planipennia). Boletín de la Asociación Española de Entomología, 3: 17-21.

Monserrat, V. J., 1979b. Segunda contribución al conocimiento de los neurópteros de Cádiz (Insecta, Planipennia). Boletín de la Real Sociedad Española de Historia Natural (Sección Biológica), 77: 409417.

Monserrat, V. J., 1980a. Sobre los Neurópteros Ibéricos (I). (Neuroptera, Planipennia). Graellsia, [1978], 34: 171-176.

Monserrat, V. J., 1980b. Contribución al conocimiento de los Neurópteros de Toledo. Graellsia, [1978], 34: 177-193.

Monserrat, V. J., 1981. Sobre los Neurópteros Ibéricos (III) (Neuroptera, Planipennia). Boletín de la Asociación Española de Entomología, 4: 151-156. 
Monserrat, V. J., 1982. Contribución al conocimiento de los Neurópteros de Cáceres (Neur., Planipennia). Graellsia, 38: 67-84.

Monserrat, V. J., 1983. Pterocroce capillaris (Klug, 1836) en Europa (Neur., Plan., Nemopteridae). Neuroptera International, 2(3): 109-128.

Monserrat, V. J., 1984a. Contribución al conocimiento de los neurópteros de Salamanca (Neur, Planipennia). Eos, 59: 165-177.

Monserrat, V. J., 1984b. Contribución al conocimiento de los neurópteros de Alicante (Neur, Planipennia). Mediterranea, Serie Biologica, 7: 91-116.

Monserrat, V. J., 1984c. Contribución al conocimiento de los neurópteros de Zamora (Neur., Planipennia). Miscellanea Zoologica, 8: 153-163.

Monserrat, V. J., 1984d. Contribución al conocimiento de los neurópteros de Huesca (Neur, Planipennia). Pirineos, 121: 29-50.

Monserrat, V. J., 1985a. Nuevos datos sobre los Myrmeleontoidea ibéricos. (Neur., Plan., Myrmeleonidae, Ascalaphidae, Nemopteridae). Actas II Congreso Ibérico Entomología, Lisboa, II: 475-489.

Monserrat, V. J., 1985b. Contribución al conocimiento de los neurópteros de Lugo (Neur, Planipennia). Trabajos Compostelanos de Biología, 12: 87-98.

Monserrat, V. J., 1985c. Contribución al conocimiento de los Neurópteros (Neuroptera: Planipennia) de Murcia. Anales de Biología (Biología Animal), 1: 81-94.

Monserrat, V. J., 1986. Sobre los Neurópteros ibéricos (IV) (Neur.). Boletín de la Asociación Española de Entomología, 10: 95-105.

Monserrat, V. J., 1987a. Contribución al conocimiento de los Neurópteros de Almería (Neur, Planipennia). Graellsia, 42: 131-147.

Monserrat, V. J., 1987b. Els megalòpters, Els Rafidiòters, Els Planipennis: crisopes, reis de formigues $i$ afins. Història Natural dels Països Catalans, 10,2. Fundació Enciclopèdia Catalana. Barcelona: 251-265.

Monserrat, V .J., 1996. Lista de los neurópteros de Aragón (Megaloptera, Raphidioptera, Planipennia). Catalogus de la entomofauna Aragonesa, 11: 11-17.

Monserrat, V. J., 2005. Catálogo de los Neurópteros de Baleares con nuevos datos sobre su fauna (Insecta, Neuroptera). Bolletin de la Sociedad de Historia Natural de Balears, 48: 71-85.

Monserrat, V. J., 2010. Nuevas o interesantes citas de neurópteros en la Península Ibérica (Insecta: neuroptera). Heteropterus Revista de Entomología, 10(1): 19-34.

Monserrat, V. J., 2011. Sobre algunas especies de neurópteros de la Península Ibérica y de las Islas Canarias de posición taxonómica problemática o con citas dudosas o cuestionables (Insecta, Neuroptera: Megaloptera, Planipennia). Boletín de la Sociedad Entomológica Aragonesa, 49: 153-178.
Monserrat, V. J. \& Acevedo, F., 2011. Nuevos datos sobre las hormigas león de la Península Ibérica (Insecta: Neuroptera: Myrmeleontidae). Heteropterus Revista de Entomología, 11(1): 123-136.

Monserrat, V. J. \& Díaz-Aranda, L. M., 1987. Contribución al conocimiento de los neurópteros (Neur.: Raphidioptera, Planipennia) de Cuenca. Boletín de la Asociación Española de Entomología, 11: 171-189.

Monserrat, V. J. \& Díaz-Aranda, L. M., 1988. Contribución al conocimiento de los Neurópteros de Castellón (Insecta,Neuropteroidea, Planipennia). Mediterranea, serie biológica, 10: 87-95.

Monserrat, V. J. \& Díaz-Aranda, L. M., 1989. Contribución al conocimiento de los neuropteros de Castellón (Insecta,Neuropteroidea,Planipennia). Mediterranea, serie biológica, 11: 47-58.

Monserrat, V. J., Gamarra, P. \& Deretsky, Z., 1999. The neuropterological fauna of the houses of the city of Madrid. Journal of Neuropterology, 2: 35-44.

Monserrat, V. J., Marín, F. \& Díaz Aranda, M. L., 1994. Contribución al conocimiento de los neurópteros de Lérida (Insecta, Neuroptera). Zoologica baetica, 5: 41-64.

Monserrat, V. J. \& Triviño, V., 2013. Atlas de los neurópteros de la Península Ibérica e Islas Baleares (Insecta, Neuroptera: Megaloptera, Raphidioptera, Planipennia) / Atlas of the Iberian and Balearic lacewings (Insecta, Neuroptera: Megaloptera, Raphidioptera, Planipennia). Monografías de la Sociedad Entomológica Aragonesa, vol. 13, Zaragoza. 154 pp., 136 mapas.

Monserrat, V. J., Triviño, V. \& Acevedo, F., 2013. Contribución al conocimiento de los neurópteros de Navarra (Insecta: Neuroptera). Heteropterus Revista de Entomología, 13, 1: 1-18.

Morgan, M. J., 1980. Contribución al catálogo faunístico del Coto Nacional de las Sierras de Cazorla y Segura. In: M. G. de Viedma (ed.). Fauna de Cazorla. Invertebrados. Monografías ICONA, 23. Ministerio Agricultura. Madrid. 129 pp.

Morton, K. J., 1907. Notes on Neuroptera collected in Corsica by Miss Fountaine. Entomologist's Monthly Magazine. 43: 1-2.

Morton, K. J., 1925. Notes on Neuroptera from Palestine, including a description of a new species of Myrmeleonidae. Transactions of the Entomological Society of London, 1925: 403-412.

Morton, K. J., 1930. Some Riviera notes chiefly concerning Odonata and Neuroptera. Entomologist's Monthly Magazine, 66: 1-5.

Morton Wheeler, W., 1930. Demons of the dust. W.W. Norton \& Company. New York. 378 pp.

Mountfort, G., 1968. Portrait of a Wilderness. The story of the Coto Doñana Expeditions. David \& Charles. Newton Abbot. 240 pp. 
Navarro, V., Baixeras, J. \& Tormos, J., 1988. Insectos de la Devesa de L'Albufera: 53. Monografías del Ayuntamiento de Valencia, 2: 1-146.

Navás, L., 1900a. Notas entomológicas III. Neurópteros de Montseny (Barcelona). Actas de la Sociedad Española de Historia Natural, 29: 92-96.

Navás, L., 1900b. Notas entomológicas VI. Algunas costumbres de las hormigas y hormigaleones. Actas de la Sociedad Española de Historia Natural, 29: 218222.

Navás, L., 1902a. Fauna entomológica estival de Brihuega (Prov. de Guadalajara). Boletín de la Sociedad aragonesa de Ciencias Naturales, 1: 8284, 213-220.

Navás, L., 1902b. Una excursió científica a la Serra Nevada. Butlletí de la Institució Catalana d'Història Natural, 2: 29-36, 46-50, 85-90, 100-105.

Navás, L., 1903. Algunos Neurópteros de España, nuevos. Boletín de la Sociedad aragonesa de Ciencias naturales, 2: 99-109.

Navás, L., 1904a. Notas neuropterológicas. V, Myrmeleonidos de España I. Butlletí de la Institució Catalana d'Història Natural, 1(2): 6-10.

Navás, L., 1904b. Notas neuropterológicas. VI, (Myrmeleonidos de España). Butlletí de la Institució Catalana d'Història Natural, 3(4): 19-25.

Navás, L., 1904c. Excursión de la Sociedad Aragonesa de Ciencias Naturales a la Sierra de Guara. Boletín de la Sociedad Aragonesa de Ciencias Naturales, 3: 190-201.

Navás, L., 1904d. Excursión al Moncayo. Boletín de la Sociedad Aragonesa de Ciencias Naturales, 3: 139167.

Navás, L., 1904e. Notas zoológicas.II. Neurópteros de la provincia de Barcelona cogidos por el P. Eugenio Saz S.J. Boletín de la Sociedad Aragonesa de Ciencias Naturales, 3: 122-128.

Navás, L., 1905a. Notas entomológicas.XII. Neurópteros de Pozuelo de Calatrava (C.Real). Boletín de la Real Sociedad Española de Historia Natural, 5: 503-509.

Navás, L., 1905b. Notas zoológicas. VIII. Mis excursiones durante el verano de 1904. Boletín de la Sociedad Aragonesa de Ciencias Naturales, 4: 107-131.

Navás, L., 1905c. Catálogo descriptivo de los insectos Neurópteros de los alrededores de Madrid. Revista de la Real Academia de Ciencias exactas, fisicas y naturales de Madrid, 2(4): 1-54.

Navás, L., 1905d. Notas neuropterológicas VII. Roberto Mac Lachlan (noticia biográfica). Butlletí de la Institució Catalana d'Història Natural, 2(3-4): 44-47.

Navás, L., 1905e. Notas neuropterológicas. VI. Neurópteros de Montserrat. Butlletí de la Institució Catalana d'Història Natural, 5: 11-21.
Navás, L., 1906a. Neurópteros de España y Portugal [parte 1]. Brotéria, 5: 145-184, [partes 2-3]: 1907, 6: 43-100, (3) 1908 7: 5-131.

Navás, L., 1907a. Nota. Boletín de la Real Sociedad Española de Historia Natural, 1907: 115.

Navás, L., 1907b. Neurópteros de España y Portugal. Brotéria, 6: 88-100.

Navás, L., 1909 a. Neurópteros de los alrededores de Madrid. Revista de la Real Academia de Ciencias exactas, fisicas y naturales de Madrid, 8: 370-380.

Navás, L., 1909b. Neurópteros nuevos de la fauna Ibérica. Actas y Memorias del Primer Congreso de Naturalistas Españoles, Zaragoza, 1908: 143-158.

Navás, L., 1909c. Notas entomológicas V. Neurópteros del Monzayo y Zaragoza. Actas de la Real Sociedad Española de Historia Natural, 29: 172-176.

Navás, L., 1910. Mis excursiones entomológicas durante el verano de 1909 (2 Julio-3 Agosto). Butlletí de la Institució Catalana d'Història Natural, 10: 32-56, 74-75.

Navás, L., 1911. Excursiones por los alrededores de Granada. Boletín de la Sociedad Aragonesa de Ciencias Naturales, 10: 204-211.

Navás, L., 1912a. Notas sobre Mirmeleónidos (Ins. Neur.). Brotéria (Zoológica), 10: 29-75, 85-97.

Navás, L., 1912b. Mirmeleónido nuevo de Canarias. Revista de la Real Academia de Ciencias exactas, fisicas y naturales de Madrid, 10: 671-673.

Navás, L., 1912c. Bemerkungen über die neuropteren der Zoologischen Staatssammlung in München. Mitteilungen der Münchner Entomologischen Gesellschaft, 3: 1-7.

Navás, L., 1912d. Nota. Boletín de la Sociedad Aragonesa de Ciencias Naturales, 11(7-8): 162.

Navás, L., 1912e. Insectos neurópteros nuevos o poco conocidos. Memorias de la Real Academia de Ciencias y Artes de Barcelona, 10: 136-202.

Navás, L., 1913a. Cuatro pequeñas colecciones de Neurópteros de la Península Ibérica. Boletín de la Sociedad Aragonesa de Ciencias Naturales, 12: 7791.

Navás, L., 1913b. Excursiones por los alrededores de Zaragoza. Boletín de la Sociedad Aragonesa de Ciencias Naturales, 12: 61-69, 75-77.

Navás, L., 1913c. Visita a S. Esteban de Litera (Huesca) (Conclusión). Boletín de la Sociedad Aragonesa de Ciencias Naturales, 12: 89-91, 98-101.

Navás, L., 1913d. Mirmeleónidos (Ins. Neur.) de la Fauna Ibérica. Asociación Española para el progreso de las Ciencias, Congreso de Madrid 5: 5-37.

Navás, L., 1913e. Algunos Neurópteros de Marruecos. Memorias de la Real Sociedad de Española Historia Natural, 8: 111-122. 
Navás, L., 1913f. Bemerkungen über die neuropteren der Zoologischen Staatssammlung in München V. Mitteilungen der Münchner Entomologischen Gesellschaft, 4: 9-15.

Navás, L., 1913g. Neurópteros nuevos de América. Brotéria, 1913(11): 45-53.

Navás, L., 1914a. Mirmeleónidos (Ins. Neur.) de Europa. (¿Proceedings?) IXe Congrès International de Zoologie, Monaco 1913: 746-766.

Navás, L., 1914b. Algunos Neurópteros de Manresa. Boletín de la Sociedad Aragonesa de Ciencias Naturales, 13: 174-176.

Navás, L., 1914c. Algunos neurópteros de los alrededores de Madrid. Boletín de la Sociedad Aragonesa de Ciencias Naturales, 13: 38-41.

Navás, L., 1914d. Neurópteros de Mallorca. Boletín de la Sociedad Aragonesa de Ciencias Naturales, 13: 185-192.

Navás, L., 1914e. Neurópteros nuevos o poco conocidos (tercera serie). Memorias de la Real Academia de Ciencias y Artes de Barcelona, 11(13): 193-215.

Navás, L., 1914f. Mirmeleónidos (Ins. Neur.) de Europa. Revista de la Real Academia de Ciencias Exactas Fisicas y Naturales de Madrid, 13: 602-635.

Navás, L., 1914g. Neurópteros del Moncayo (Zaragoza). Boletín de la Sociedad Aragonesa de Ciencias Naturales, 13: 207-218.

Navás, L., 1914h. Excursión anual de la Sociedad Aragonesa de Ciencias Naturales a Ortigosa y Valvanera (Logroño). Conclusión. Boletín de la Sociedad Aragonesa de Ciencias Naturales, 13: 2937.

Navás, L., 1915. Notas entomológicas, $2^{\mathrm{a}}$ Serie. Excursiones por Cataluña. Julio 1914. Boletín de la Sociedad Aragonesa de Ciencias Naturales, 14: 2732, 35-59, 66-80.

Navás, L., 1916a. Excursions entomològiques al nort de la provincia de Lleida. Butlletí de la Institució Catalana d'Història Natural, 16: 150-158.

Navás, L., 1916b. Excursiones por el norte de España. Congreso de la Asociación Española Progreso Ciencias, 6: 161-179.

Navás, L., 1916c. Excursión al valle de Arán (Lérida). Boletín de la Sociedad Aragonesa de Ciencias Naturales, 15: 179-194.

Navás, L., 1916d. Nota. Boletín de la Sociedad Aragonesa de Ciencias Naturales, 15(8): 178.

Navás, L., 1916e. Les Myrméléonides d'Europe et des Contrées limitrophes. Insecta, 61: 12-18, 64: 79-84.

Navás, L., 1917. Comunicaciones entomológicas. 2. Excursiones entomológicas por Aragón y Navarra. Revista de la Academia Ciencias de Zaragoza, 2: 8191.
Navás, L., 1918. Excursiones entomológicas por el norte de la provincia de Lérida. Butlletí de la Institució Catalana d'Història Natural, 18: 36-49.

Navás, L., 1919a. Excursiones entomológicas por Cataluña durante el verano de 1918. Memorias de la Real Academia de Ciencias Artes de Barcelona, 15: 181-214.

Navás, L., 1919b. Neurópteros de España nuevos, segunda serie. Boletín de la Sociedad Entomológica Española, 11, 7-8: 218-223.

Navás, L., 1919c. Notas entomológicas, $2^{\mathrm{a}}$ serie. Excursión anual de la Sociedad Aragonesa de Ciencias Naturales al Valle de Ordesa (Huesca) (2229 de julio de 1918). Boletín de la Sociedad Ibérica de Ciencias Naturales, 18: 37-44.

Navás, L., 1919d. Once neurópteros nuevos españoles. Boletín de la Sociedad Entomológica Española, 2,1: 48-56.

Navás, L., 1921a. Mis excursiones del verano de 1919. Memorias de la Real Academia de Ciencias y Artes de Barcelona, 17, 6: 143-169.

Navás, L., 1921b. Excursiones científicas realizadas durante el verano de 1920. Congreso de la Asociación Española para el Progreso Ciencias, sec. 4A: 59-74.

Navás L., 1922a. Excursions entomològiques de L'istiu de 1922. Arxius Institut Ciencies, 8: 1-34.

Navás, L., 1922b. Algunos insectos del Museo de París. Revista de la Academia de Ciencias de Zaragoza, 7: 15-51.

Navás, L., 1922c. Mis excursiones entomológicas durante el verano de 1921. Boletín de la Sociedad Entomológica Española, 5: 107-119.

Navás, L., 1922d. Algunos insectos recogidos por D. Fermin Cervera en las provincias de Tarragona, Castellón y Valencia. Boletín de la Sociedad Entomológica Española, 5: 147-148.

Navás, L., 1922e. Névroptères de Barbarie. Bulletin de la Société d'Histoire Naturelle de l'Afrique du Nord, 13: 251-253.

Navás, L., 1923. Excursiones por Aragón durante el verano de 1923. Boletín de la Sociedad Ibérica de Ciencias Naturales, 22(9-10): 161-176.

Navás, L., 1924a. Entomologia de Catalunya. Neuròpters. Fasc. I. Neuròpters propis. Fauna de Catalunya. Institut d'Estudis Catalans, secció de ciències. Barcelona. 271 pp.

Navás, L., 1924b. Insectes de l'excursio de D.Ascensi Codina a Castella i Andalusia al Juny de 1923. Trabajos del Museo de Ciencias Naturales de Barcelona, 4(11): 3-10.

Navás, L., 1924c. Mis excursiones entomológicas del verano de 1924. Brotéria, 21(3): 115-150.

Navás, L., 1925a. Insectos de Sena (Huesca). Boletín de la Sociedad Ibérica de Ciencias Naturales, 24: 91-95. 
Navás, L., 1925b. Sinopsis de los Neurópteros (Ins.) de la Península Ibérica. Memorias de la Sociedad Ibérica de Ciencias Naturales, 4: 1-150.

Navás, L., 1925c. Mis excursiones del verano de 1925. Brotéria, 22: 131-140.

Navás, L., 1927a. Insectos del Museo de Estocolmo. Revista de la Academia de Ciencias de Madrid, 24: 28-39

Navás, L., 1927b. Insekten aus der ehemaligen Ordnung der Neuropteren, gesammelt im nördlichen und östlichen Spanien, hauptsächlich von Dr. F. Haas in den Jahren 1914-1918. Senckenbergiana, 9(3-4): 112114.

Navás, L., 1927c. Mis excursiones científicas en 1926, Revista de la Academia de Ciencias exactas, físicas, químicas y naturales de Zaragoza, 10: 81-124.

Navás, L., 1927d. Insectos recogidos en España por el doctor F. Haas. Boletín de la Sociedad Entomologica de España, 10: 121-124.

Navás, L., 1927e. Insectos nuevos de la península ibérica. Boletín de la Sociedad Entomológica Española, 10: 78-84.

Navás, L., 1928a. Comunicaciones entomológicas. 10. Mis excursiones científicas en 1927. Revista de la Academia de Ciencias de Zaragoza, 11: 79-134.

Navás, L., 1928b. Insectos de Valencia, recogidos por D. José M. Carbajosa. Boletín de la Sociedad Entomológica Española, 11: 164-165.

Navás, L., 1928c. Excursiones por la provincia de Gerona, Butlletí de la Institució Catalana d'Història Natural, 8(1): 37-53.

Navás, L., 1928d. Insetti europei del Museo Civico di Genova. Bolletino della Societa Entomologica Italiana, 60(5): 75-83.

Navás, L., 1929a. Insectos Neuropteros y afines. Boletín de la Sociedad Entomológica Española, 12: 38-42.

Navás, L., 1929b. Excursiones por la provincia de Gerona en julio y agosto de 1928. Butlletí de la Institució Catalana d'Història Natural, 2(9): 27-48.

Navás, L., 1930a. Excursió entomológica a la vall de Noguera de Cardós (LLeida). Butlletí de la Institució Catalana d'Història Natural, 10: 156-169.

Navás, L., 1930b. Excursió entomológica a la vall de Noguera de Cardós (LLeida). Butlletí de la Institució Catalana d'Història Natural, 10: 156-169.

Navás, L., 1931a. De mis últimas excursiones entomológicas (1930-1931). Boletín de la Sociedad Entomologica de España, 14: 116-130.

Navás, L., 1931b. Entomología del Pirineo. Publicaciones de la Academia de Ciencias de Zaragoza, 1931-1932: 233-246.

Navás, L., 1932a. Les fourmilions (Insectes Névroptères) franco-belges. Compte Rendu Assotiation Française pour l'avancement des Sciences, 56: 285-288.
Navás, L., 1932b. Fáunula de Sobradiel (Zaragoza). Publicaciones de la Academia de Ciencias de Zaragoza, 16: 11-28.

New, T. R., 1983. Notes on the New Zealand antlion, Weeleus acutus (Neuroptera). New Zealand Journal of Zoology, 10: 281-284.

New, T. R., 1986. A review of the Biology of Neuroptera Planipennia. Neuroptera International. Supplement, 1: $1-58$.

New, T. R., 1989. Planipennia, Lacewings. Handbuch der Zoologie IV, 30. Walter de Gruyter. Berlin. 132 pp.

Nicoli Aldini, R., 2007. Observations on the larval morphology of the antlion Myrmeleon bore (Tjeder, 1941) (Neuroptera Myrmeleontidae) and its life cycle in the Po Valley (northern Italy). In: R. A. Pantaleoni, A. Letardi \& C. Corazza (eds.). Proceedings of the Ninth International Symposium on Neuropterology (20-23 June 2005, Ferrara). Annali del Museo Civico di Storia Naturale di Ferrara, 8: 59-66.

Novak, G. B., 1891. Terzo cenno sulla fauna dell'Isola Lesina in Dalmazia. Neuroptera. Societas HistoricoNaturalis Croatica, 1891: 1-9.

Okamoto, H., 1910. Die Myrmeleoniden Japans. Wiener Entomologische Zeitung, 29: 275-300.

Pantaleoni, R. A., 1999. Neuropterida described by A. Costa with type designation. Deutsche Entomologische Zeitschrift (N.F.), 46: 249-261.

Pantaleoni, R. A. \& Badano, D., 2012. Myrmeleon punicanus $\mathrm{n}$. sp., a new pitbuilding antlion (Neuroptera Myrmeleontidae) from Sicily and Pantelleria. Bulletin of Insectology, 65(1): 139-148.

Pantaleoni, R. A., Cesaroni, C. \& Nicoli Aldini, R., 2010. Myrmeleon mariaemathildae $\mathrm{n}$. sp.: a new Mediterranean pit-building antlion (Neuropterida Myrmeleontidae). Bulletin of Insectology, 63(1): 9198.

Percheron, A., 1833. Note sur la larve du Myrmeleon libelluloïdes (Extrait d'une Monographie de la tribu des Myrméléonides). Magasin de Zoologie, d'Anatomie Comparée et de Palaeontologie (Guérin-Méneville), 3: [1]-[6].

Perris, E., 1857. Nouvelles excursions dans las grandes landes. Annales de la Société Linnéene de Lyon, (2) 4: 83-180.

Pictet, F. J., 1865. Synopsis des Névroptères d'Espagne. Section II. Neuroptera. H. G. Baillière \& F. Savy. Paris: 51-84,108-114,116-117.

Pitarque, A., 1908. Excursión al Burgo. Boletín e la Sociedad Aragonesa de Ciencias Naturales, 7: 22-23.

Popov, A., 1973. Über die präimaginalen Stadien paläarktischer Vertreter der Ordnung Neuroptera und Versuch einer neuen systematischen Gruppierung der Familien mit Rücksicht auf ihre morphologischen 
und ökologischen Besonderheiten, Bulletin de l'Institut de Zoologie et Musée, Academie Bulgare des Sciences, Section de Biologie, 37: 79-101.

Popov, A., 1977. Wissenschaftliches Ergebnises der zoologischen Expedition des Nationalmuseum in Prag nach der Türkei Raphidioptera, Neuroptera und Mecoptera, Acta Entomologica Musei Nationalis Pragae, 39: 271-277.

Principi, M. M., 1943. Contributi allo studio dei Neurotteri Italiani. II. Myrmeleon inconspicuus Ramb. ed Euroleon nostras Fourcroy. Bollettino dell'Istituto di Entomologia dell'Università degli Studi di Bologna, 14: 131-192.

Principi, M. M., 1947. Contributi allo studio dei Neurotteri Italiani. VI. Synclisis baetica Ramb. (Myrmeleonidae - Acanthaclisini). Bollettino dell'Istituto di Entomologia della Università degli Studi di Bologna, 16: 234-253.

Principi, M. M., 1952. Ricerche Zoologiche sul Massiccio del Pollino (Lucania-Calabria) VI. Neurotteri. Annuario dell'Istituto e Museo di Zoologia dell'Università di Napoli, 4, 10: 1-22.

Principi, M. M., 1966. Neurotteri della Basilicata, della Calabria e della Sicilia (Contributi allo studio dei Neurotteri italiani XVIII). Memoire del Museo Civico di Storia Naturale di Verona, 14: 363-388.

Rambur, M. P., 1842. Histoire Naturelle des Insectes, Névroptères. Librairie encyclopédique de Roret. Fain et Thunot: Paris. [xviii] + 534 pp., 12 lám.

Réaumur, R. A. F., 1742. Mémoires pour servir à l'histoire des insectes. Vol. 6. Imprimerie Royale. Paris.

Redtenbacher, J., 1883. Zur Kenntnis der MyrmeleonidenLarven. Wiener Entomologische Zeitung, 2: 289-296.

Redtenbacher, J., 1884. Übersicht der MyrmeleonidenLarven. Denkschriften der Akademie der Wissenschaften Wien, MathematischeNaturwissenschaftliche Klasse, 48: 335-368.

Richard, G., 1952. Contribution à l'étude de la biologie des Fourmilions. Bulletin de la Société Zoologique de France, 77: 252-263.

Richard, G. \& Pons, R., 1951. Contribution á létude écologique des Fourmilions dans les PyrénéesOrientales. Vie et Milieu, 2: 381-387.

Rosenhauer, W. G., 1856. Die thiere Andalusiens nach dem Resultate einer Reise zusammengestellt, nebst den Beschereinbungen von 249 neuen order bis jetzt noch unbeschreibenen Gattungen und Arten. Theodor Blaesing. Erlangen. 429 pp.

Rösel von Rosenhof, A. J., 1755. Der monatlich- herausgegeben Insecten-Belustigung. Theil 3. Johann Joseph Fleischmann. Nürnberg. 624+14 pp.

Saffré, G., 1957. Le tentorium de la larve du troisiéme stade d'Acanthaclisis (Synclisis) baetica Ramb. Bulletin de la Société zoologique de France, 82(1): 28-37.
Satar, A., Suludere, Z., Canbulat, S. \& Özbay, C., 2006. Rearing the larval of Distoleon tetragrammicus (Fabricius, 1798) (Neuroptera: Myrmeleontidae) from egg to adult, with notes on their behaviour. Zootaxa, 1371: 57-64.

Schneider, W. G., 1845. Verzeichniss der von Herrn Oberlehrex Zeller in Jahre 1844 in Sicilien und Italien Gesammelten Neuroptera, mit Beschreibung einiger neuen Arten. Stettiner Entomologische Zeitung, 11(6): 338-346.

Sherborn, C. D., 1937. On the dates of publication of Costa (O. G.) and (A.) Fauna del Regno di Napoli, 18291886. Journal of the Society for the Bibliography of Natural History, 1:35-47.

Séméria, Y. \& Berland, L., 1988. Atlas des Névroptères de France, et d'Europe. Mégaloptères - RaphidioptèresNévroptères Planipennes. N. Boubée \& Cie. Paris. $190 \mathrm{pp}$.

Stange, L. A., 2004. A systematic catalog, bibliography and classification of the world antlions (Insecta: Neuroptera: Myrmeleontidae). Memoirs of the American Entomological Institute, 74: iv + 565 pp.

Stange, L. A. \& Miller, R. B., 1985. A generic review of the Acanthaclisine antlions based on larvae (Neuroptera: Myrmeleontidae). Insecta Mundi, 1: 29-42.

Stange, L. A. \& Miller, R. B., 1990. Classification of the Myrmeleontidae based on larvae (Insecta: Neuroptera). In: M. W. Mansell \& H. Aspöck (eds.). Advances in Neuropterology. Proceedings of the Third International Symposium on Neuropterology (3-4 February 1988, Berg en Dal, Kruger National Park). South African Department of Agricultural Development. Pretoria: 151-169.

Steffan, J. R., 1965. Les larves de Megistopus flavicornis (Rossi), Creoleon lugdunense (Villers), Neuroleon ocreatus (Navás) et $N$. nemausiensis (Borkh.) (Planipennes, Myrmeleontidae). Vie et Milieu, 15: 693-707.

Steffan, J. R., 1971. Contribution à l'étude des Neuroleon (Planipennes, Myrmeleontidae) de la faune de France. Annales de la Société Entomologique de France (N.S.), 7: 797-839.

Steffan, J. R., 1975. Les larves de Fourmilions (Planipennes: Myrmeleontidae) de la faune de France. Annales de la Société Entomologique de France (N.S.), 11, 2: 383-410.

Steinmann, H., 1963. Magyarország haugyalesöi (Neuroptera). Rovartani Köztemenyek, S.N., 16: 211226.

Tjeder, B., 1954. Myrmeleon formicarius s.L. in the Helsingfors Museum. Notulae Entomologicae, 34: 59-60.

Tröger, E. J., 1988. Weitere Nachweise von Acanthaclisis baetica Rambur (Neuropteroidea: Planipennia: Myrmeleontidae) und ihren Larven im westlichen 
Mittelmeergebiet und in Nordwestafrika. Entomologische Zeitschrift, 98(15): 220-223.

Ventalló, D., 1904. Neuropters de Tarrasa. Butlletí de la Institució Catalana d'Història Natural, 8(9): 113115.

Vicente, M., 1902. Algunos insectos de Ortigosa, Boletín de la Sociedad Aragonesa de Ciencias Naturales, 1: 186-189.

Vidal y López, M., 1917. Junto al Río Almanzora. Boletín de la Sociedad Aragonesa de Ciencias Naturales, 16: 27-32.

Vidal y López, M., 1943. Catálogo provisional de Neurópteros de la región levantina. Graellsia, 1(6): 13-24.

Walker, F., 1853. List of specimens of Neuropterous insects in the collection of the British Museum (Part II Sialidae-Nemopterides), Notes Leyden Museum, 2: 193-476.

Whittington, A. E., 2002. Resources in Scottish Neuropterology, Acta Zoologica Academiae Scientiarum Hungaricae, 48(2): 371-387.
Willmann, R., 1977. Die Myrmeleontidae (Insecta, Neuroptera) der Dodekanes/Ägäis. Zoologische Jahrbücher. Abteilung für Systematik, Geographie und Biologie, 104: 98-136.

Zacwilichowski, J., 1938. Eine für Polen neue Murmeleoniden-Art, Megistopus falvicornis Rossi. Fragmenta faunistica, 3: 435-438.

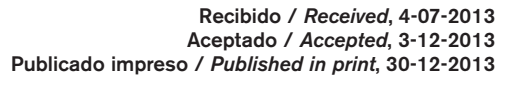

